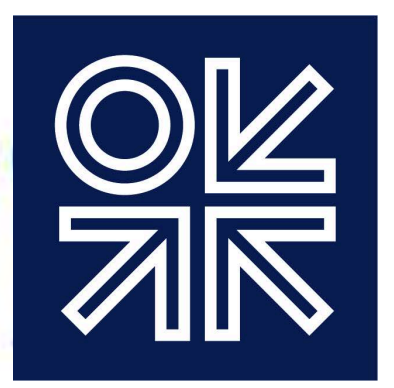

THE OXFORD

INSTITUTE

FOR ENERGY

STUDIES

December 2018

\title{
The Outlook for Natural Gas and LNG in China in the War against Air Pollution
}

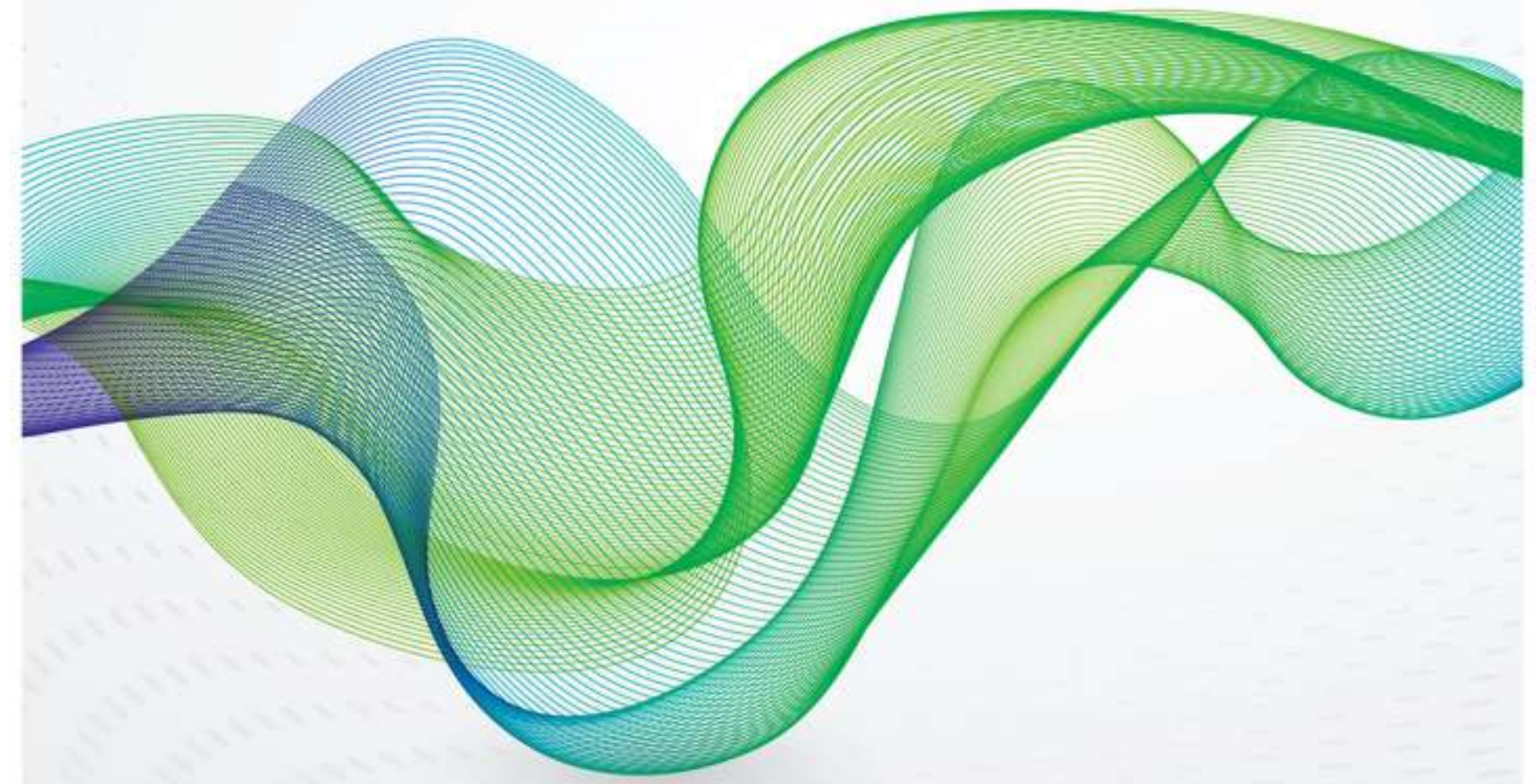



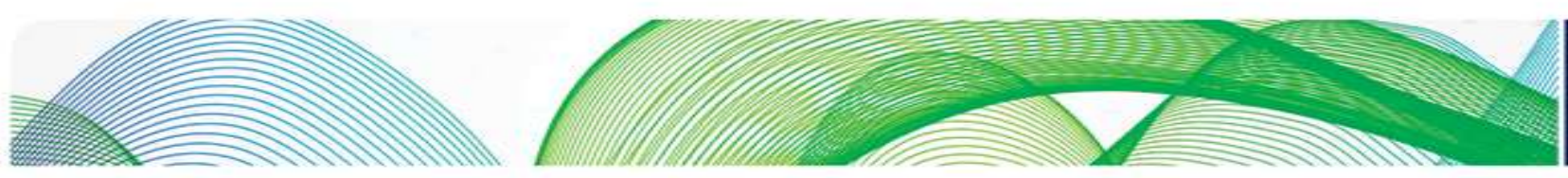

\section{인잦}

The contents of this paper are the authors' sole responsibility. They do not necessarily represent the views of the Oxford Institute for Energy Studies or any of its members.

Copyright $\odot 2018$

Oxford Institute for Energy Studies

(Registered Charity, No. 286084)

This publication may be reproduced in part for educational or non-profit purposes without special permission from the copyright holder, provided acknowledgment of the source is made. No use of this publication may be made for resale or for any other commercial purpose whatsoever without prior permission in writing from the Oxford Institute for Energy Studies.

ISBN: 978-1-78467-124-2

DOI: https://doi.org/10.26889/9781784671242

Akira Miyamoto

Executive Researcher, Energy Resources and International Business Unit

Osaka Gas Co., Ltd.

e-mail:akira-miyamoto@osakagas.co.jp

Chikako Ishiguro

Senior Analyst, Energy Resources and International Business Unit

Osaka Gas Co., Ltd.

e-mail:cisiguro@osakagas.co.jp 

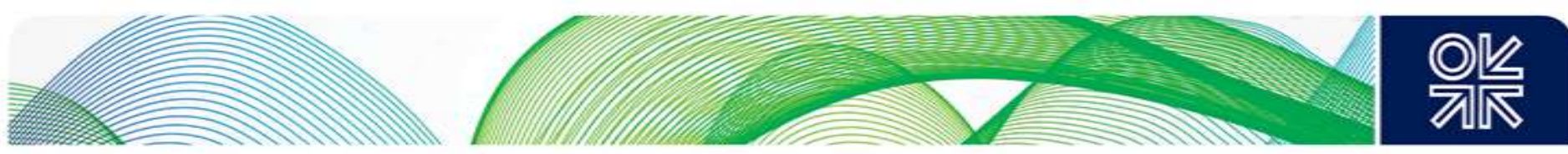

\section{Acknowledgements}

The authors wish to express their sincere gratitude to all those for their help in the writing of this paper. Our special thanks are due to those from the OIES: firstly, Professor Jonathan Stern not only for arranging this writing opportunity but also for his valuable advice and helpful suggestions; and $\mathrm{Dr}$ James Henderson, not only for his valuable comments and suggestions but also for undertaking the publication of this report. Our special thanks also go to Ms. Kate Teasdale and Ms. Catherine Gaunt for editing the final draft.

Finally, we would also like to express our warmest gratitude to Mr. Kunihiko Kashitani, Mr. Toyoshi Matsumoto, Mr. Yi Ding, Mr. Makoto Matsumoto, Mr. Kohei Hata, Mr. Masaya Takamoto, Ms. Tomoko Nakaie, Ms. Yoshie Shinbo, Ms. Kumie Hasebe of the Research Team of the Planning Department of Osaka Gas's Energy Resources and International Business Unit for their valuable assistance with the visits made to China, information gathering, analysis of international LNG market trends and improving the language. 

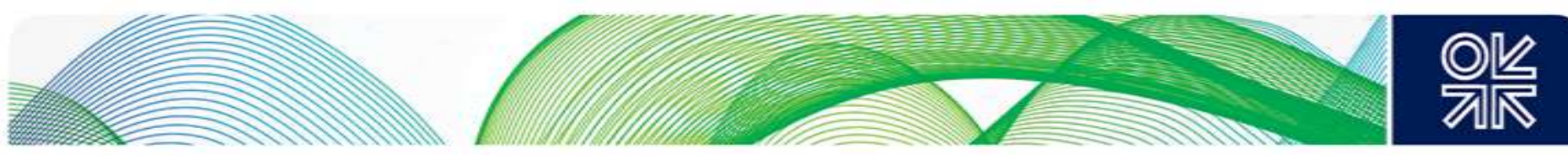

\section{Preface}

The outlook for gas demand in China is one of the most important questions facing the global gas market, as it will have significant consequences for gas producers and consumers across the world. The rapid rise in China's gas demand has been catalysed by environmental concerns, in particular air quality, in the country's major cities and the authors of this report, Akira Miyamoto and Chikako Ishiguro, provide a detailed analysis of the progress that has been made in introducing environmental legislation to pursue the goal of cleaning up China's skies. They consider the impact that his has had on gas consumption in China over the past decade before analysing the major goals of the Blue Sky Action Plan and outlining its potential consequences for gas demand over the next two to three years. After briefly addressing the issue of domestic gas production, the authors then assess the key question for global gas producers and exporters - what will China's gas import requirement be and from what sources will it come? Following the gas shortages in China during the winter of 2017/18 this is clearly a highly relevant and topical question, and this paper provides both a detailed analysis of the fundamental drivers of China's rapid demand growth and import requirement and also an insightful view of future trends. We thank them and their employer, Osaka Gas, for taking the time to provide this comprehensive analysis of a vitally important topic.

\section{James Henderson}

Director, Natural Gas Programme

Oxford Institute for Energy Studies 

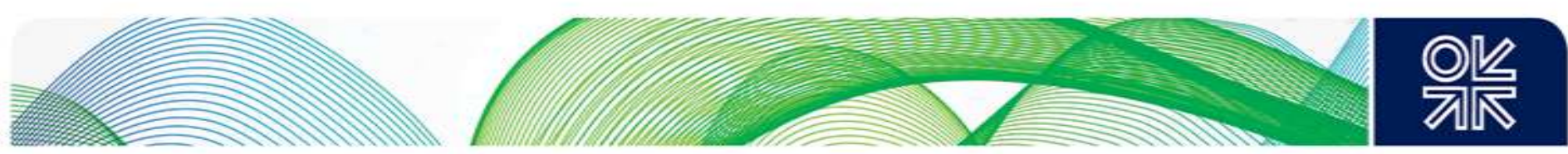

\section{Contents}

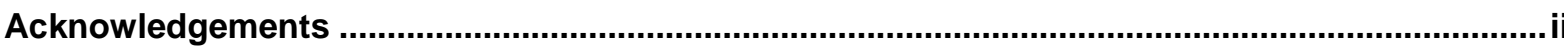

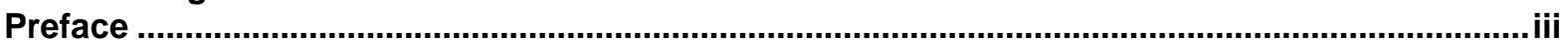

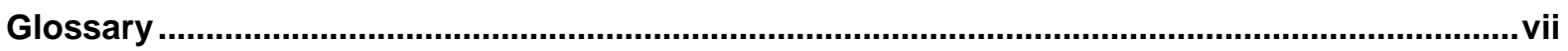

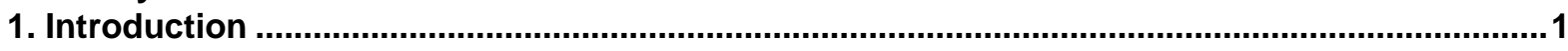

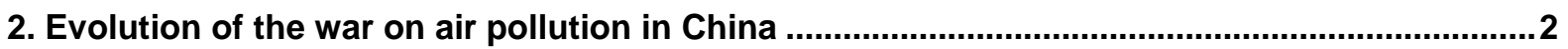

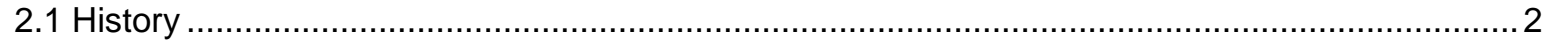

2.2 Strengthened measures against $\mathrm{SO}_{2}$ and $\mathrm{NO}_{x}$ under the 11th Five-Year Plan (2006-10) ..........

2.3 Introduction of PM2.5 controls under the 12th Five-Year Plan (2011-15) ................................6

2.4 The Air Pollution Prevention and Control Action Plan (2013-17) and reduction of coal use .......8

2.4.1 The Air Pollution Prevention and Control Action Plan (2013-17) ..................................... 8

2.4.2 Measures to promote reduction of coal use ................................................................ 10

2.4.3 Revision of the Environment Protection Law and administrative systems of responsibility for

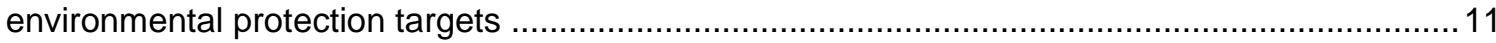

2.4.4 The Action Plan for Preventing Air Pollution: the final step in strengthening air pollution

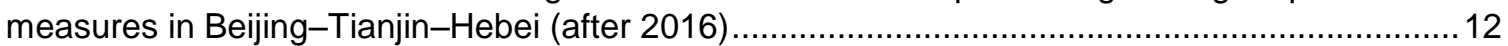

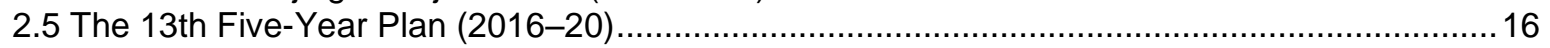

2.6 The Winter Clean Heating Plan in Northern Area (2017-21) ..............................................17

2.7 The Action Plan to Win the Blue Sky Defence War (2018-20) ........................................... 18

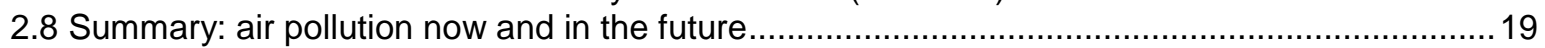

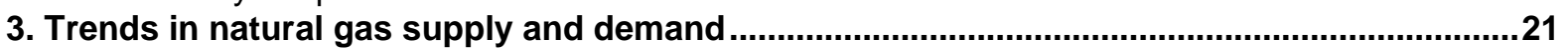

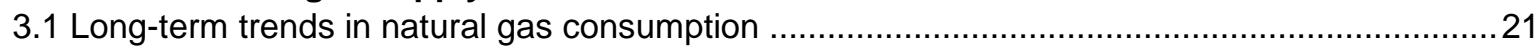

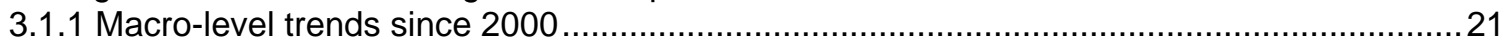

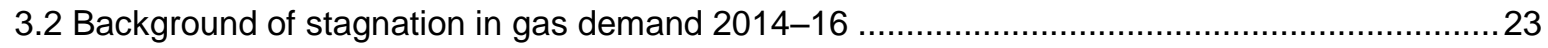

3.2.1 Trends in natural gas and environmental policies: shortage of supply (around 2013) ........23

3.2.2 Natural gas price reforms and changes in price competitiveness $(2014-16)$.....................23

3.3 Impact of measures against air pollution on natural gas supply and demand $(2017-18) \ldots \ldots \ldots .25$

3.3.1 Trends in supply and demand for natural gas in 2017-18 ….......................................25

3.3.2 Impact of action on air pollution and the problem of gas shortages .................................28

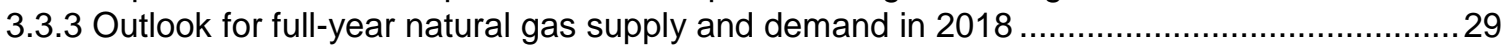

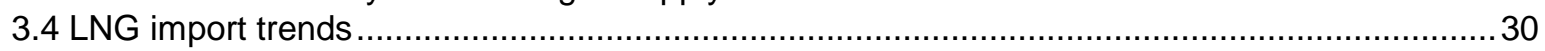

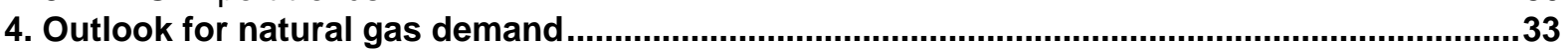

4.1 Projections for long term natural gas supply and demand by various organizations .................33

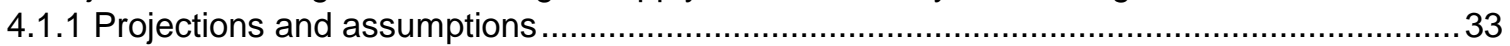

4.1.2 NDRC position document on establishing long-term stable natural gas supply system .......34

4.1.3 CNPC estimates of potential natural gas demand generated by coal-to-gas switching........ 35

4.1.4 Key figures in the Winter Clean Heating plan in the northern area ......................................36

4.1.5 Subsidies to promote use of natural gas under air pollution measures ................................38

4.2 Discussion on outlook for medium-term natural gas consumption (up to 2020)........................39

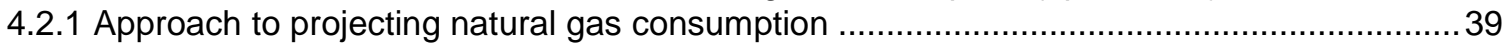

5. Outlook for medium-term LNG demand and impact on the international market....................42

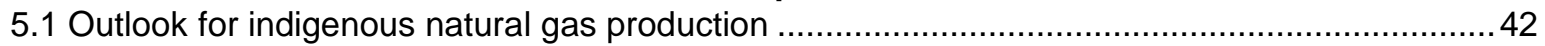

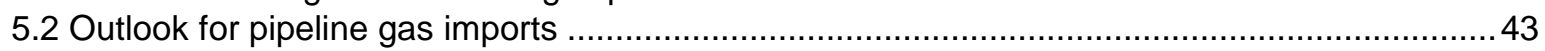

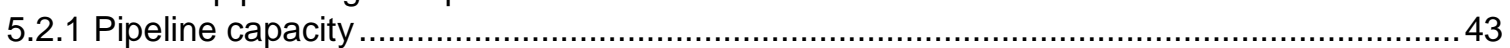

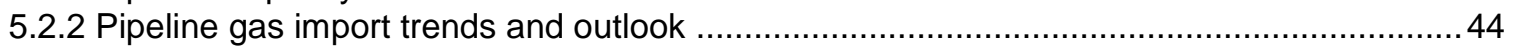

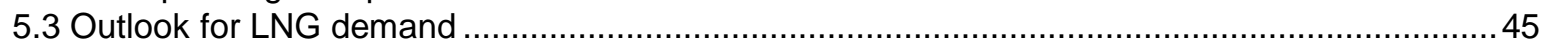

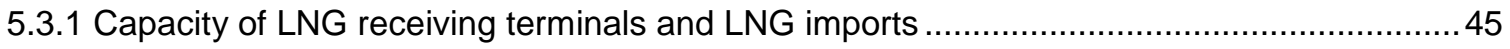

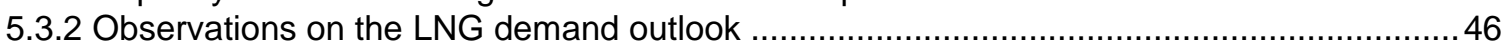

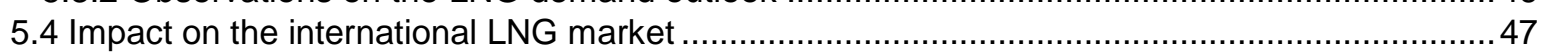

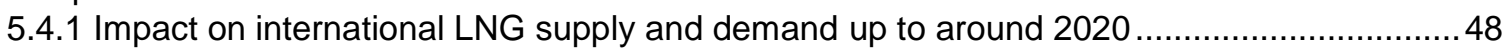

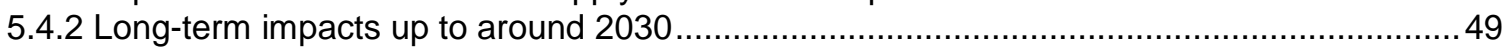

References 

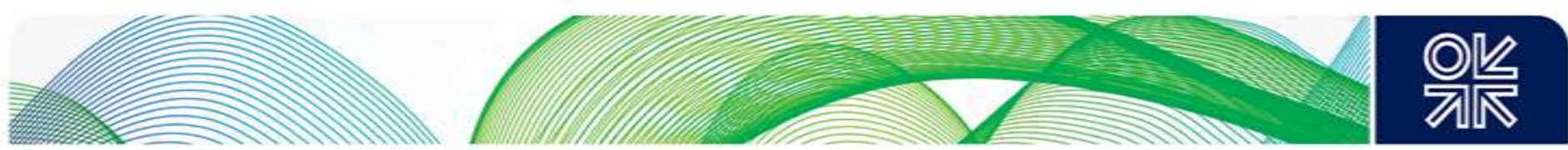

\section{Figures}

Figure 2.1: Development of environmental policies and measures ...............................................2

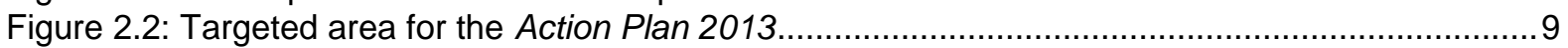

Figure 2.3: Daily PM2.5 levels and targets in Beijing, Tianjin and Shijiazhuang (Hebei) .....................12

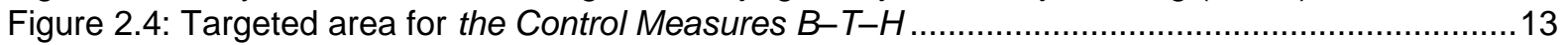

Figure 2.5: Daily PM2.5 levels and daily targets in Beijing, Tianjin and Shijiazhuang (Hebei)............ 14

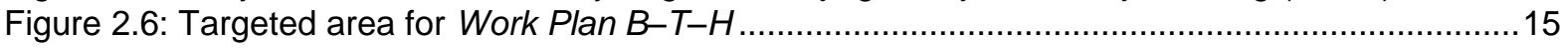

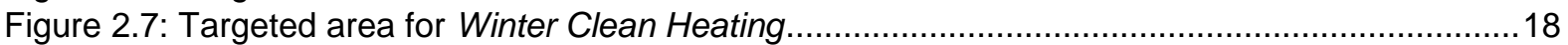

Figure 2.8: Targeted area for the Blue Sky Action Plan ...........................................................19

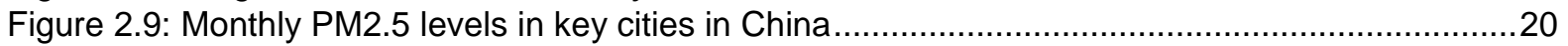

Figure 3.1: Growth rate of GDP, total energy and natural gas consumption ....................................22

Figure 3.2: Historical data and outlook for LNG receiving capacity and utilization rate .......................32

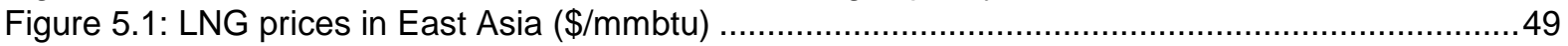

Figure 5.2: Outlook for LNG supply and demand in the global market..........................................49

\section{Tables}

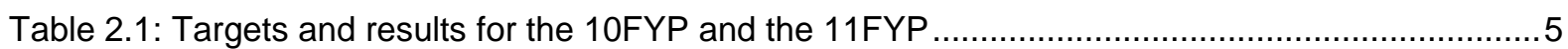

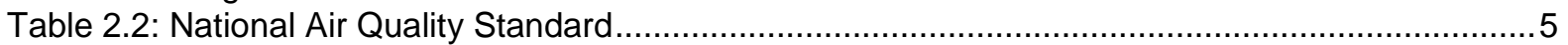

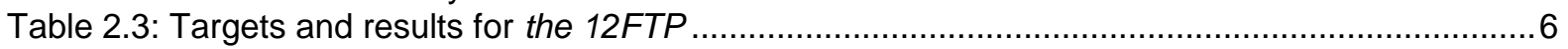

Table 2.4: Air pollution reduction targets (\%) in 19 key areas by 2015 (reduction percentage over

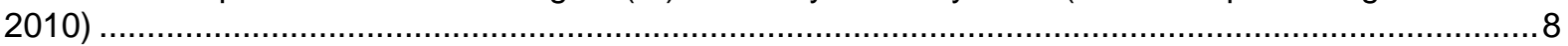

Table 2.5: The target for reduction for coal consumption and actual demand $(\mathrm{mt})$...........................11

Table 2.6: Annual targets for PM2.5 in 2017 regulated by the Intensive Air Pollution Prevention and

Control Measures for Beijing-Tianjin-Hebei (2016-17) ............................................................. 14

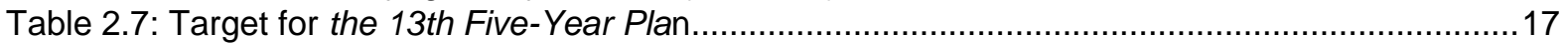

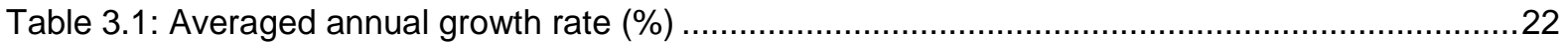

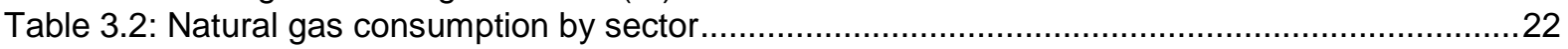

Table 3.3: Price competitiveness of natural gas against competing fuels .........................................25

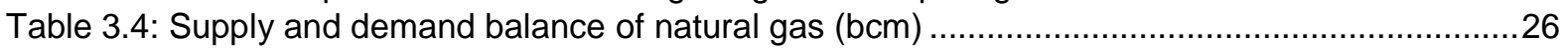

Table 3.5: Growth rate of monthly natural gas consumption (\% over the same month of the previous

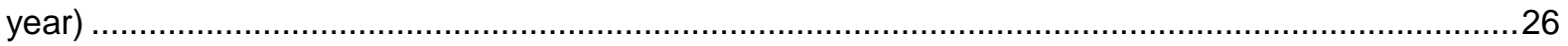

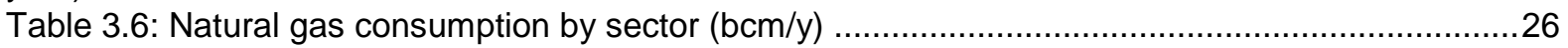

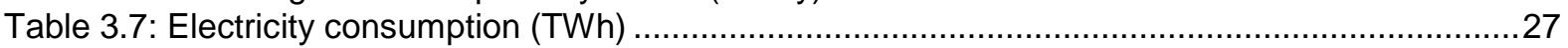

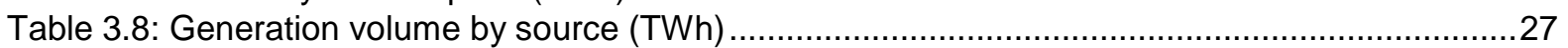

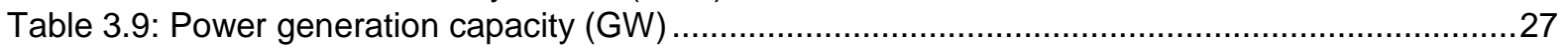

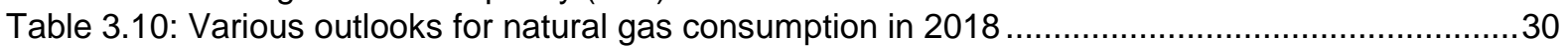

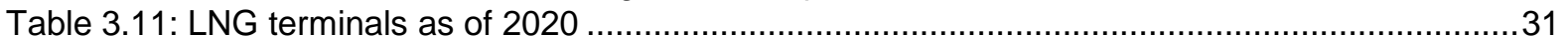

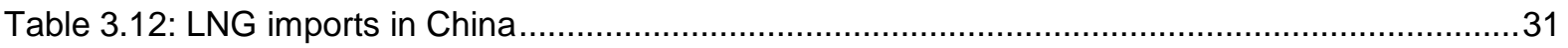

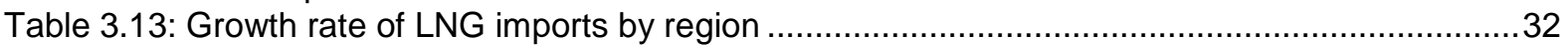

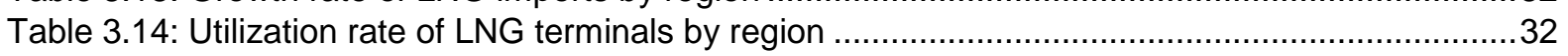

Table 4.1: Outlooks for natural gas demand by various organizations $(\mathrm{Bcm})$..................................33

Table 4.2: Outlooks for natural gas supply by various organizations ............................................. 34

Table 4.3: Additional natural gas demand generated by coal-to-gas switching projects (From 2016 to

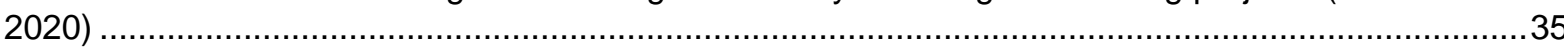

Table 4.4: Share of region regarding additional natural gas demand generated by coal-to-gas

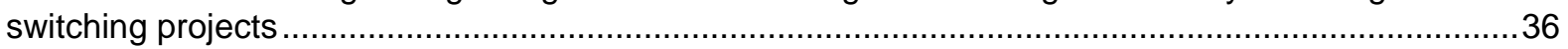

Table 4.5: The targets of the Winter Clean Heating Plan in the northern area....................................37

Table 4.6: Heating area (in which gas is currently used) and gas consumption in the targeted regions

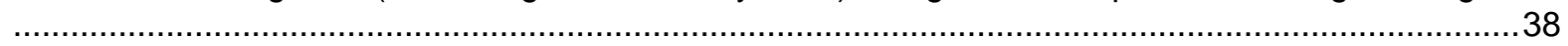

Table 4.7: Targets and natural gas demand for natural gas heating systems in the ' $2+26$ ' .................38

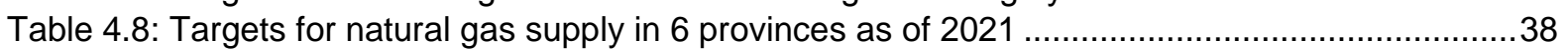



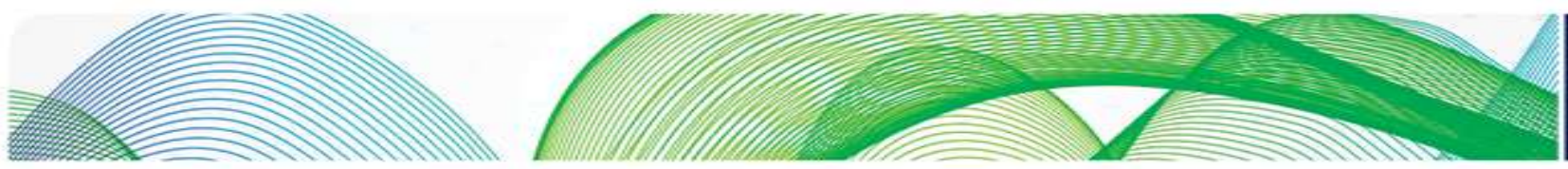

\section{OVI}

Table 4.9: Subsidy for using natural gas for residential heating

39

Table 4.10: Key data to predict natural gas demand by 2020

.. 40

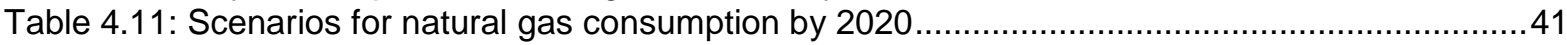

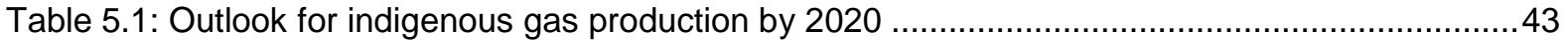

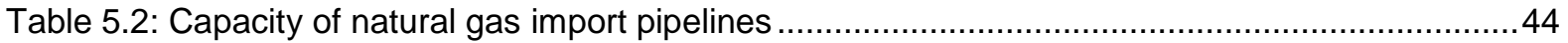

Table 5.3: Outlook for pipeline gas imports $(\mathrm{bcm} / \mathrm{y})$............................................................45

Table 5.4: Outlook for LNG demand in 2020 by natural gas consumption case ............................47 


\section{Glossary}

\begin{tabular}{|c|c|}
\hline tce & tonnes coal equivalent \\
\hline mtce & million tonnes coal equivalent \\
\hline $\mathrm{mt}$ & million tonnes \\
\hline $\mathrm{mt} / \mathrm{y}$ & million tonnes per year \\
\hline $\mathrm{mcm}$ & million cubic metres \\
\hline bcm & billion cubic metres \\
\hline tcm & trillion cubic metres \\
\hline $\mathrm{bcm} / \mathrm{y}$ & billion cubic metres per year \\
\hline $\mathrm{t} / \mathrm{h}$ & ton of steam per hour \\
\hline$\mu \mathrm{g} / \mathrm{m}^{3}$ & micro grammes per cubic metres \\
\hline$\$ / b b l$ & US Dollars per barrel \\
\hline$\$ / \mathrm{mmbtu}$ & US Dollars per million British thermal unit \\
\hline yuan $/ \mathrm{m}^{3}$ & Chinese Yuan per cubic metre \\
\hline yoy & year-on-year \\
\hline GW & gigawatt \\
\hline TWh & terawatt hour \\
\hline $\mathrm{m}^{3} /$ day & cubic metres per day \\
\hline $\mathrm{bm}^{2}$ & billion square metres \\
\hline $\mathrm{SO}_{2}$ & Sulphur dioxide \\
\hline $\mathrm{NOx}$ & Nitrogen oxides \\
\hline CBM & Coalbed methane \\
\hline SNG & Synthetic natural gas \\
\hline CNG & Compressed natural gas \\
\hline CCGT & Combined Cycle Gas Turbine \\
\hline $\mathrm{CHP}$ & Combined heat and power \\
\hline NOC & National Oil Company \\
\hline NDRC & National Development and Reform Commission \\
\hline CNOOC & China National Offshore Oil Corporation \\
\hline CNPC & China National Petroleum Corporation \\
\hline GHE & Guanghui Energy Co.,LTD. \\
\hline GIIGNL & The International Group of Liquefied Natural Gas Importers \\
\hline IHS & IHS Markit \\
\hline KOGAS & Korea Gas Corporation \\
\hline MOGE & Myanmar Oil and Gas Enterprise \\
\hline ONGC & Oil and Natural Gas Corporation Limited \\
\hline
\end{tabular}



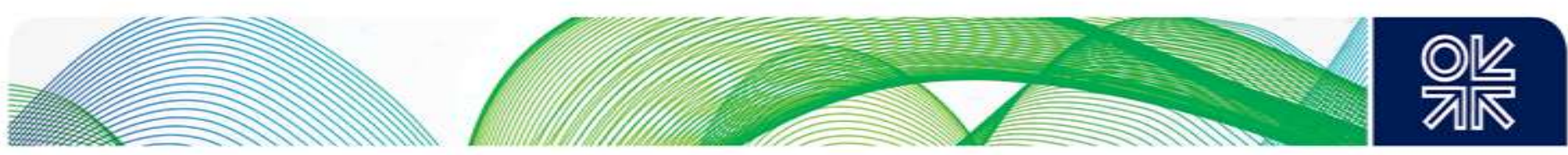

\section{Introduction}

All eyes in the international LNG market are on the future course of China's surging growth in imports. Since 2017, natural gas consumption in China has risen sharply as a result of strengthened action against air pollution, which has cut the use of low-grade 'dirty' coal and vigorously promoted the use of electricity and natural gas in place of coal - namely 'coal-to-gas switching'. It is well-known in the world that these measures triggered a natural gas supply shortage, which became a matter of social concern in the winter of 2017/18. Many energy experts on China expected the sharp upward trend in natural gas consumption to ease and growth to slow in 2018. As of August 2018, however, there were no signs of this happening. How long and to what extent China's 'war on air pollution' will continue, how long the sharp upward trend in natural gas and LNG demand will continue, and what will happen to the supply and demand balance of natural gas in the winter of 2018/19, are thus questions of major interest.

This report has three objectives:

1. To review the measures taken against air pollution since the late 2000 s and trace the impact of such environmental action on demand for natural gas and LNG;

2. To analyse the facts, together with the background, that provoked the unexpected sharp rise in natural gas and LNG imports during 2017 and the first half of 2018;

3. To consider the outlook for natural gas supply and demand and for LNG imports up to around 2020 on the basis of this analysis, and to assess the impact of trends in natural gas consumption in China on the international LNG market. 

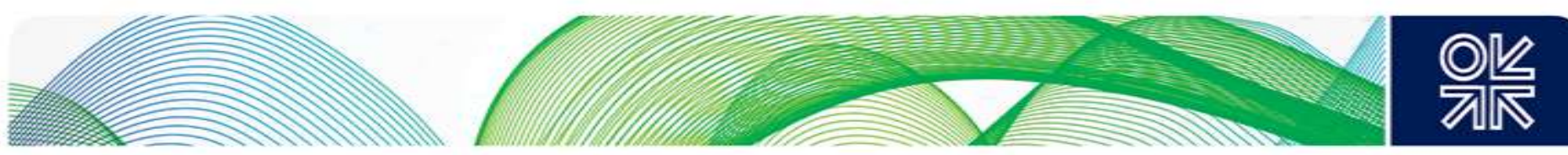

\section{Evolution of the war on air pollution in China}

\subsection{History}

Focusing on balancing economic development and environmental protection, China began stepping up action to tackle worsening air pollution in 1973. Action then got into full swing with the formation of the National Environmental Protection Agency in 1984, followed by the enactment of the Environment Protection Law (trialled in 1979) in December 1989.

Until the period of the 11th Five-Year Plan (11FYP) (NPC, Mar.2006) the main measures to tackle air pollution were focused on the reduction of $\mathrm{SO}_{2}$ and $\mathrm{NO}_{x}$ emissions and the results were fairly successful. But a major turning point appeared in 2011-12 when data on PM2.5 emissions sent out on Twitter from the US embassy in Beijing gradually began to draw people's attention. This eventually became a political issue and targets for PM2.5 emissions were added to the government's policy goals in the middle of the period of the 12th Five-Year plan (12FYP) (NPC, Mar.2011). Yet, the results of the actual observation data of PM2.5 were fairly poor and the process of achieving these environmental goals was expected to follow a rocky path.

The watershed year for environmental policy, however, was 2013. Until then, the aim had been to achieve macro-level quantitative targets set under five-year plans that focused on enhanced efficient use of energy and clean use of coal. This changed with the Air Pollution Prevention and Control Action Plan (2013-17) (Action Plan 2013) (SCPRC, Sep.2013), which set more concrete numerical targets for air pollution and laid out more robust policies to achieve them. Despite the contradictions and dislocations that have accompanied these policies, China has determinedly moved to pursue a course of switching from coal to other energy sources. Milestones in the development of air pollution policies since the 11FYP are shown in Figure 2.1 and this chapter will review these developments, focusing on those air pollution measures that affect supply and demand for natural gas.

Figure 2.1: Development of environmental policies and measures

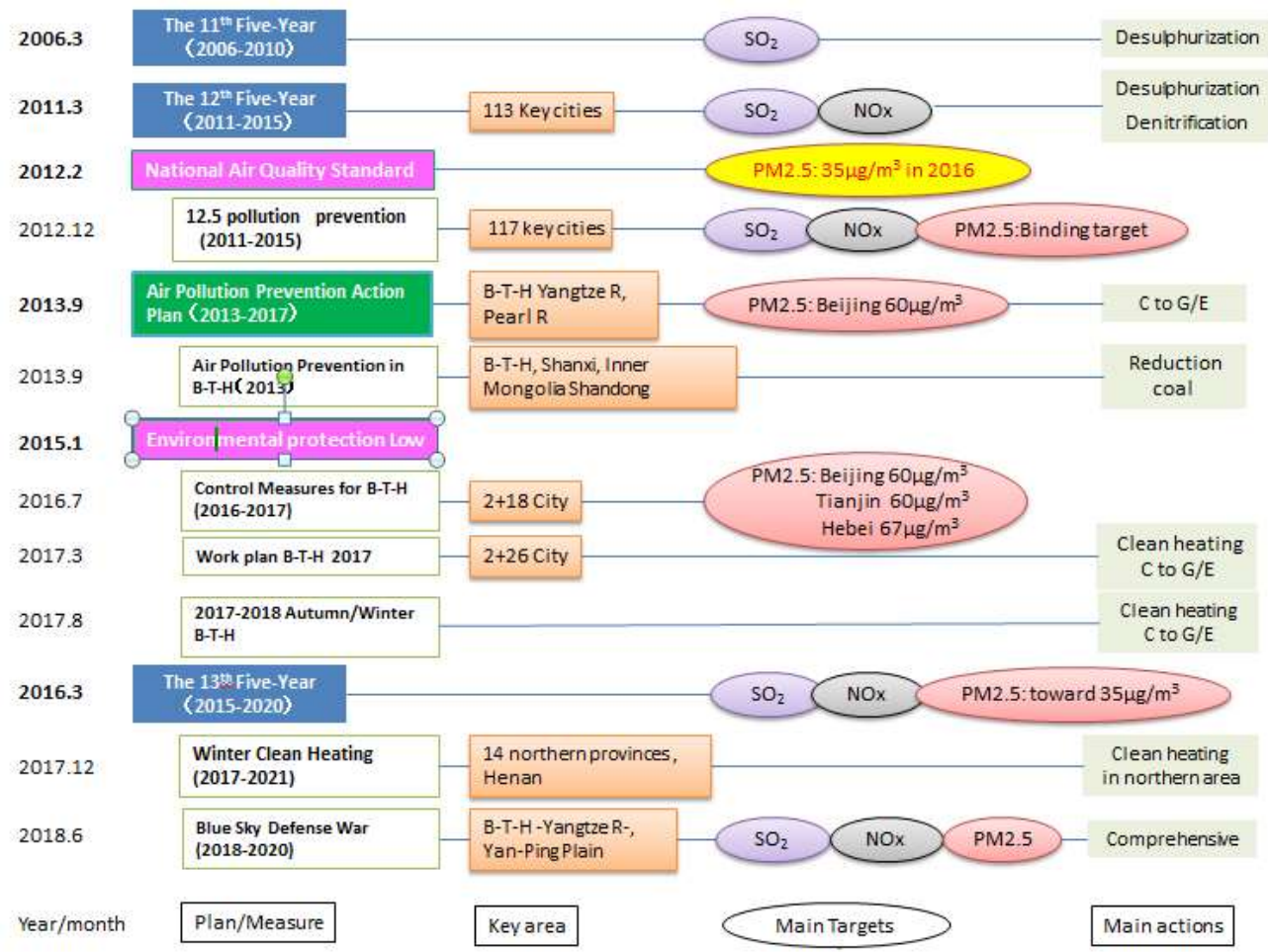

Source: By C. Ishiguro based on various materials. 

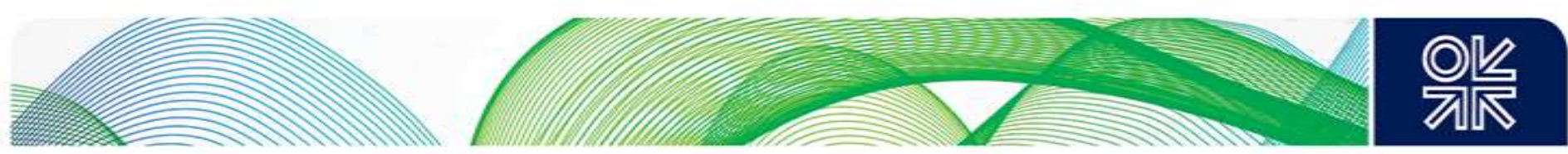

\subsection{Strengthened measures against $\mathrm{SO}_{2}$ and $\mathrm{NO}_{x}$ under the 11th Five-Year Plan (2006-10)}

Starting with the 11FYP, which targeted the period 2006 to 2010, the main features of China's energy and environmental policies were mapped out as follows.

Energy efficiency: The 11FYP called for the promotion of energy conservation and set a binding target of reducing energy consumption per unit of GDP by 20 per cent from the 2005 level. This was the first time a numerical target for energy consumption had been set as a 'binding' target. However, it was not intended to impose quantitative constraints, since targeted economic growth rate was set at 7.5 per cent per year, so even if energy efficiency improved by 20 per cent, total energy consumption was projected to increase from 2,360 mtce to 2,700 mtce in the 11FYP, as shown in Table 2.1.

Environmental policy: the 11th Five-Year Plan for National Environmental Protection (11FYPE) (MNEP, 2007), promulgated in November 2007, made environmental policy a core national strategy, and presented solutions for balancing China's excessive economic growth on the one hand and growth-inhibiting resource depletion and deteriorating environmental problems on the other. During this period, action on air pollution targeted $\mathrm{SO}_{2}$ but measures against $\mathrm{NO}_{x}$ were in their infancy. The priority areas identified under the 11FYPE included:

- the designation of 113 key cities ${ }^{1}$ for improvement of urban air quality in order to combat $\mathrm{SO}_{2}$ and acid rain,

- promoting the installation of flue gas desulphurization systems at coal-fired power generation plants, ${ }^{2}$

- the use of low-sulphur coal,

- $\quad$ equipping boilers with desulphurization systems.

Steps were also taken to reduce the number of inefficient small power generation plants and overcapacity in the steel, nonferrous metal, and coal industries, and to enhance production efficiency in energy-intensive industries.

The policy of achieving urban air quality superior to the Grade II National Air Quality Standard (see Table 2.2) for more than 292 days per year in 75 per cent of key cities was adopted ${ }^{3}$ as an environmental target. Also, a reduction of $\mathrm{SO}_{2}$ emissions by 10 per cent from 2005 levels was adopted as a priority binding target, due to the failure to achieve the target of reducing $\mathrm{SO}_{2}$ emissions by 10 per cent from 2000 levels during the period covered by the 10th Five-Year Plan (instead, emissions had risen by 27.8 per cent, see Table 2.1).

During this period, natural gas use was promoted in the power generation sector to reduce $\mathrm{SO}_{2}$ emissions. After that, however, the government's policy priority for natural gas use shifted from the power generation sector to other sectors such as the city gas and industrial sectors, mainly due to the problem of the price competitiveness of natural gas. ${ }^{4}$

\footnotetext{
1 The municipalities of Beijing, Tianjin, Shanghai and Chongqing, the capital cities of 22 provincial and five autonomous regions, together with another 82 cities.

${ }^{2}$ Installation of flue gas desulphurization systems at $167 \mathrm{GW}$ of existing power generating capacity and at $188 \mathrm{GW}$ of new capacity by 2009. The 11th Five-Year Plan for Sulphur Dioxide Emission Control in Existing Coal-fired Power Plants (NDRC and MNEP, Mar.2017).

${ }^{3}$ The target was based on the previous National Air Quality Standards set in 1996

${ }^{4}$ For details see Miyamoto and Ishiguro (2006)
} 

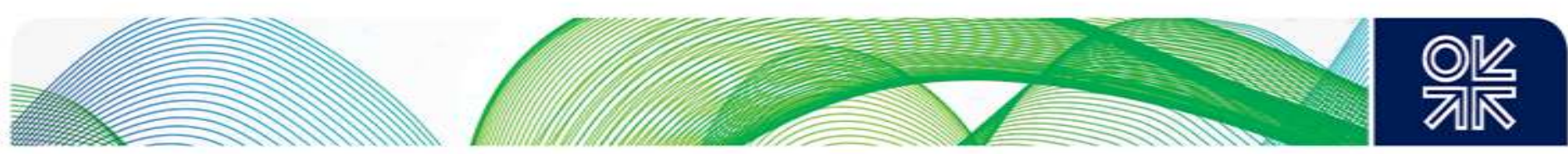

Strengthening environmental obligations: owing to the perceived difficulty of achieving these binding targets, various rules were introduced 5 to make local governments and major firms ensure a steady implementation of environmental measures.

In May 2010, the government published a document entitled Guidance on Joint Prevention and Control Work for Air Pollution for Improving Regional Air Quality (Guidance) (SCPRC, May 2010). This was China's first comprehensive policy document on air pollution; it called for the development of arrangements for planning, supervising, and managing measures to tackle air pollution at the regional level, together with effective environmental action through joint implementation of plans. More specifically, to achieve the target of meeting the Grade II National Air Quality Standard in the key cities and regions by 2015, local governments should introduce regional laws and regulations and establish regional cooperation mechanisms for the necessary control measures. Also, major firms should attain national environmental standards. The designated key cities and regions were BeijingTianjin-Hebei, the Yangtze River Delta, Central Liaoning, Shandong, and others. ${ }^{6}$ One important point of the new guidance was that $\mathrm{NO}_{x}$ and PM10 were added to the objectives of air pollution measures, on top of $\mathrm{SO}_{2}$. Specific measures adopted included not only the mandatory installation of flue gas desulphurization systems at coal-fired power plants, but also the nationwide installation of denitrification equipment before the end of the 12FYP. In the key cities and regions, such measures as: restrictions on the construction of new coal power plants, the promotion of clean coal in the power generation and industrial sectors, the pursuit of pilot projects to control coal consumption, the promotion of clean energy use including natural gas, and the development of air monitoring systems, were introduced. Also, in the residential heating sector, procedures to remove small coal-fired heating boilers and to install high-efficiency central heating systems were adopted.

As a result of the above efforts, the percentage of coal-fired power plants fitted with denitrification equipment had risen to 90 per cent by the end of the 11FYP in 2010. While tighter administration caused difficulties in some regions - including temporary forced shutdowns at brick and tile factories due to worsened air pollution in the winter - the air pollution situation did improve and some targets were achieved ahead of schedule during this period (see Table 2.1).

\footnotetext{
${ }^{5}$ For example, the 'one-vote veto' system was introduced; this means that if someone in a responsible position missed an environmental target, that person would fail a subsequent comprehensive personnel evaluation. Also, local governments are required to report annually to the central government and to report on attainment in the final year of the plan.

${ }^{6}$ Wuhan, Changsha, Zhuzhou, Xiangtan, Chengdu, and the Taiwan Strait coast.
} 

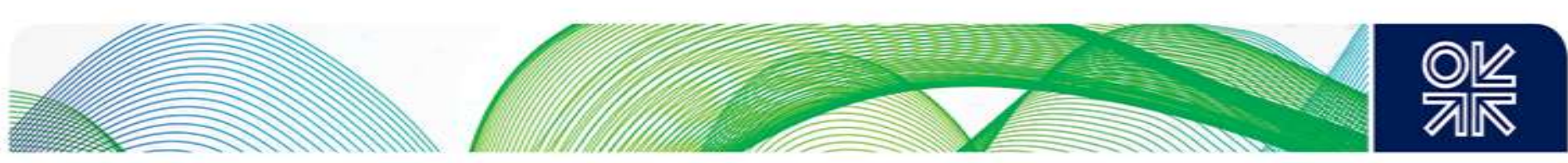

Table 2.1: Targets and results for the 10FYP and the 11FYP

\begin{tabular}{|c|c|c|c|c|c|}
\hline & 2000 & $\begin{array}{l}\text { 10FYP } \\
\text { target }\end{array}$ & $\begin{array}{c}2005 \\
\text { result }\end{array}$ & $\begin{array}{l}\text { 11FYP } \\
\text { target }\end{array}$ & $\begin{array}{l}2010 \\
\text { result }\end{array}$ \\
\hline GDP (trillion Yuan) & 9.9 & 12.5 & 18.5 & & 39.8 \\
\hline Annual growth rate (\%) & & 7 & 9.5 & 7.5 & 11.2 \\
\hline \multicolumn{6}{|l|}{ Energy } \\
\hline $\begin{array}{l}\text { Energy consumption per GDP } \\
\text { (tce/10000 yuan) }\end{array}$ & & & 1.22 & 0.98 & 0.81 \\
\hline $\begin{array}{l}\text { Change over the previous period } \\
(\%)\end{array}$ & & -15 to -17 & & $-20 * 1$ & -19.1 \\
\hline TEC (mtce) & 1,386 & & 2,360 & 2,700 & 3,250 \\
\hline Annual growth rate (\%) & & & 10.5 & 4 & 6.6 \\
\hline Coal consumption (mt) & 1,320 & & 2,167 & & 3,240 \\
\hline Annual growth rate (\%) & & & 10.4 & & 6.6 \\
\hline Share of TEC (\%) & 61.0 & -3.9 & 69.1 & 66.1 & 69.2 \\
\hline Natural gas consumption (bcm) & 24.5 & & 47.9 & & 107.5 \\
\hline Annual growth rate (\%) & & & 14.4 & & 14.0 \\
\hline Share of TEC (\%) & 3.3 & & 2.8 & 5.3 & 4.4 \\
\hline \multicolumn{6}{|l|}{ Environment } \\
\hline $\mathrm{SO}_{2}$ emission $(\mathrm{mt})$ & 19.95 & 18.00 & 25.49 & 22.95 & 22.68 \\
\hline $\begin{array}{l}\text { Change over the previous period } \\
(\%)\end{array}$ & & -10 & +27.8 & $-10^{* 1}$ & -14.3 \\
\hline $\begin{array}{l}\text { Achievement rate for Grade II } \\
\text { National Air Quality Standard (\%)*2 }\end{array}$ & 36.5 & 50.0 & 54.0 & & \\
\hline $\begin{array}{l}\text { Achievement rate for } 292 \text { days/y of } \\
\text { Grade II in AQS*2 in key cities (\%) }\end{array}$ & & & 69.4 & 75.0 & 72.0 \\
\hline
\end{tabular}

Note: *1 Binding target. *2 The target was based on National Air Quality Standard in 1996.

Source: The 10th Five-Year Plan (NPC, Mar 2001); 11FYP; the 11th Five-Year-Plan for National Energy

Development; (NDRC, Apr.2007); 11FYPE; China Energy Statistical Yearbook 2017.

Table 2.2: National Air Quality Standard

\begin{tabular}{|c|c|c|c|c|c|c|c|c|c|c|}
\hline \multicolumn{4}{|c|}{ Implementation in 1996*1 } & \multicolumn{4}{c|}{$\begin{array}{c}\text { Amendment in 2012*2 } \\
\text { Implementation in 2016 }\end{array}$} \\
\hline$\mu \mathrm{g} / \mathbf{m}^{3}$ & Grade I & \multicolumn{2}{|c|}{ Grade II } & \multicolumn{2}{c|}{ Grade III } & \multicolumn{2}{c|}{ Grade I } & \multicolumn{3}{c|}{ Grade II } \\
\hline & Annual & Daily & Annual & Daily & Annual & Daily & Annual & Daily & Annual & Daily \\
\hline $\mathbf{S O}_{2}$ & 20 & 50 & 60 & 150 & 100 & 250 & 20 & 50 & 60 & 150 \\
\hline $\mathbf{N O}_{2}$ & 40 & 80 & 80 & 120 & 80 & 120 & 40 & 80 & 40 & 80 \\
\hline $\mathbf{N O}_{\mathbf{x}}$ & & & & & & & 50 & 100 & 50 & 100 \\
\hline PM10 & 40 & 50 & 100 & 150 & 150 & 250 & 40 & 50 & 70 & 150 \\
\hline PM2.5 & & & & & & & 15 & 35 & 35 & 75 \\
\hline
\end{tabular}

Note: *1. Initial National Air Quality Standards were set in 1996. *2. Revised in 2012 and implemented in 2016, as described in the next section.

Source: Ministry of National Environmental Protection, the Ambient National Air Quality Standard (NEP, Feb. 2012). 

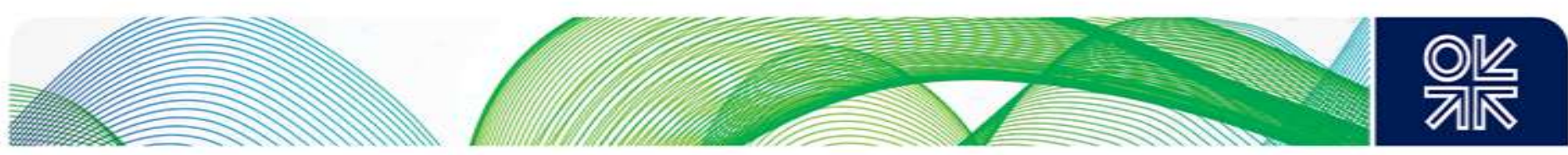

\subsection{Introduction of PM2.5 controls under the 12th Five-Year Plan (2011-15)}

Following better-than-targeted performance during the 11FYP, the 12th Five-Year Plan (12FYP) went further by setting targets for a 16 per cent reduction in energy consumption per unit of GDP and an 8 per cent reduction in $\mathrm{SO}_{2}$ emissions compared to 2010 by 2015. It also set new binding targets for similar reductions of 10 per cent in $\mathrm{NO}_{x}$ emissions.

Despite this strengthening of action to tackle air pollution in China, smog and similar phenomena in Beijing and other major cities saw little improvement, while PM2.5 monitoring data published on Twitter by the US Embassy in Beijing from around the autumn of 2011 increasingly caused an international stir. Developments such as these put considerable pressure on the Chinese government, leading Premier Li Keqiang to publicly announce the inclusion of PM2.5 in air pollution standards, at an address during a conference on the environment at the end of 2011. The central government committed itself to develop a PM2.5 monitoring system and to draw up new air pollution standards by the end of 2012.

PM2.5 levels in certain areas became subject to controls under the 12th Five-Year Plan for National Environmental Protection (12FYPE) (MNEP, 2011), and it was announced that PM2.5 would be included in air quality monitoring in the Beijing-Tianjin-Hebei, Yangtze River Delta, and Pearl River Delta regions. The number of key cities for air pollution control was additionally expanded from 113 to 333, and local governments were given a greater role and responsibility for implementation of environmental measures.

Table 2.3: Targets and results for the 12th Five-Year Plan

\begin{tabular}{|c|c|c|c|c|}
\hline & $\begin{array}{c}2010 \\
\text { result }\end{array}$ & $\begin{array}{l}12 F Y P \\
\text { target }\end{array}$ & Status & $\begin{array}{c}2015 \\
\text { result }\end{array}$ \\
\hline GDP (trillion Yuan) & 39.8 & 55.8 & & 67.7 \\
\hline Annual growth rate (\%) & 11.2 & 7.0 & & 7.8 \\
\hline \multicolumn{5}{|l|}{ Energy } \\
\hline $\begin{array}{l}\text { Energy consumption per GDP } \\
\text { (tce/10,000yuan) }\end{array}$ & 0.81 & 0.68 & Binding & 1.48 \\
\hline Over the previous period (\%) & -19.1 & -16.0 & Binding & -18.2 \\
\hline TEC (mtce) & $3,250^{\star 1}$ & 4,000 & & 4,300 \\
\hline Annual growth rate (\%) & & 4.3 & & 3.6 \\
\hline Coal consumption (mt) & 3,240 & & & 3,960 \\
\hline Share of TEC (\%) & 69.2 & 65.0 & & 64.0 \\
\hline Natural gas consumption (bcm) & 107.5 & & & 193.1 \\
\hline Share of TEC (\%) & 4.0 & 7.5 & & 5.9 \\
\hline \multicolumn{5}{|l|}{ Environment } \\
\hline $\mathrm{SO}_{2}$ emission (mt) & 22.68 & 20.86 & \multirow[t]{2}{*}{ Binding } & \\
\hline Over the previous period (\%) & -14.3 & -8.0 & & -18.0 \\
\hline $\mathrm{NO}_{\mathrm{x}}$ emission $(\mathrm{mt})$ & 22.73 & 20.46 & \multirow[t]{2}{*}{ Binding } & \\
\hline Over the previous period & & -10.0 & & -18.6 \\
\hline $\begin{array}{l}\text { Achievement rate for } 292 \text { days/y of Grade II } \\
\text { in AQS in key cities (\%) }\end{array}$ & 72.0 & $\geqq 80.0$ & & 69.4 \\
\hline
\end{tabular}

Note: *1 Figure for TEC result in 2010 was revised to 3,610 mtce in the document of the 13FYP, (NPC, Mar.2016).

Source: 12FYP; the 12th Five-Year-Plan for National Energy Development (NDRC, Jan.2013a); 12FYPE; China Energy Statistical Yearbook 2017. 

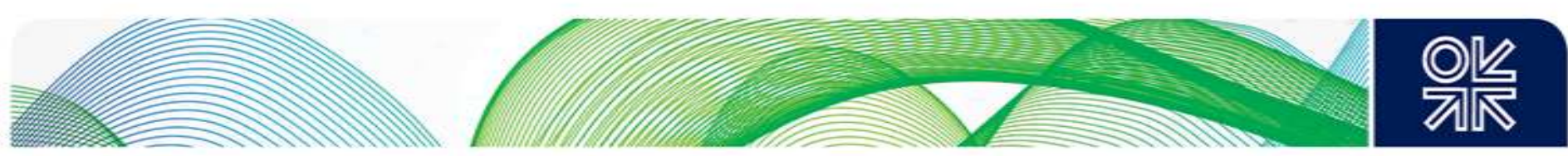

It was against this backdrop that the amended National Air Quality Standard introducing new standards on air quality (see Table 2.2) was announced in February 2012. Under the new standards, the annual average Grade II PM10 limit was lowered from $100 \mu \mathrm{g} / \mathrm{m}^{3}$ to $70 \mu \mathrm{g} / \mathrm{m}^{3}$, and a new standard for PM2.5 was set. The area subject to this new standard was initially limited to urban parts of Beijing-Tianjin-Hebei, the Yangtze River Delta, and the Pearl River Delta, where PM2.5 pollution was particularly severe. It was stipulated, however, that the coverage would subsequently be rolled out to the 113 key cities in 2013 , then to urban areas in each province in 2015 , and ultimately nationwide in January 2016. The new standard also stated that the key regions of Beijing-Tianjin-Hebei, the Yangtze River Delta, and the Pearl River Delta would lead the way for other regions by actively adopting the new standards, pursuing the adoption of clean energies in order to control coal consumption, and making efforts to introduce tighter regulations against air pollution.

Under the 12th Five-Year Plan for the Prevention and Control of Air Pollution in Key Areas, published in December 2012 (MNEP, Dec.2012), common PM10, SO, $\mathrm{NO}_{x}$, and PM2.5 targets for attainment by 2015 were set for designated regions. The targets consisted of a 10 per cent reduction in PM10, 10 per cent reduction in $\mathrm{SO}_{2}, 7$ per cent reduction in $\mathrm{NO}_{x}$, and 5 per cent reduction in PM2.5 compared to levels in 2010, and applied to 117 of above prefecture-level cities and seven other cities in 19 of provinces, autonomous regions, and direct-controlled municipalities, including Beijing-TianjinHebei, the Yangtze River Delta, the Pearl River Delta. (These locations were spread in total, 13.8 per cent of China's land area.) As pollution was especially severe in the Beijing-Tianjin-Hebei, Yangtze River Delta, and Pearl River Delta regions, the lowering of averaged annual concentrations by 6 per cent compared to 2010 levels was made a binding target in these regions as a whole (see Table 2.4). The plan incorporated a number of specific measures, including the closure of heavy emitters of pollutants and/or excessive production capacity, expansion of the use of clean energies such as natural gas, restraint of total coal consumption, adoption of clean coal technologies, enhanced action against $\mathrm{SO}_{2}$ and $\mathrm{NO}_{x}$ emissions, and development of air monitoring systems. ${ }^{7}$

Natural gas was positioned as an important solution for environmental protection and the plan laid out strategies in accordance with the 12FYP including the development of infrastructure such as pipelines, LNG receiving terminals, and city gas supply systems; however, it only included a moderate expansion of natural gas-fired power generating capacity.

Regarding coal, the plan established a new goal of drawing up mid/long-term targets for individual regions to curb total coal consumption. This was in addition to existing policy requiring the decommissioning of coal-fired boilers in regions with central heating supply systems, and a progressive shutdown of small coal-fired boilers with a capacity of $10 \mathrm{t} / \mathrm{h}$ or under in urban areas.

\footnotetext{
7 These measures had to be in place up to the end of 2012 in Beijing-Tianjin-Hebei, the Yangtze River Delta, and the Pearl River Delta and up to the end of 2015 in other regions.
} 

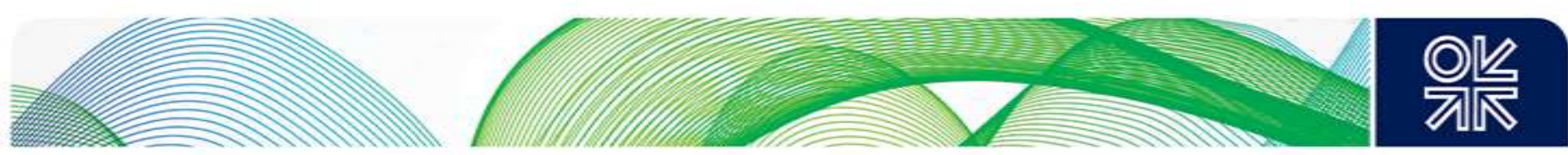

Table 2.4: Air pollution reduction targets (\%) in 19 key areas by 2015 (reduction percentage over 2010)

\begin{tabular}{|l|l|c|c|c|c|c|}
\hline Region & $\mathbf{S O}_{2}$ & NOx & PM10 & \multicolumn{2}{|c|}{ PM2.5 } \\
\hline \multirow{3}{*}{ B-T-H } & Beijing, & -10 & -7 & -15 & $\mathbf{- 1 5}$ & binding \\
\cline { 2 - 7 } & Tianjin & -8 & -9 & -12 & $\mathbf{- 6}$ & binding \\
\cline { 2 - 7 } & Hebei & -11 & -7 & -12 & $\mathbf{- 6}$ & binding \\
\hline \multirow{2}{*}{$\begin{array}{l}\text { Yangtze River } \\
\text { Pelta }\end{array}$} & Shanghai & -11 & -9 & -10 & $\mathbf{- 6}$ & binding \\
\cline { 2 - 7 } & Jiangsu & -12 & -10 & -14 & $\mathbf{- 7}$ & binding \\
\cline { 2 - 7 } & Zhejiang & -11 & -10 & -10 & $\mathbf{- 5}$ & binding \\
\hline & Guangdong & -12 & -9 & -8 & $\mathbf{- 5}$ & binding \\
\hline & Liaoning & -11 & -9 & -12 & $\mathbf{- 6}$ & \\
\hline & Shandong & -14 & -10 & -14 & $\mathbf{- 7}$ & \\
\hline & Wuhan & -7 & -4 & -10 & $\mathbf{- 5}$ & \\
\hline & Changsha & -9 & -5 & -10 & $\mathbf{- 5}$ & \\
\hline & Chongqing & -6 & -4 & -12 & $\mathbf{- 6}$ & \\
\hline & Sichuan & -9 & -5 & -10 & $\mathbf{- 5}$ & \\
\hline & Taiwan Strait coast & -6 & -5 & -8 & $\mathbf{- 4}$ & \\
\hline & Shanxi & -10 & -7 & -12 & $\mathbf{- 4}$ & \\
\hline & Shaanxi & -7 & -5 & -14 & $\mathbf{- 4}$ & \\
\hline & Gansu & -14 & -8 & -14 & $\mathbf{- 4}$ & \\
\hline & Ningxia & -10 & -7 & -10 & $\mathbf{- 5}$ & \\
\hline & Urumqi & -9 & -9 & -12 & $\mathbf{- 4}$ & \\
\hline
\end{tabular}

Note: PM2.5 reduction targets were made mandatory for Beijing, Tianjin, Hebei, Shanghai, Jiangsu, Zhejiang, and Guangdong for the first time, but remained non-binding targets for other regions. Averaged reduction target was minus 6 per cent in Beijing, Tianjin, Hebei, Shanghai, Jiangsu, Zhejiang, and Guangdong as a whole.

Source: (MNEP, Dec.2012).

\subsection{The Air Pollution Prevention and Control Action Plan (2013-17) and reduction of coal use}

\subsubsection{The Air Pollution Prevention and Control Action Plan (2013-17)}

Placing limits on PM2.5 levels during the 12FYP thus necessitated stricter action on the environment and on energy use, and the Air Pollution Prevention and Control Action Plan (Action Plan 2013) (SCPRC Sep.2013) signalled a major shift of direction in energy use to restrict the use of coal.

Official PM2.5 figures released by China from January 2013 exceeded emission standards by a wide margin. ${ }^{8}$ Public interest in air pollution increased and demands for stronger action arose in response, leading to promulgation of the Action Plan 2013 in September 2013. In contrast to the macro-level targets set by five-year plans hitherto, this plan focused solely on bringing down PM10 and PM2.5 levels and made provisions for various detailed countermeasures.

The following key binding targets were set with the aim of significantly improving the air quality situation by 2017 :

- a reduction in PM10 concentrations of at least 10 per cent from 2012 levels in 360 prefecturelevel cities nationwide;

\footnotetext{
${ }^{8}$ According to MNEP (Aug.2013), the average concentration of PM2.5 in 74 cities (496 points) was $76 \mu \mathrm{g} / \mathrm{m}^{3}$ (between $24 \mu \mathrm{g} / \mathrm{m}^{3}$ and $172 \mu \mathrm{g} / \mathrm{m}^{3}$ ), which exceeded the Grade II target of $35 \mu \mathrm{g} / \mathrm{m}^{3}$. As for PM10, the average concentration was $123 \mu \mathrm{g} / \mathrm{m}^{3}$ (between $43 \mu \mathrm{g} / \mathrm{m}^{3}$ and $331 \mu \mathrm{g} / \mathrm{m}^{3}$ ) compared with the Grade II target of $70 \mu \mathrm{g} / \mathrm{m}^{3}$. As for $\mathrm{SO}_{2}$, the figure was $43 \mu \mathrm{g} / \mathrm{m}^{3}\left(6 \mu \mathrm{g} / \mathrm{m}^{3}\right.$ to $\left.138 \mu \mathrm{g} / \mathrm{m}^{3}\right)$ against $60 \mu \mathrm{g} / \mathrm{m}^{3}$.
} 

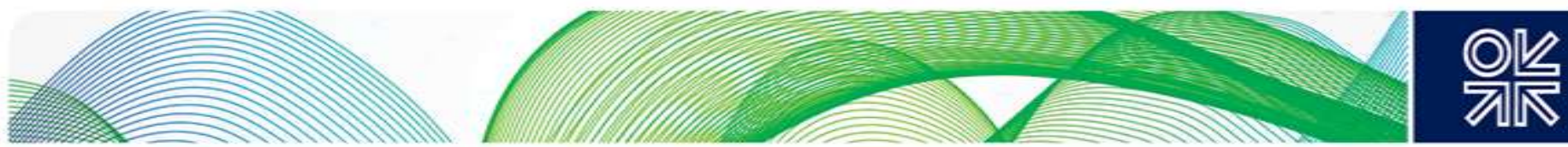

- $\quad$ reductions in PM2.5 concentrations (from 2012 levels) of:

- 25 per cent in Beijing-Tianjin-Hebei,

- 20 per cent in the Yangtze River Delta,

- 15 per cent in the Pearl River Delta;

- $\quad$ limitation of the concentration of PM2.5 in Beijing City to approximately $60 \mu \mathrm{g} / \mathrm{m}^{3} .9$

As for the measures relating to energy use, it should be noted that the Action Plan 2013 called specifically for switching from 'coal to gas' and/or from 'coal to electricity' for small boilers, and it also placed numerical limits on coal use by establishing mid- to long-term targets for reducing total coal consumption and correspondingly reducing coal's share of total primary energy consumption to not more than 65 per cent by 2017. The Action Plan 2013 also stated that the natural gas pricing system should be revised to secure price competitiveness that could facilitate coal-to-gas switching.

Figure 2.2: Targeted area for the Action Plan 2013

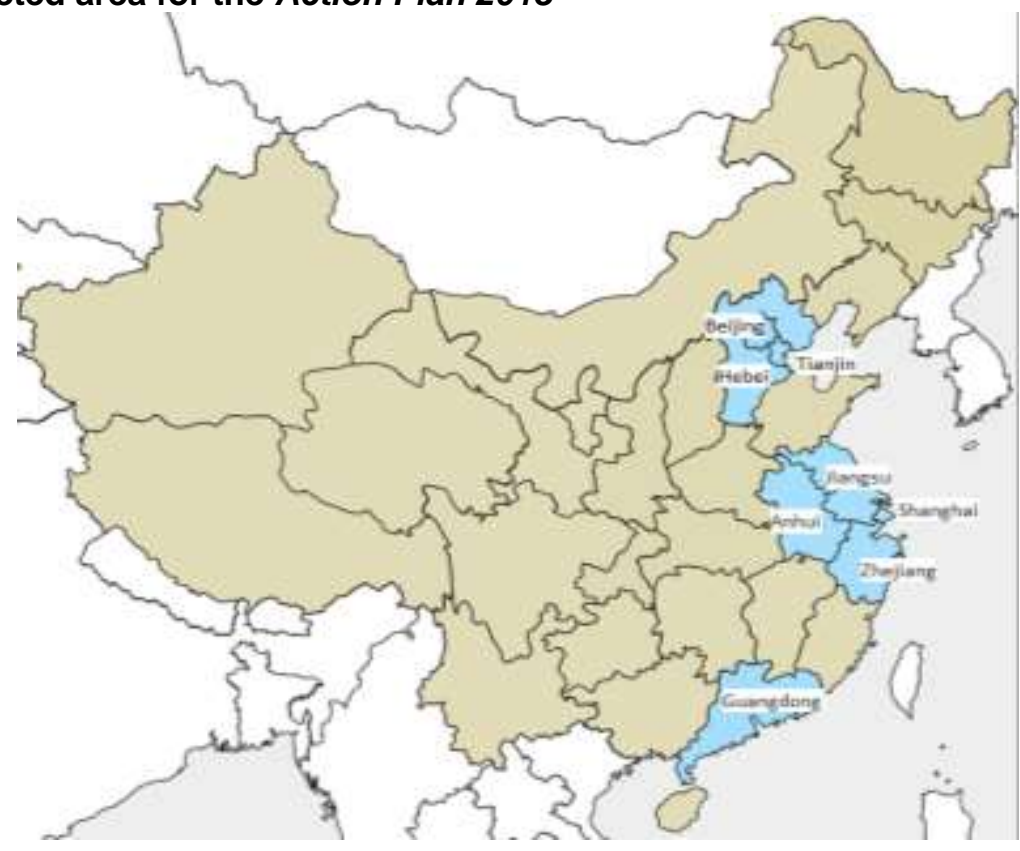

Source: Based on Action Plan 2013.

Based on the Action Plan 2013, the Implementation Rules for Action Plan for Air Pollution Prevention in Beijing-Tianjin-Hebei and Surrounding Area (Action Plan B-T-H) (MNEP, Sep.2013) was published in the same month. It mainly provided concrete measures and targets for Beijing-TianjinHebei and the surrounding areas (Shanxi, Inner Mongolia Autonomous Region, and Shandong Province) and regions. These consisted of:

Further lowering the PM2.5 targets $^{10}$ from those set under the Action Plan 2013 and broadening the geographical scope of regulation.

\footnotetext{
${ }^{9}$ Although binding targets for PM2.5 emissions were set in (MNEP, Dec.2012), no methods of assessing attainment were provided. In June 2014, however, methods and plans of assessing rates of attainment of PM2.5 and PM10 targets in each sector were established.

${ }^{10}$ It added the following targets for reductions in PM2.5 from 2012 levels by 2017: -25\% in Beijing-Tianjin-Hebei, the Yangtze River Delta, and the Pearl River Delta as a whole; $-20 \%$ in the provinces of Shanxi and Shandong; and $-10 \%$ in the Inner Mongolia Autonomous Region.
} 

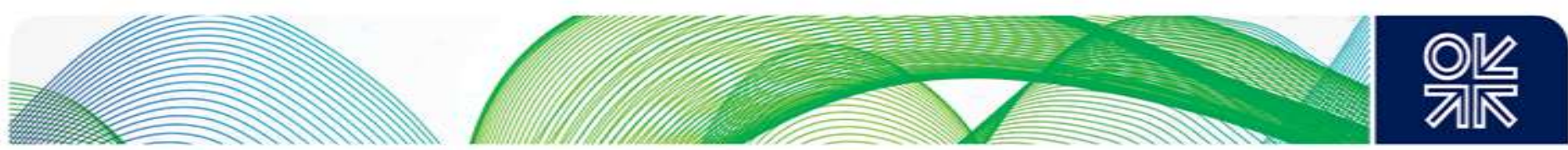

The complete phasing out of boilers with a capacity of $10 \mathrm{t} / \mathrm{h}$ or under in prefecture-level cities in Beijing-Tianjin-Hebei and the surrounding area by the end of 2015, and the conversion of all coal furnaces to other fuels in central Beijing.

The decommissioning of coal-fired boilers up to a capacity of $35 \mathrm{t} / \mathrm{h}$ in the urban areas of Beijing-Tianjin-Hebei, the decommissioning of coal-fired boilers up to a capacity of $10 \mathrm{t} / \mathrm{h}$ in suburban areas, and the conversion of coal-fired boilers to natural gas use at chemical, paper, printing, and other plants in Beijing, Tianjin, Hebei, Shanxi, and in the development zones of Shandong by the end of 2017.

In addition, specific provision was made for reducing coal consumption by $83 \mathrm{mt}$ in Beijing-TianjinHebei and Shandong by the end of 2017, by promoting energy conservation and conversion to clean fuels (see Table 2.5).

As a result of various efforts to achieve the above concrete air pollution targets, there was a considerable growth in demand for natural gas, as energy users moved away from coal use in key cities. Accordingly, in the second and third quarters of 2013, CNPC restricted supplies of natural gas to industrial customers, and the widening gap between supply and demand ${ }^{11}$ led to a severe natural gas shortage in the winter of 2013/14. LNG imports consequently rose sharply, causing the international LNG market to tighten temporarily.

\subsubsection{Measures to promote reduction of coal use}

This subsection reviews the developments of environmental policy since 2014, when the curbing of coal use emerged as a clear policy objective.

In May 2014, the Reinforced Work Program for Air Pollution Prevention in Energy Industry (NDRC, Mar.2014) was announced. This outlined environmental policy dedicated to the energy industry and provided short, medium, and long-term plans for power generation plants and boilers.

It was followed by the announcement of the Strategic Action Plan for Energy Development (2014-20) (Strategic Action Plan) (SCPRC, Nov.2014) in November. The plan established targets for energy supply and demand for the six years up to 2020; its principal objective was to reduce coal consumption and encourage users to switch to other fuels. The main elements of this plan are summarized as follows:

- It aimed to reduce total primary energy consumption (to 4.8 billion tce in 2020) by increasing energy efficiency. This was due to concern over energy security, triggered by increased dependence on energy imports in 2013.

- $\quad$ The plan called for a reduction of coal consumption to 4.2 billion tons and a shrinking of its share of total primary energy consumption to 62 per cent by 2020 , in order to mitigate air pollution and emissions of greenhouse gases. In particular, it strengthened curbs on coal use in the Beijing-Tianjin-Hebei, Yangtze River Delta, and Pearl River Delta regions, where consumption was to be reduced from 2012 levels; Beijing-Tianjin-Hebei was set the especially demanding target of a $100 \mathrm{mt}$ reduction.

- The plan also called for the promotion of city gas use in urban areas and an increase in natural gas's share of total primary energy consumption to at least 10 per cent in 2020 . To achieve this, the plan set targets for expanding domestic production of natural gas: raising the production of conventional gas to $185 \mathrm{bcm} / \mathrm{y}$, of shale gas to $30 \mathrm{bcm} / \mathrm{y}$, and of CBM to $30 \mathrm{bcm} / \mathrm{y}$. At the same time, it set out a policy of reforming energy prices and transitioning to market prices.

\footnotetext{
${ }^{11}$ Source: ( NDRC, Oct.2013), and also remarks at the 'Natural Gas Supply in Peak Winter Coordination Meeting'; 'Natural gas demand growth during the peak season in 2013 was $13.5 \%$, while production growth was $9.2 \%$ '.
} 

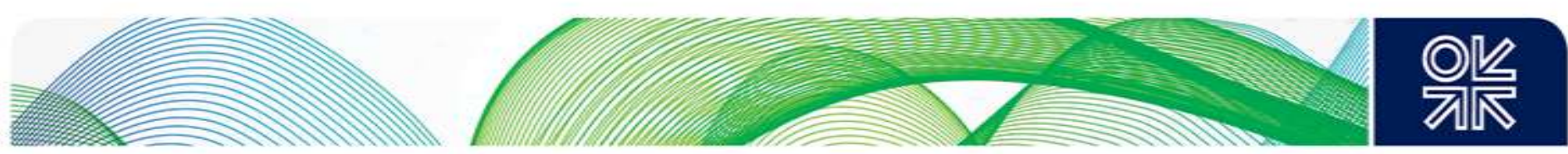

December of the same year then saw the release of the Interim Measures for Management of Substitution and Reduction of Coal Consumption in Key Areas (NDRC, Dec.2014). This plan broke down the targets to be attained by regional governments to the level of individual companies and also called for the key areas that had been assigned targets under the previously described Action Plan $\boldsymbol{B}-\boldsymbol{T}-\boldsymbol{H}$ to formulate annual plans for concrete reductions. Furthermore, it required Shanghai, Jiangsu, Zhejiang, and Fujian to set coal reduction targets and report to central government by the end of June 2015. These regulations thus expanded the regions where coal consumption had to be reduced and strengthened their feasibility. In parallel, the plan made compulsory the adoption of renewables and natural gas, as alternatives to coal.

The Strengthened Work Plan for Controlling Air Pollution and Total Coal Consumption in Key Cities subsequently published in July 2015 (NDRC and MNEP, Jul.2015) revealed the names of the 10 worst cities ${ }^{12}$ for air pollution and called for stronger action to be taken by these cities to reduce coal use.

Strengthened steps have thus been taken since 2013 to reduce coal use and break the impasse in tackling air pollution. The reductions achieved as a result are summarized in Table 2.5.

Table 2.5: The target for reduction for coal consumption and actual demand ( $\mathrm{mt}$ )

\begin{tabular}{|l|c|c|c|c|}
\hline & 2012 actual & $\begin{array}{c}2017 \text { reduction } \\
\text { target }\end{array}$ & 2017 target & 2016 actual \\
\hline Beijing & 23 & -13 & 10 & 8.5 \\
\hline Tianjin & 55 & -10 & 45 & 42.3 \\
\hline Hebei & 320 & -40 & 280 & 281 \\
\hline Shandong & 400 & -20 & 380 & $409^{\star 1}$ \\
\hline
\end{tabular}

Note: According to NDRC's report, increased volume was $7 \mathrm{mt}$ and $13 \mathrm{mt}$ in Jiangsu compared with 2012.

Source: Action Plan B-T-H. *1 China Energy Statistical Year Book 2017.

\subsubsection{Revision of the Environment Protection Law and administrative systems of responsibility for environmental protection targets}

Measures to tackle air pollution were thus strengthened by being set out in more concrete detail, and their robust implementation was ensured by the enforcement of the revised Environment Protection Law on January 2015. The revised law stipulates that 'environmental protection is a basic policy of the state.' It also strengthened the enforcement powers of the local government officers in charge of environmental protection, and at the same time it provided for more severe punishment of offenders by, for example, eliminating the ceiling on fines imposed on offenders and placing enforcement under the authority of the police.

Revisions made to the Air Pollution and Control Law in August 2015 (which entered into force in January 2016) incorporated stricter penalties against offenders under the Environment Protection Law. As just described, it tightened compliance with environmental standards, ${ }^{13}$ it also provided a legal foundation for clearer accountability. Systems of responsibility ${ }^{14}$ were subsequently further enhanced to ensure more robust implementation of environmental measures. This is thought to have contributed indirectly to the social dislocation caused by the shortage of natural gas in 2017 that is discussed below.

\footnotetext{
12 Seven cities in Hebei included: Shijiazhuang, Jinan in Shandong, Zhengzhou in Henan, and Tianjin.

${ }^{13}$ For example, economic activities are suspended in the event of a worsening of air pollution.

${ }^{14}$ For example, publicizing the attainment rate of air pollution improvement targets as a performance indicator of regional government officials.
} 

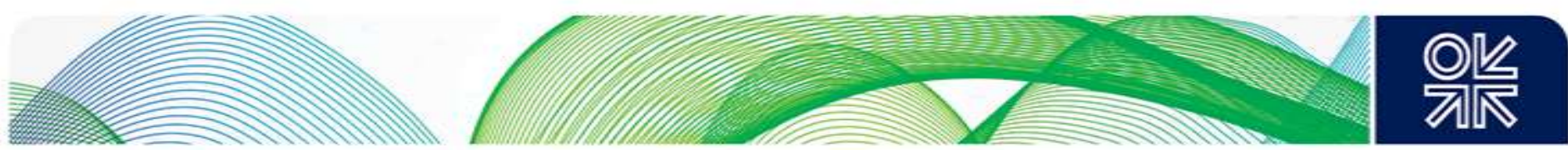

\subsubsection{The Action Plan for Preventing Air Pollution: the final step in strengthening air pollution measures in Beijing-Tianjin-Hebei (after 2016)}

Despite these significant efforts to counter air pollution, the actual state of air quality remained disappointing (see Figure 2.3). In November 2015, shortly before the Air Quality Standard went into effect on 1 January 2016, severe air pollution occurred over wide areas of the north-east and BeijingTianjin-Hebei. The situation remained poor in December, when a 'red alert' was declared in Beijing. As a result, many factories had to suspend operations, schools were closed, and even arrivals and departures at Beijing Airport were affected.

\section{Figure 2.3: Daily PM2.5 levels and targets in Beijing, Tianjin and Shijiazhuang (Hebei)}

\section{From Jan. 2015 to Aug. 2018}

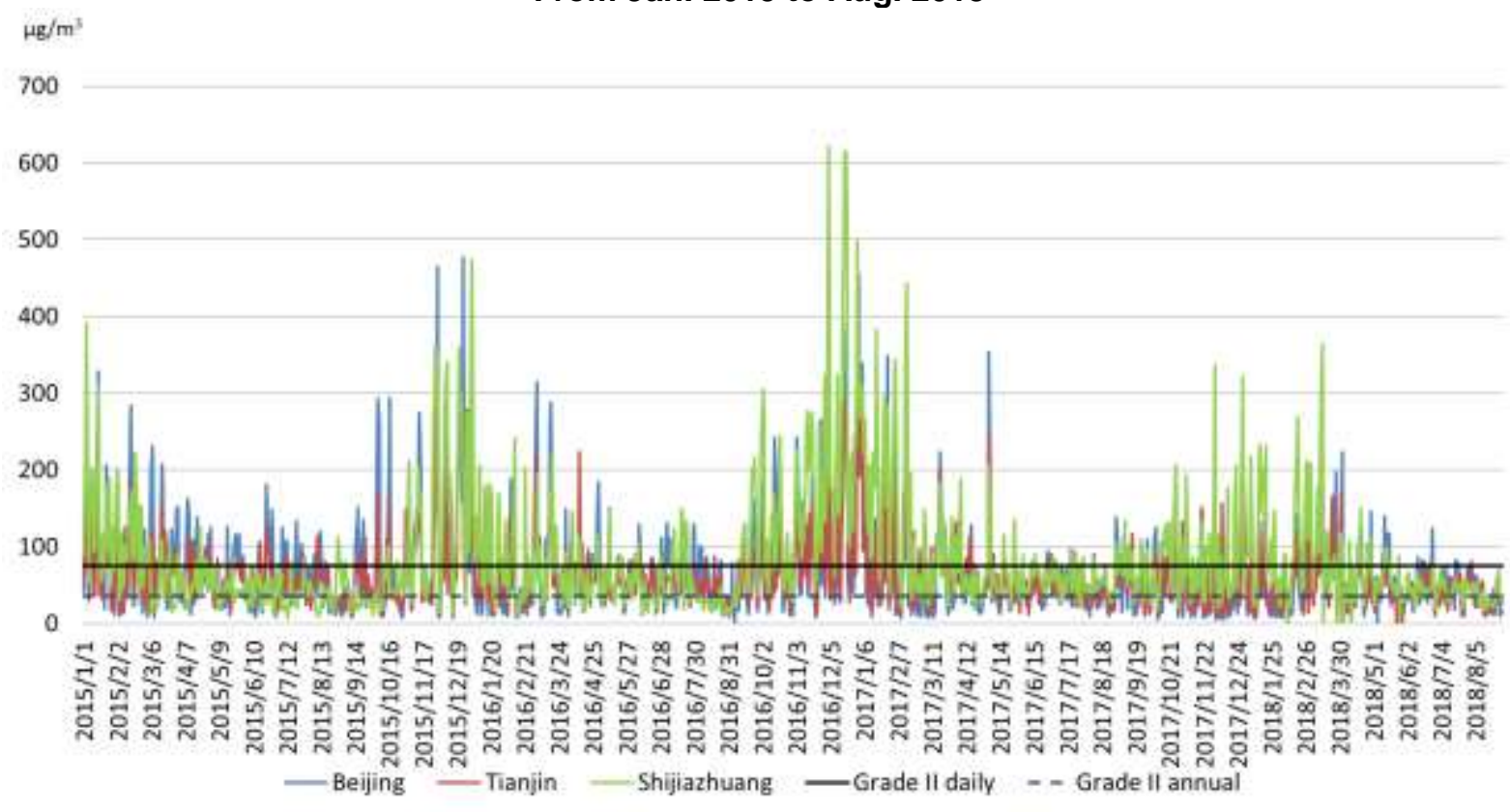

Source: Based on data published by Ministry of National Environmental Protection.

In July 2016, the Ministry of National Environmental Protection published its Interim Report on the Air Pollution Prevention and Control Action Plan (2013) (MNEP, Jul.2016). Regarding air pollution in urban areas, the report found that PM2.5 levels had improved in 74 cities from $72 \mu \mathrm{g} / \mathrm{m}^{3}$ in 2013 to $55 \mu \mathrm{g} / \mathrm{m}^{3}$ in 2015 , and that interim targets for both PM2.5 and PM10 ${ }^{15}$ had been met in many provinces. However, the pollution situation remained serious in winter, and further efforts were needed in Beijing in particular to meet the 2017 target. The report observed that there was a particular need for stronger action to reduce coal use during the autumn and winter months when heating appliances were used, and it also noted that it was necessary to promote natural gas use throughout the whole of Beijing-Tianjin-Hebei, reduce the use of coal in industry, promote the use of electricity and gas in place of coal, and pursue measures to combat air pollution in winter.

Also in July 2016, the Ministry of National Environmental Protection and the governments of Beijing, Tianjin, and Hebei announced the Intensive Air Pollution Prevention and Control Measures for Beijing-Tianjin-Hebei (2016-17) (Control Measures B-T-H) (MNEP, 2016). These were designed to achieve the new national standard targets for 2017 (see Table 2.6), and provided short-term measures to enhance prevention of PM2.5 pollution in selected regions. The target area was extended to ' $2+18$ ' and among these, the ' $2+4$ ' cities (Beijing, Tianjin, Baoding, Langfang, Tangshan,

\footnotetext{
${ }^{15}$ See section 2.4.1.
} 

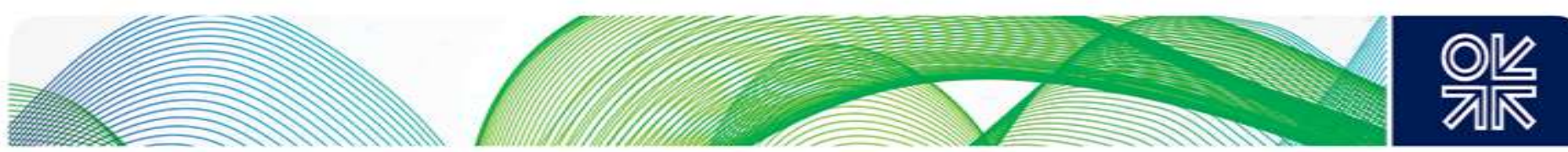

and Zhangzhou) and the '1+2' cities (Beijing, Baoding and Langfang) were given a particularly important role in pollution prevention (see Figure 2.4). The main measures were as follows:

- $\quad$ Promoting conversion from coal to other fuels (gas and electricity) in rural areas. In particular, the complete prohibition of coal use in Beijing by October 2017 and the promotion of conversion from coal to electricity and gas in Baoding and Langfang.

- $\quad$ The phasing out of small boilers (boilers with capacities of up to $35 \mathrm{t} / \mathrm{h}$ in urban parts of Beijing, Tianjin, and Hebei, and of $10 \mathrm{t} / \mathrm{h}$ boilers in other regions by the end of October 2017).

Strengthened measures in the industrial sector (enhanced environmental action on coalfired power plants and reform of the iron and steel sector by the end of October 2016).

Strengthened emergency measures in the event of a temporary worsening of air pollution (such as temporary factory shutdowns).

- $\quad$ Adjustment of production at factories in urban areas between November and January.

- $\quad$ Tightened supervision and inspection (quarterly ranking by the Ministry of National Environmental Protection of regions by air pollution, central government supervision of ' $2+4$ ' cities, and the introduction of liability for non-attainment of targets).

Figure 2.4: Targeted area for the Control Measures B-T-H

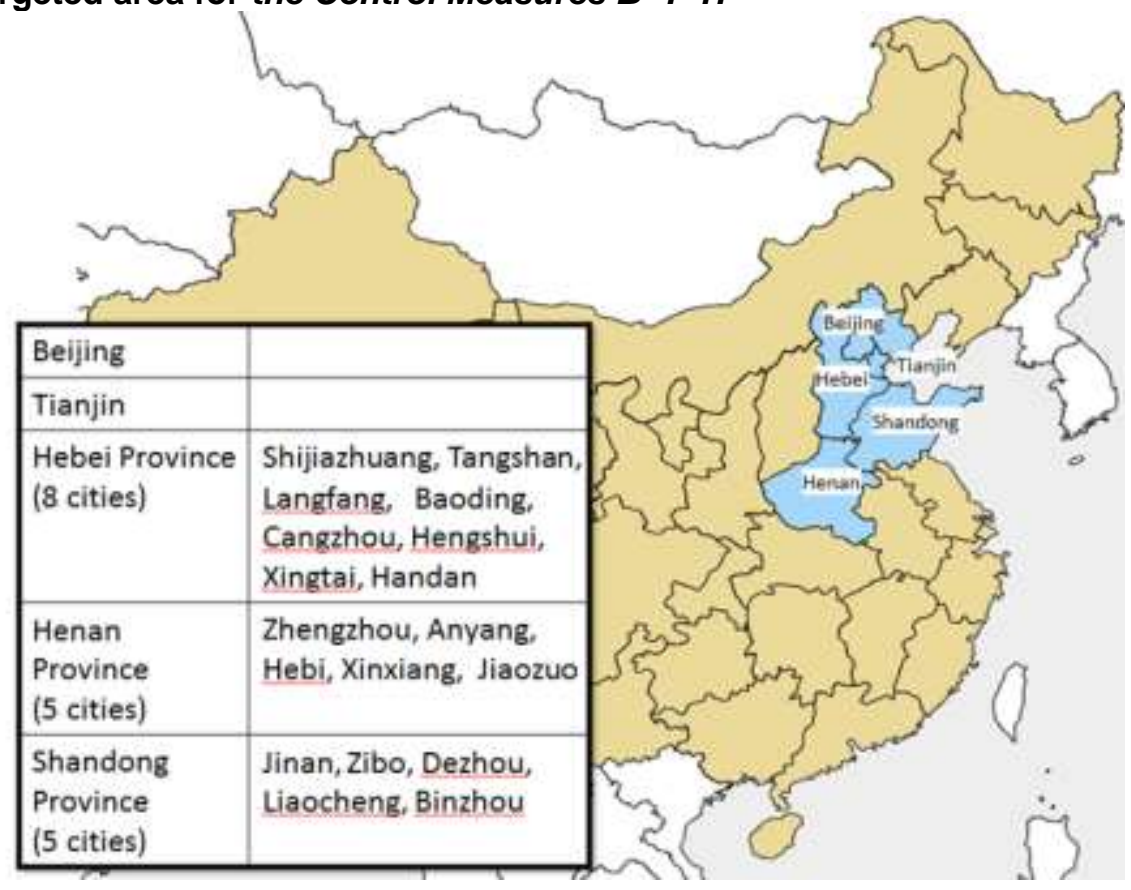

Source: Based on Control Measures B-T-H.

Despite these strengthened measures, however, serious air pollution occurred again in some cities in the Beijing-Tianjin-Hebei region on 30 September and 1 October 2016, forcing the Ministry of National Environmental Protection to convene an emergency meeting on 2 October in response. As shown in Figure 2.5, the situation in winter 2016 was still severe in Beijing and the Tianjin area and even worse in Hebei. 

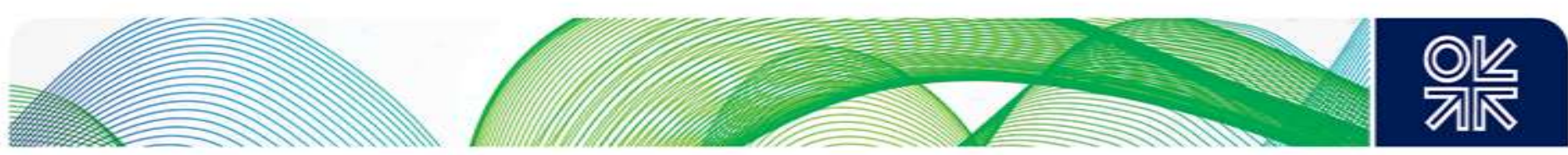

Figure 2.5: Daily PM2.5 levels and daily targets in Beijing, Tianjin and Shijiazhuang (Hebei) From September 2016 to December 2016

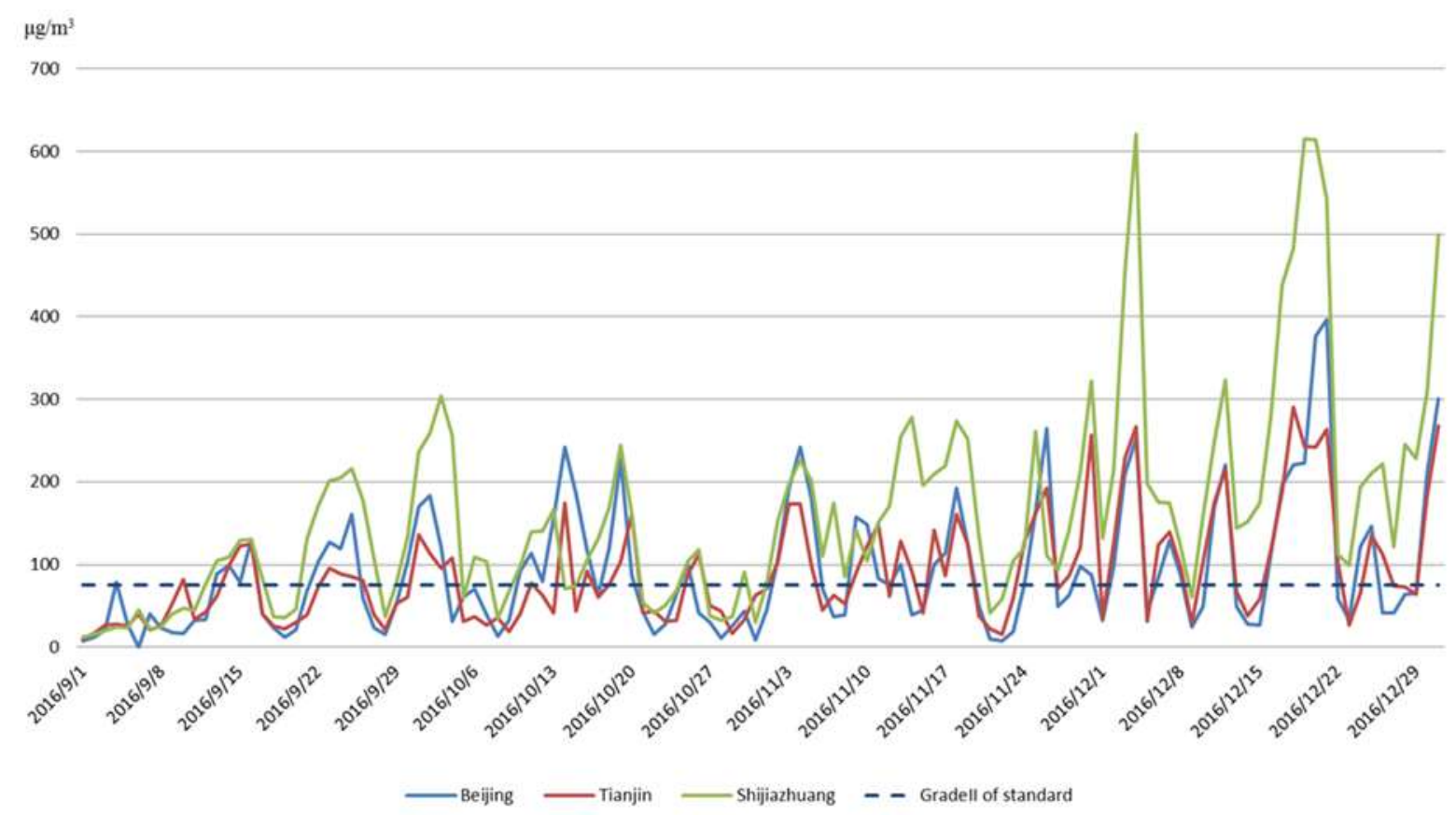

Source: Based on the data published by Ministry of National Environmental Protection.

Table 2.6: Annual targets for PM2.5 in 2017 regulated by the Intensive Air Pollution Prevention and Control Measures for Beijing-Tianjin-Hebei (2016-17)

\begin{tabular}{|l|l|}
\hline Beijing & $60 \mu \mathrm{g} / \mathrm{m}^{3}$ \\
\hline Fengtai, Tongzhou, Fangshan, Daxing & $65 \mu \mathrm{g} / \mathrm{m}^{3}$ \\
\hline Tianjin & $60 \mu \mathrm{g} / \mathrm{m}^{3}$ \\
\hline Wuqing District, Baodi District and Jixian County & below $60 \mu \mathrm{g} / \mathrm{m}^{3}$ \\
\hline Hebei & $67 \mu \mathrm{g} / \mathrm{m}^{3}$ \\
\hline Baoding & $77 \mu \mathrm{g} / \mathrm{m}^{3}$ \\
\hline Langfang & $65 \mu \mathrm{g} / \mathrm{m}^{3}$ \\
\hline
\end{tabular}

Note: The annual standard for PM2.5 regulated by the National Air Quality Standard is $35 \mu \mathrm{g} / \mathrm{m}^{3}$.

Source: (MNEP, Jul.2016).

In March 2017, the Ministry of National Environmental Protection published its Work plan for air pollution prevention and control in Beijing, Tianjin and Hebei and surrounding areas in 2017 (Work Plan $\boldsymbol{B}-\boldsymbol{T}-\boldsymbol{H}$ ) (MNEP, Mar.2017). This expanded the areas subject to strengthened action to '2+26' cities (see Figure 2.6) and incorporated the following specific measures:

- $\quad$ reinforcement of the responsibility of local governments;

- $\quad$ development of natural gas and electricity supply systems to encourage the use of gas and electricity instead of coal by CNPC, SINOPEC, CNOOC, and the State Grid Corporation of China in cooperation with local governments;

- development and strengthening of scheduling and inspection mechanisms by the Ministry of National Environmental Protection.

More importantly, the ' $2+26$ ' cities were designated to be the first to implement clean heating plans in the winter in the northern region, and plans were put into effect to scale up to the replacement of $50,000-100,000$ coal-fired home heaters by gas or electricity ones by October 2017. Phasing out of 

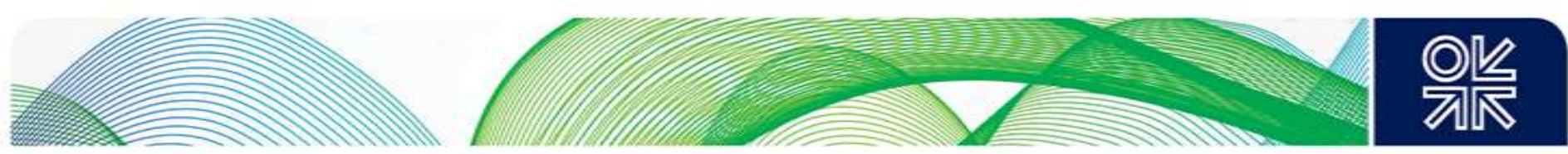

coal-fired boilers with a capacity of up to $10 \mathrm{t} / \mathrm{h}$ was also pursued, and explicit policy-based incentives were provided to assist in this process.

\section{Figure 2.6: Targeted area for Work Plan B-T-H}

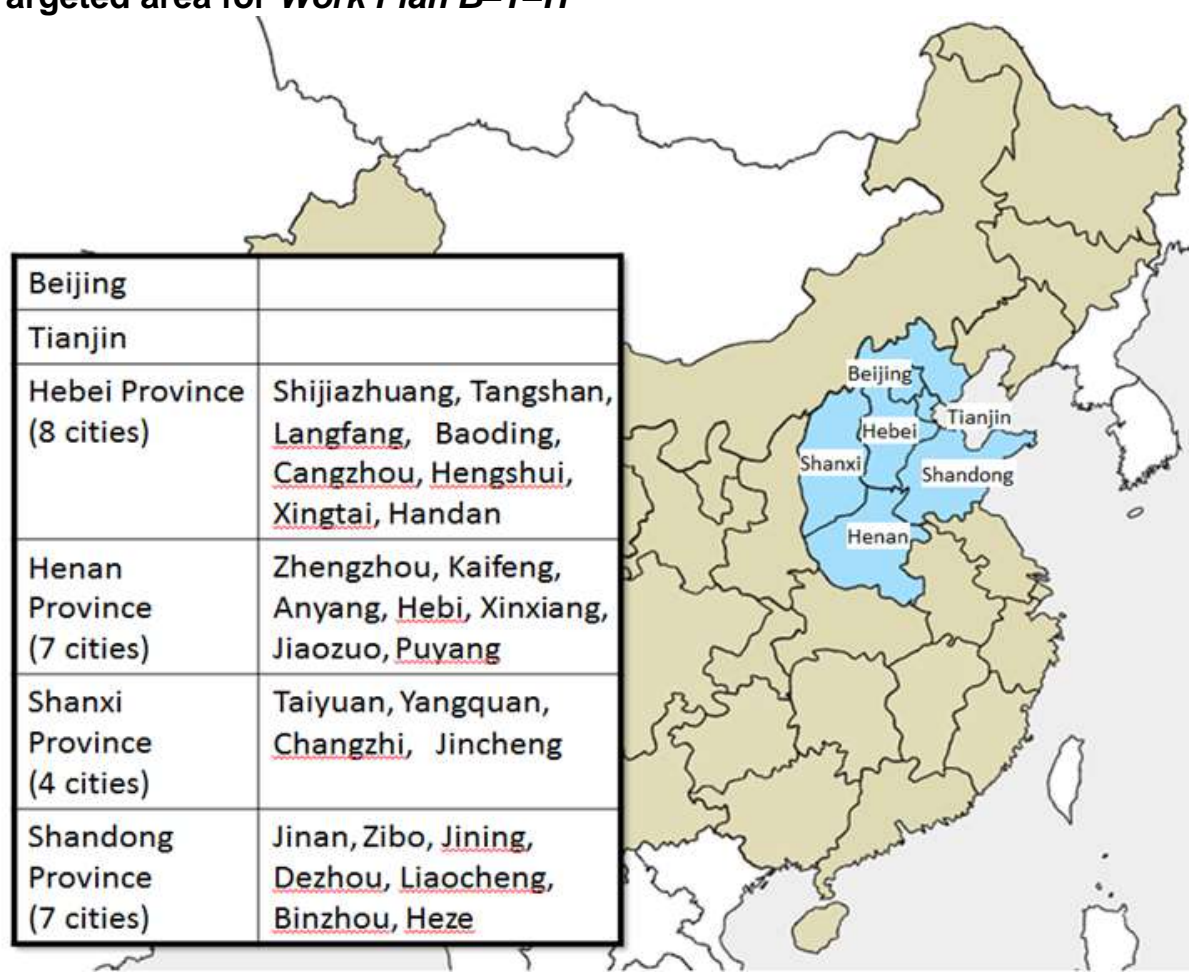

Source: Based on Work Plan B-T-H.

However, the air pollution situation in Beijing-Tianjin-Hebei remained serious in the first half of 2017. The Ministry of National Environmental Protection therefore promulgated a further measure, the 2017-18 Autumn/Winter Action and Inspection Plan for Tackling and Comprehensive Management of Air Pollution in Beijing-Tianjin-Hebei and Surrounding Areas in August 2017 (2017 Autumn/Winter B-T-C) (MNEP, Aug.2017a). This was set for implementation between October 2017 and March 2018, which meant that it extended beyond the period covered by the Action Plan 2013. 2017 Autumn/Winter B-T-C laid out a detailed list of targets to be achieved by individual sectors and regions, including:

- completion of the replacement of coal by gas or electricity in 3 million households (including 300,000 in Beijing, 290,000 in Tianjin, and 1,800,000 in Hebei) by October 2017 ,

- the phasing out of coal-fired boilers (specifically, the complete phasing out of $10 \mathrm{t} / \mathrm{h}$ boilers and the phasing out of boilers up to $35 \mathrm{t} / \mathrm{h}$ in urban areas),

- $\quad$ reduction of coal consumption. ${ }^{16}$

Along with the 2017 Autumn/Winter B-T-C, the 2017-18 Autumn/Winter Action and Inspection Plan for Tackling and Comprehensive Management of Air Pollution in Beijing-Tianjin-Hebei and Surrounding Areas - Strengthened Supervision Plan (MNEP, Aug.2017b) was published to strengthen accountability and inspection-related arrangements. In concrete terms, this introduced a system of 'one-on-two responsibilities' (under which two individuals were made responsible for one

\footnotetext{
${ }^{16}$ The 44,000 boilers designated to be phased out in 2017 included: 1,500 boilers in Beijing, 5,640 boilers in Tianjin, and 17,000 boilers in Hebei. The actual replacement was 56,000 .
} 

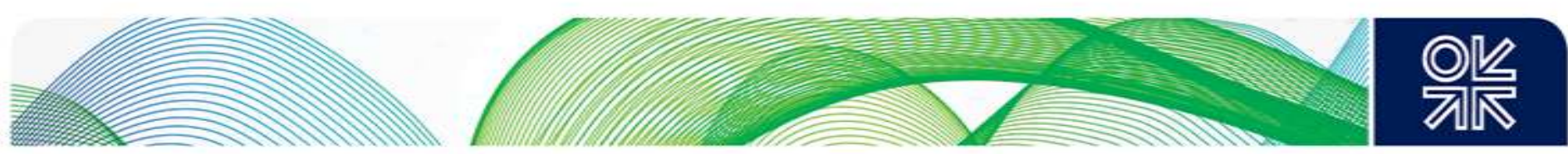

event) and 102 inspection teams consisting of a total of 2,480 personnel were dispatched to the '2+26' cities between September 2017 and January 2018. These inspections exposed numerous employees and government officials who were responsible for air pollution.

According to data released by the Chinese government in March 2018, these strengthened measures resulted in 4.74 million households (out of the 5.33 million households targeted) switching from coal to gas or electricity by the end of 2017 . The number exceeded the original plan, which had a target of 3.55 million households. Among them, 3.94 million households in Beijing-Tianjin-Hebei and the surrounding areas switched from coal to gas or electricity. ${ }^{17}$

\subsection{The 13th Five-Year Plan (2016-20)}

The 13th Five-Year Plan (13FYP) (NPC, Mar.2016) announced in March 2016 set a binding target of lowering both $\mathrm{SO}_{2}$ and $\mathrm{NOx}$ emissions by 15 per cent compared to levels in 2015, and a binding target of lowering PM2.5 level by 18 per cent in cities that had failed to achieve a PM2.5 level of $35 \mu \mathrm{g} / \mathrm{m}^{3}$.

The 13th Five-Year-Plan for National Energy Development (NDRC, Dec.2016) published in December of that year called for the control of total energy consumption, efficient use of energy, expansion of clean energies, and energy market reform. One element that attracted particular attention was its incorporation of plans to rapidly expand the use of renewables. The plan set binding targets for a deceleration of the annual rate of growth in energy consumption to less than 3 per cent and a reduction in total primary energy consumption to less than 5.0 billion tce by the final year of the plan. It also set a binding target of reducing coal consumption's share of total primary energy consumption from 64 per cent to 58 per cent, along with a binding target of increasing non-fossil fuels' share to 15 per cent. Coal consumption, which came to 3.96 billion tons in 2015 , was consequently strictly limited to not more than 4.1 billion tons, which was even less than the 4.2 billion tons set as a target under the previously announced Strategic Action Plan (in 2014). The Beijing-Tianjin-Hebei, Yangtze River Delta, and Pearl River Delta regions remained designated as the key regions for reduction of coal use, and were newly joined by the North-east region. Under coal-to-gas switching projects, $189,000 \mathrm{t} / \mathrm{h}$ of boiler capacity is to be converted from coal to gas and this is expected to generate natural gas demand of $45 \mathrm{bcm}$. The plan additionally called for coal-fired power generating capacity in 2020 to be reduced to $1,100 \mathrm{GW}$ by cancelling plans for the construction of coal-fired power plants and postponing the approval for construction of private coal-fired power generation plants.

\footnotetext{
${ }^{17}$ According to Hebei government, the gas supply to about 180,000 households was shelved during 2017 due to the shortage of natural gas supply in Hebei, where 2.54 million households had completed switching from coal. While gas demand had been projected to reach $8.2 \mathrm{bcm}$ during the heating season, the planned supply volume was only $6.5 \mathrm{bcm}$. There was thus an estimated shortfall of $1.7 \mathrm{bcm}$.
} 

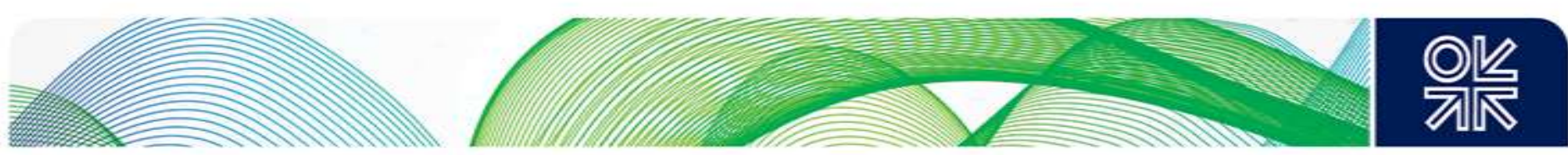

Table 2.7: Target for the 13th Five-Year Plan

\begin{tabular}{|c|c|c|c|c|c|}
\hline & $\begin{array}{l}2010 \\
\text { Actual }\end{array}$ & $\begin{array}{c}2015 \\
\text { Actual }\end{array}$ & $\begin{array}{l}\text { 13FYP } \\
\text { Target }\end{array}$ & Status & $\begin{array}{l}\text { Strategic } \\
\text { Action } \\
\text { Plan }\end{array}$ \\
\hline GDP ( trillion Yuan ) & 39.8 & 67.7 & $<92.7$ & & \\
\hline Annual growth rate (\%) & & 7.8 & $<6.5$ & & \\
\hline \multicolumn{6}{|l|}{ Energy } \\
\hline $\begin{array}{l}\text { Energy consumption per GDP } \\
\text { over previous period (\%) }\end{array}$ & & -18.2 & -15.0 & Binding & \\
\hline TEC (mtce) & 3,610 & 4,300 & $<5,000$ & & 4,800 \\
\hline Annual growth rate (\%) & & & $<3$ & & \\
\hline Coal consumption (mt) & 3,490 & 3,960 & $<4,100$ & & 4,200 \\
\hline Annual growth rate (\%) & & & 0.7 & & \\
\hline Share of TEC (\%) & 69.2 & 64 & $<58$ & & 62.0 \\
\hline Natural gas consumption (bcm) & 107.5 & 193.1 & & & \\
\hline Annual growth rate (\%) & & 1.9 & 4.1 & & \\
\hline Share of TEC (\%) & 4.0 & 5.9 & 10.0 & & 10.0 \\
\hline \multicolumn{6}{|l|}{ Environment } \\
\hline $\mathrm{SO}_{2}$ emission & & $-18.0 \%$ & $-15.0 \%$ & Binding & \\
\hline $\mathrm{NO}_{\mathrm{x}}$ emission & & $-18.6 \%$ & $-15.0 \%$ & Binding & \\
\hline $\begin{array}{l}\text { Achievement rate for } 292 \text { days/y } \\
\text { of Grade II in AQS in key cities } \\
(\%)\end{array}$ & & 76.7 & $>80.0$ & Binding & \\
\hline $\begin{array}{l}\text { Share of unachieved cities for } \\
\text { PM2.5 target }\left(35 \mu \mathrm{g} / \mathrm{m}^{3}\right)(\%)\end{array}$ & & & -18.0 & Binding & \\
\hline
\end{tabular}

Source: 13FYP; 13FYPE; 13th Five-Year Plan for National Energy Development (NDRC Dec.2016b); the 13th Five-Year-Plan for Natural Gas Development (NDRC, Dec.2016a); China Energy Statistical Year Book 2017.

\subsection{The Winter Clean Heating Plan in Northern Area (2017-21)}

As previously noted, the series of measures taken to tackle air pollution included the implementation of plans to reduce the use of low-grade coal and encourage conversion to clean heating in the residential sector. Under the Work Plan $\boldsymbol{B}-\boldsymbol{T}-\boldsymbol{H}$, measures to promote clean heating during the winter months in these regions were implemented upfront. After that, the five-year plan, the so-called Winter Clean Heating Plan in Northern Area (2017-21) (NDRC, Dec.2017) (Winter Clean Heating) - to make winter heating cleaner in 14 Northern provinces and part of Henan - was announced in December 2017. This plan, which will be described in detail in a later section, provides extremely useful insights for estimating natural gas demand. 

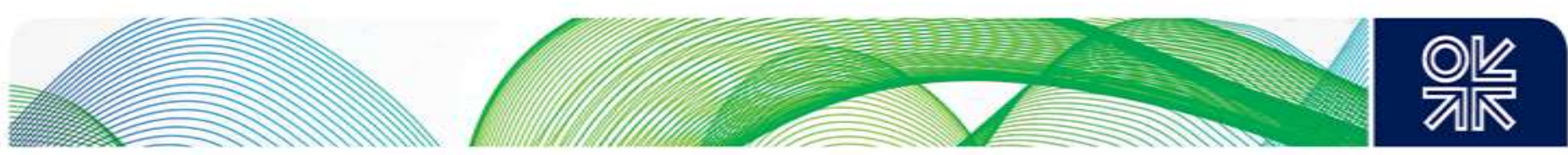

Figure 2.7: Targeted area for Winter Clean Heating

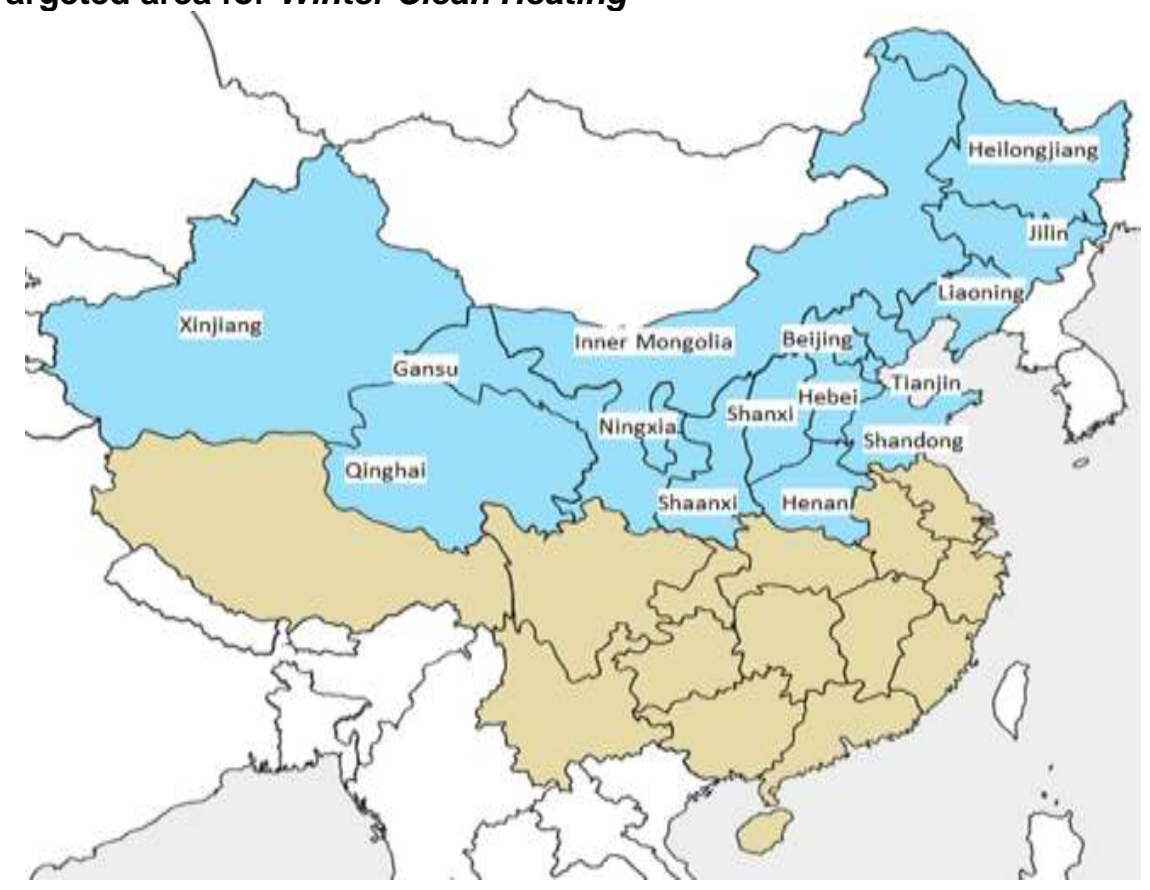

Source: Based on Winter Clean Heating.

\subsection{The Action Plan to Win the Blue Sky Defence War (2018-20)}

On 27 June 2018, the State Council of the People's Republic of China published its Action Plan to Win the Blue Sky Defence War (Blue Sky Action Plan) (SCPRC, Jun.2018) for the years 2018-20. This is a three-year comprehensive action plan to tackle air pollution in line with the 13FYP, and it designates Beijing-Tianjin-Hebei and surrounding areas, the Yangtze River Delta, and the Yan-Ping Plain region as the key cities and regions. ${ }^{18}$

The plan sets a number of targets to be achieved by 2020. These include the reduction of $\mathrm{SO}_{2}$ and $\mathrm{NO}_{x}$ emissions by at least 15 per cent from 2015 levels, and the reduction of PM2.5 concentrations by at least 18 per cent from 2015 levels and their maintenance within regulatory limits. The plan also provides concrete details of a highly comprehensive set of measures for achieving these targets. These include the transformation of industrial structures, the pursuit of plans to make heating cleaner in the north, limitation of coal use, the phasing out of coal-fired boilers, improvement of energy utilization efficiency, promoting the introduction of clean energies, and the reduction of emissions in the transport sector. Other matters covered range from legal, regulatory, and supervisory arrangements to administrative responses and information disclosure. In its breadth and depth of scope, this three-year action plan provides evidence of the present administration's strong commitment to the war on air pollution. 

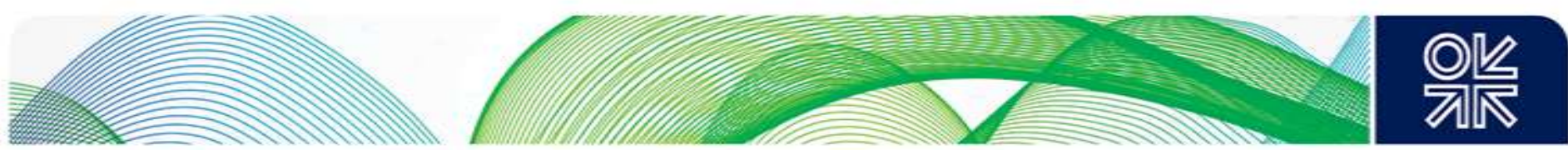

Figure 2.8: Targeted area for the Blue Sky Action Plan

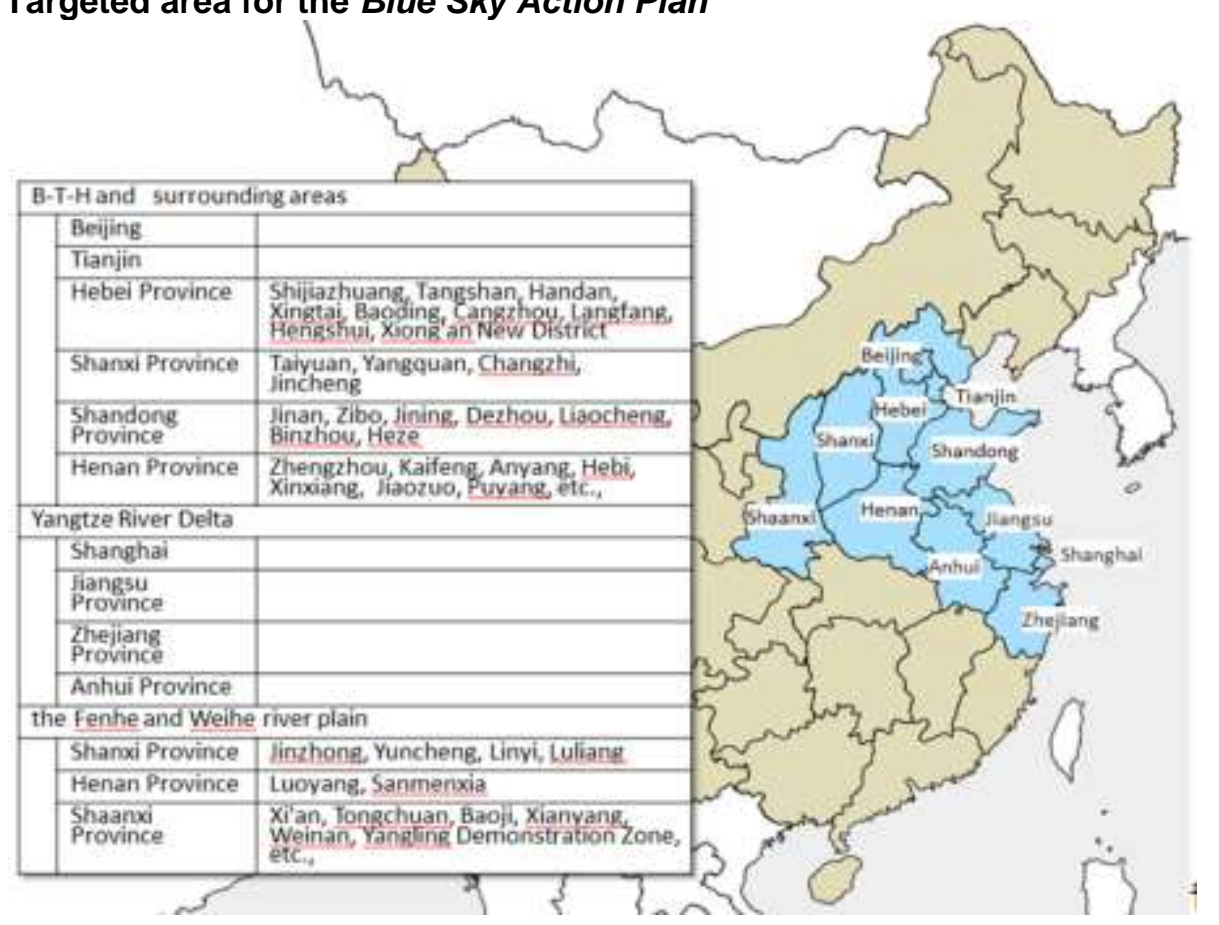

Source: Based on (SCPRC, Jun.2018).

\subsection{Summary: air pollution now and in the future}

This chapter concludes with some brief remarks on the current air pollution situation and how it may evolve in the future.

Firstly, although various policy measures to reduce PM 2.5 emissions had been implemented on the basis of the Action Plan 2013, there were few improvements in actual observed data as of the end of 2015. As a result, the government introduced a series of hard-hitting measures focused on BeijingTianjin-Hebei and its surrounding areas by the end of 2017 - the final year of the Action Plan 2013. Despite such serious efforts, air pollution failed to reach a satisfactory level. The average monthly PM2.5 concentration exceeded $100 \mu \mathrm{g} / \mathrm{m}^{3}$ between the end of 2017 and March 2018 in designated key cities in Hebei, the Yangtze River Delta, Shaanxi, Henan, Xinjiang, Uyghur, among others. (see Figure 2.9).

Looking ahead, the focus of interest will be on the extent to which improvements are made as a result of strengthened action on air pollution. Although the Blue Sky Action Plan sets targets for improvement compared with 2015 levels, these figures remain relatively lax by international standards. ${ }^{19}$ Therefore, it is highly likely that these targets will be made more stringent and strong action will continue to be pursued, judging by the present administration's strict stance on air pollution.

According to the Action Plan for Comprehensive Management of Air Pollution in Autumn and Winter in Beijing-Tianjin-Hebei and surrounding areas 2018-19 (NDRC, MEE, and RG, Sep.2018), published in September 2018, plans to remove small coal-fired boilers in the industrial sector and to replace coal-fired space heating in the residential sector ${ }^{20}$ are scheduled to be implemented steadily on a broad scale.

\footnotetext{
${ }^{19}$ For example, the Japanese annual standard for PM2.5 is set at $15 \mu \mathrm{g} / \mathrm{m}^{3}$ and at $35 \mu \mathrm{g} / \mathrm{m}^{3}$ for daily bases. In 2018 , it was reported that the annual average number was $12 \mu \mathrm{g} / \mathrm{m}^{3}$ in Kanto region (Source: materials published by Japan Environment Agency Council). In the USA, the annual standard is set $12 \mu \mathrm{g} / \mathrm{m}^{3}$ (Source: US EPA' Clean Air Act').

${ }^{20}$ Such replacements in around 3.6 million households in the region are scheduled for implementation.
} 

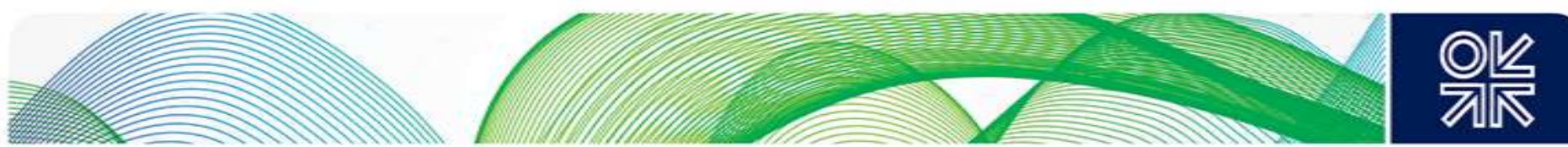

In sum, when we assess the achievements of environmental policy in China, the reductions of $\mathrm{SO}_{2}$ and $\mathrm{NO}_{x}$ emissions from the large power generation plants and industrial facilities were successfully completed in a relatively short period, partly because counter-measures (installing desulphurization and/or de-nitrification plants and facilities) were fairly simple.

However, as measures to reduce PM2.5 emissions have to cover all sectors including transportation, and there are so many sources of emissions, the process may not be complete in a decade - as can be seen by Japan's experiences. ${ }^{21}$

Therefore, the anti-pollution steps taken in China can be considered to have been far from perfect, but there has never been failure in the long term.

Yet, unexpected social problems arising from shortages of natural gas supply occurred during the 2017/18 winter season, and it has become obvious that reducing coal consumption remains an important issue to be resolved. Natural gas is definitely one of the key solutions, but at the same time it has become evident that there are constraints on its supply capacity, which we shall consider in the following chapters.

\section{Figure 2.9: Monthly PM2.5 levels in key cities in China}

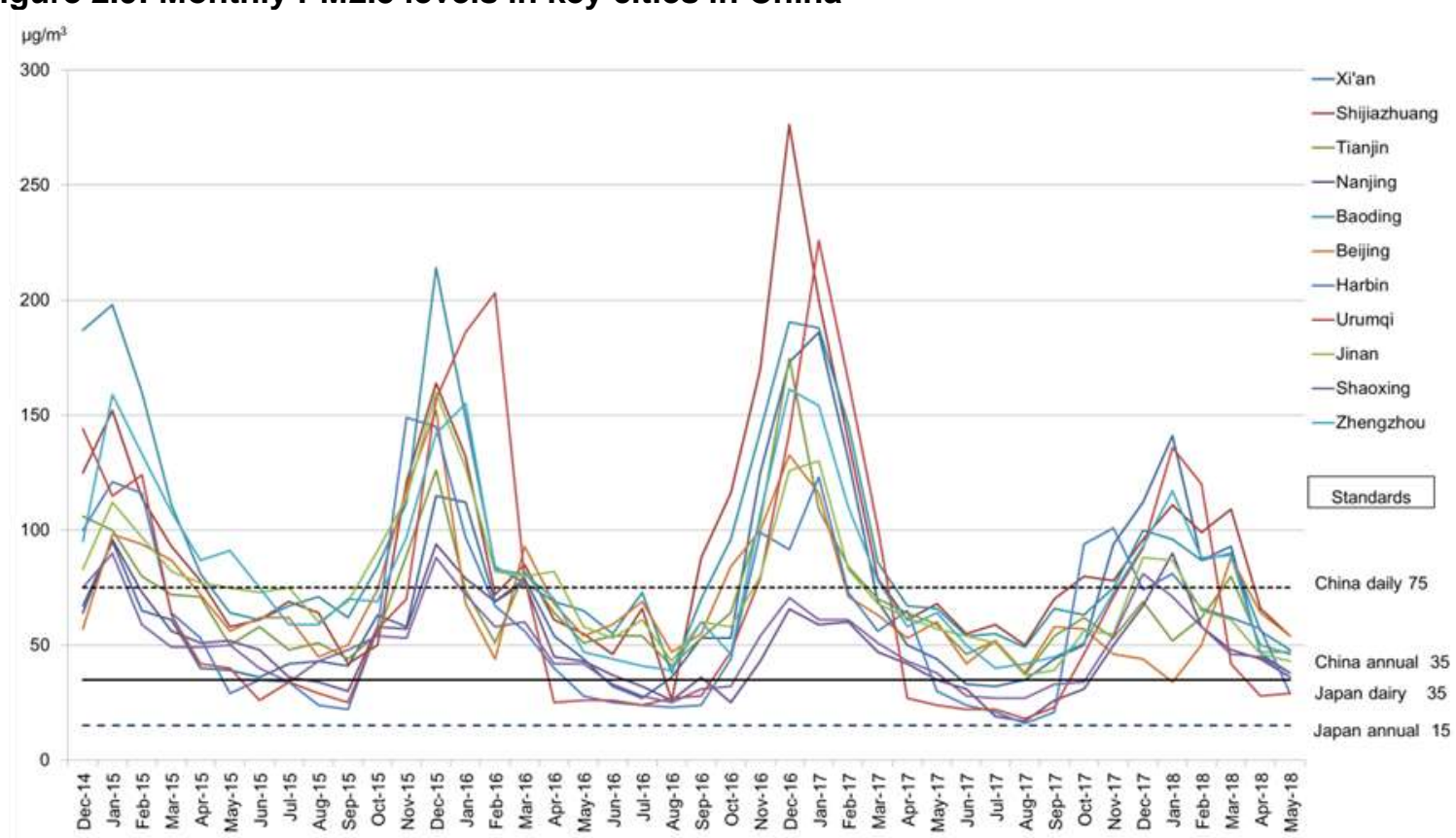

Source: Based on the data published by Ministry of National Environmental Protection.

\footnotetext{
${ }^{21}$ For example, in Japan, the Automobile NO Emission Law was revised in 2001 and PM2.5 (emission regulations on diesel cars) was added to the targets. However, even after this, measures have had to be strengthened in polluted areas. Also in China, it is expected that the focus of countermeasures will shift to $\mathrm{NO}_{x}$ and PM 2.5 emissions in the transportation sector, as described in Blue Sky Action Plan and in (NDRC, MEE, and RG Sep.2018). For example, the introduction of new energy or clean energy vehicles has been promoted in Beijing city and there are already restrictions on vehicles fuelled by fossil fuels.
} 

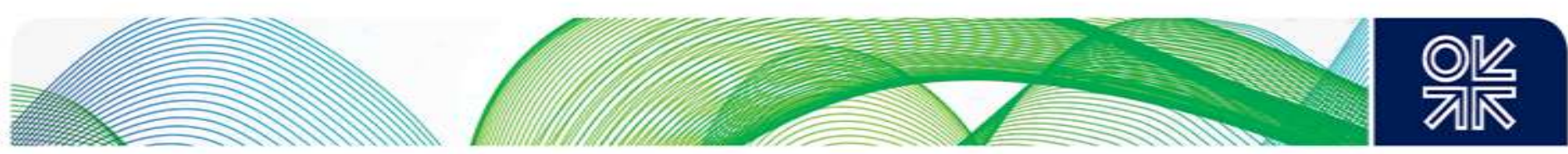

\section{Trends in natural gas supply and demand}

This chapter outlines trends in the natural gas market in China that have taken place over the past 20 years and then analyses their effect on the supply and demand of natural gas by examining the confusion resulting from the country's intensified war on air pollution.

\subsection{Long-term trends in natural gas consumption}

\subsubsection{Macro-level trends since 2000}

We begin by briefly reviewing the role played by natural gas in energy supply and demand as a whole. Figure 3.1 shows trends in year-on-year rates of growth in GDP, total energy consumption, and natural gas consumption. At the beginning of the 2000s, the main source of gas supply was China's indigenous gas production and this was consumed largely as a feedstock in industry, with very little being used in the power generation and residential sectors. After that, however, the WestEast pipeline (which linked the gas fields of western China to demand centres on the east coast) had started operation in 2005 and natural gas consumption posted double-digit annual growth rates. In 2006 the growth rate exceeded 20 per cent, when LNG began to be imported. Furthermore, this was followed by the commencement of pipeline gas imports from Central Asia in 2010 and also by the accelerated development of domestic trunk pipelines, including the expansion of capacity of the Shaanxi-Beijing Pipeline and the construction of a second and third East-West Pipeline, which significantly expanded the geographical extent of the natural gas market. As Figure 3.1 shows, consumption of natural gas grew considerably faster than the economy, taking natural gas's share of primary energy consumption to 6.7 per cent ${ }^{22}$ by 2016.

Natural gas consumption during this period was characterized by fully fledged growth in all sectors. This included growth in:

- use for power generation - alongside increasing adoption of high-efficiency power plants such as CCGT,

- industrial, residential, and commercial use - with the development of supply infrastructure, facilities, and appliances,

- use for CNG and LNG vehicles in the transport sector.

On the supply side, domestic production grew strongly at an annual rate of more than 10 per cent. Nevertheless, this was insufficient to keep up with the vigorous growth in demand, and LNG and pipeline gas imports rose sharply.

However, growth was not all plain sailing; the vast size of the energy market created its own problems, causing consumption to stall in 2014-16. As Table 3.1 shows, there was a clear slowing of growth during this period. Although partially attributable to macro-level factors such as the economic downturn and changes in industrial structure, other particular factors were also involved. These included:

- increased impacts of energy and environmental policies (including measures to tackle air pollution),

- complex price adjustments in the supply chain of natural gas (this problem had emerged with the significant growth of imports),

- $\quad$ ever-changing international energy prices.

These will be briefly considered in the following section.

\footnotetext{
${ }^{22}$ By calorific value calculation, China Energy Statistical Yearbook 2017.
} 

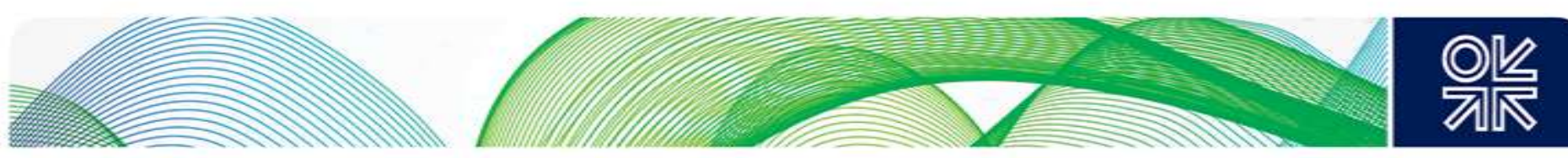

Following the temporary lull in growth, natural gas consumption spiked in 2017 and the upward trend continued into the first half of 2018. This is clearly attributable to measures to tackle air pollution, and may well mark major turning point natural gas consumption. At all events, natural gas has, over the past 20 years, transformed from being a minor domestically produced resource, into a key energy source that is fundamental to China's huge energy market. Owing to its huge size, the changes in LNG imports that partially support this supply will undoubtedly exert an enormous impact on the international LNG market.

\section{Figure 3.1: Growth rate of GDP, total energy and natural gas consumption}

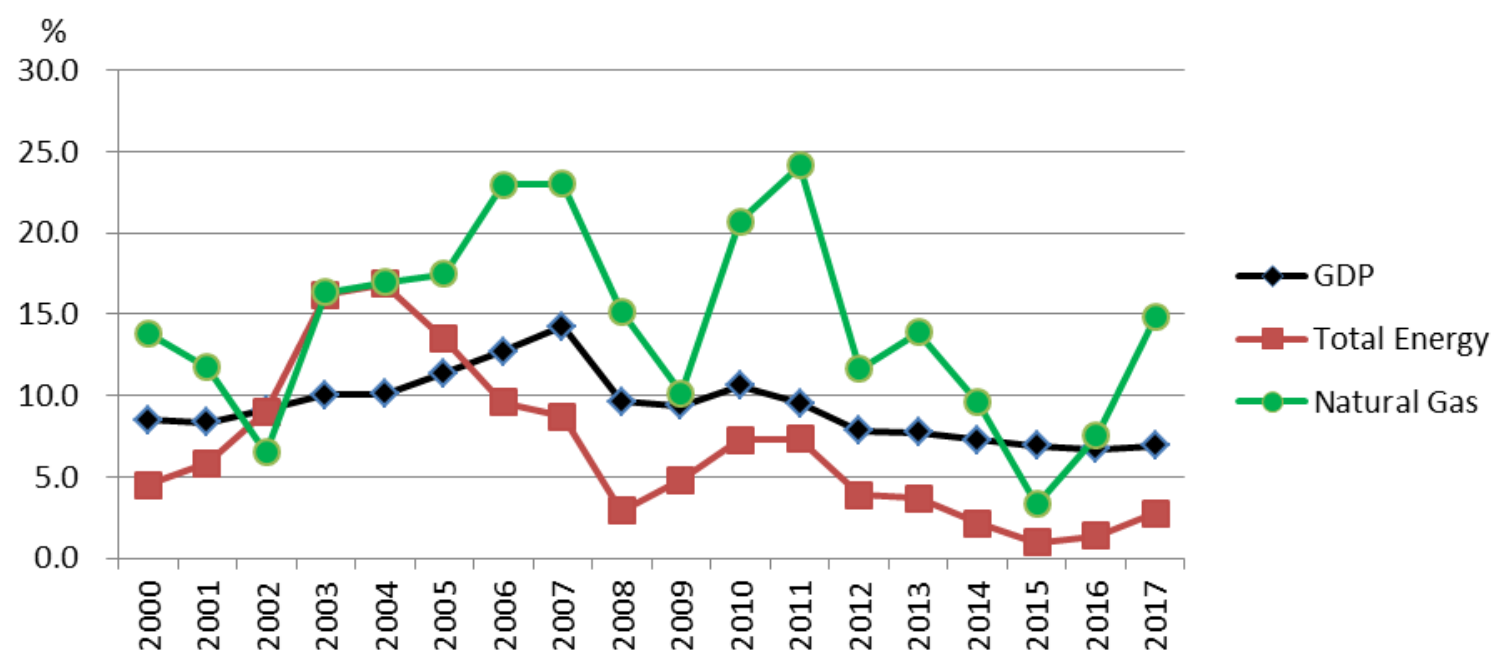

Source: China Energy Statistics Yearbook 2017; Articles published by NDRC.

Table 3.1: Averaged annual growth rate (\%)

\begin{tabular}{|l|c|c|c|}
\hline Year & $2000-13$ & $2014-16$ & 2017 \\
\hline GDP & 10.0 & 7.0 & 6.9 \\
\hline Total Energy Consumption & 8.4 & 1.4 & 2.8 \\
\hline Natural Gas Consumption & 16.2 & 6.8 & 15.1 \\
\hline Natural Gas production & 12.8 & 1.8 & 8.5 \\
\hline
\end{tabular}

Source: China Energy Statistics Yearbook 2017; Articles published by NDRC.

Table 3.2: Natural gas consumption by sector

\begin{tabular}{|c|c|c|c|c|c|c|c|c|c|}
\hline \multirow[b]{2}{*}{ Sector } & \multicolumn{2}{|c|}{2000} & \multicolumn{2}{|c|}{2005} & \multicolumn{2}{|c|}{2010} & \multicolumn{2}{|c|}{2016} & \multirow{2}{*}{$\begin{array}{l}\text { Annual growth } \\
\text { rate 2000-16 (\%) }\end{array}$} \\
\hline & bcm & $\begin{array}{l}\text { share } \\
(\%)\end{array}$ & bcm & $\begin{array}{l}\text { share } \\
(\%)\end{array}$ & $\mathrm{bcm}$ & share (\%) & $\mathrm{bcm}$ & $\begin{array}{l}\text { share } \\
(\%)\end{array}$ & \\
\hline Industrial & 19.3 & 78.6 & 31.0 & 66.5 & 51.1 & 47.3 & 93.1 & 44.8 & 10.3 \\
\hline $\begin{array}{c}\text { Power } \\
\text { Generation }\end{array}$ & 0.6 & 2.6 & 1.7 & 3.8 & 18.1 & 16.7 & 40.8 & 19.6 & 29.6 \\
\hline Residential & 3.2 & 13.2 & 7.9 & 17.0 & 22.7 & 21.0 & 38.0 & 18.3 & 16.6 \\
\hline Commercial & 1.4 & 5.6 & 5.9 & 12.7 & 16.2 & 15.0 & 36.0 & 17.3 & 22.7 \\
\hline Demand Total & 24.5 & & 46.6 & & 108.0 & & 207.8 & & 14.3 \\
\hline $\begin{array}{l}\text { Indigenous } \\
\text { Production }\end{array}$ & 27.2 & & 49.3 & & 95.6 & & 136.9 & & 10.6 \\
\hline
\end{tabular}

Source: China Energy Statistical Yearbook 2017. 

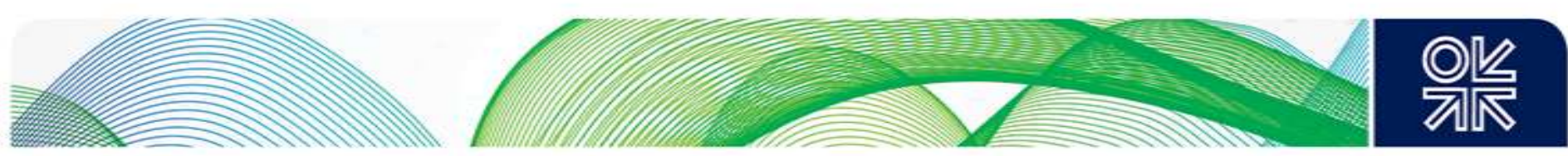

\subsection{Background of stagnation in gas demand 2014-16}

The stagnating natural gas consumption during the period 2014-16 was a manifestation of the structural problems that beset China's natural gas market; the factors that gave rise to the stagnation provide crucial clues to understanding how the natural gas market may develop in the future. The main factors to consider are as follows:

Promoting the consumption of natural gas was originally adopted as a long-term energy policy goal for several reasons, that included:

- optimization of the energy mix,

- ensuring a stable energy supply,

- environmental protection (to combat air pollution, global warming, and so on).

Deregulation and revisions to the price adjustment system were continuously pursued by the government with the long-term aim of creating a natural gas market governed by market mechanisms. ${ }^{23}$

- $\quad$ The state of supply and demand for natural gas meant, however, that imports had to be increased due to the shortage of indigenous gas production. Contrary to its long-term policy of deregulation, the government was consequently forced, in the short and medium term, to allocate supplies and to adjust prices by an extremely complex fashion in order to deal with the gaps between prices relating to upstream/downstream domestic pricing and pipeline gas/LNG import prices.

- $\quad$ The slump in demand between 2014 and 2016 appears to have been attributable in part to the unsuccessful 'comprehensive adjustments' made in the context of the above.

Below, we will consider the situation at the time from the perspective of policy and prices.

\subsubsection{Trends in natural gas and environmental policies: shortage of supply (around 2013)}

As described in the previous chapter, coal-to-gas switching projects were pursued under the 12FYP and a temporary shortage of supply occurred in 2013 (see section 2.4 for details). This was due to insufficient supplies of domestically produced gas and led to a spike in LNG imports. Evidently, however, quantitative adjustments were made on the domestic market by, for example, limiting supplies of natural gas to specific sectors and sharing supplies between regions. In addition, price adjustments had to be made when high-priced LNG imports increased.

\subsubsection{Natural gas price reforms and changes in price competitiveness (2014-16)}

Next, we consider the situation at the time from the point of view of the price competitiveness of natural gas relative to competing fuels.

Firstly, focusing on the government's policy on natural gas prices, a number of basic goals were adopted during the 12FYP. These included:

1. developing a natural gas pricing mechanism that can reflect resource shortages and the balance of supply and demand in the market,

\footnotetext{
${ }^{23}$ In reality, however, it is very difficult for the government to promote deregulation of the natural gas market under the current market environment - which is dominated by severe gas supply shortages. When we look at the confusion in the gas market in winter 2017, we can easily understand that stable gas supplies would never be achieved by deregulation but only by the application of government controls in terms of both supply volumes and prices.

More concretely, the gas supply had to be diverted from the south and the east to the northern regions and also from the power generation and industrial sectors to the residential sector, by complex administrative adjustments. In such a situation, market reforms and/or deregulation introducing market mechanism may simply increase the number of problems and the confusion. Therefore, we can assume that the current government is promoting gas market reforms from the long-term point of view.
} 

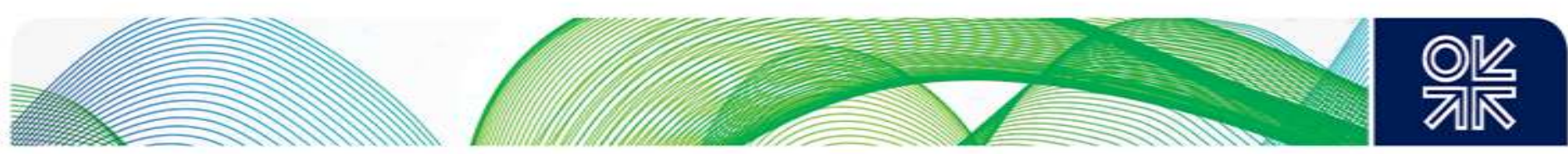

2. establishing natural gas pricing that can reflect a more reasonable relationship between natural gas and alternative energies,

3. developing a rational price transmission mechanism extending from upstream to downstream,

4. considering policy-led pricing - introducing a new price mechanism that could reduce seasonal gaps in natural gas demand and/or special contracts to allow the interruption of gas supplies.

The actual revisions made to natural gas prices are shown in Table 3.3. As can be seen, the Chinese government raised the City Gate Price in July 2013 and September 2014 to address the shortage of supply of natural gas and the high energy prices that were mainly due to high crude oil prices.

Regarding trends in the price of crude oil, on the other hand, the price per barrel began to decline from above $\$ 100 / \mathrm{bbl}$ from around the fourth quarter of 2014 . The following year it sank to between $\$ 40 / \mathrm{bbl}$ and $\$ 50 / \mathrm{bbl}$, and it then fell below $\$ 30 / \mathrm{bbl}$ in the first half of 2016 . (In fact, the price of crude oil began to fall immediately after the price of natural gas price had been increased.) Although the City Gate price was subsequently revised in April 2015 (when the crude oil price was in a downward phase) only to abolish the comparatively higher gas price paid by new users, the City Gas price remained high and was not lowered until December 2015.

The changes in the price competitiveness of natural gas relative to competitor fuels are shown in Table 3.3.

We consider firstly steam coal, which is a competitor to natural gas in the power generation and industrial sectors. At this time, China's coal industry was undergoing structural reforms, including the closure of unprofitable coal mines. On the other hand, demand increased as the economy recovered from the downturn precipitated by the bankruptcy of Lehman Brothers, and in 2010, the tight coal supply and demand situation caused the price of coal to spike sharply. From 2012, however, the trend was reversed and the price plunged ${ }^{24}$ as supply and demand for coal eased due to the slump in coal demand resulting from the economic slowdown, changes in industrial structure, and also the problem of excess production capacity.

The price of fuel oil, ${ }^{25}$ which competes with natural gas in industry and other sectors, followed largely the same trend as that outlined for crude oil above. It thus headed downward from the fourth quarter of 2014.

Thus, while steam coal and fuel oil prices were trending downward between 2014 and 2016, the price of natural gas was not lowered until the end of 2015. The price competitiveness of natural gas against these fuels consequently clearly worsened during this period, and this was undoubtedly one reason for the slump in natural gas consumption, particularly in the power generation and industrial sectors. Price competitiveness against other fuels is therefore an important factor to take into account when considering future demand for natural gas.

\footnotetext{
${ }^{24}$ The annual average price of Bohai Rim steam coal (5500k) decreased from 817 yuan/t in 2011to 703 yuan/t in 2012, 589 yuan/t in 2013, 523 yuan/ton in 2014, and 427 yuan/t in 2015. Source: CCRI (2016).

${ }^{25}$ Annual average prices of imported fuel oil are quoted here because it was difficult to obtain information about domestic prices of fuel oil.
} 

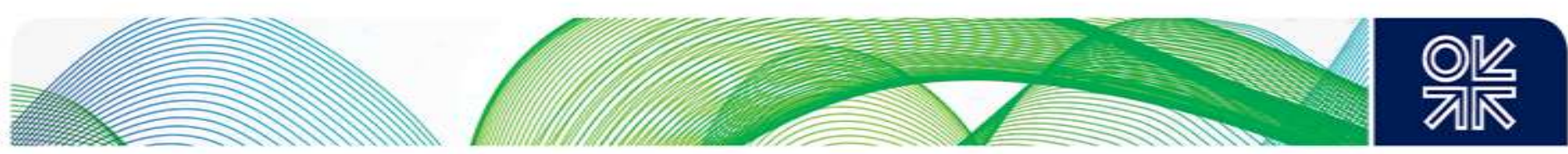

Table 3.3: Price competitiveness of natural gas against competing fuels

\begin{tabular}{|c|c|c|c|c|c|}
\hline Period & Demand & $\begin{array}{l}\text { Beijing } \\
\text { City Gate Price } \\
\left(\text { yuan } / \mathrm{m}^{3}\right)\end{array}$ & $\begin{array}{l}\text { vs } \\
\text { Steam Coal }{ }^{* 1}\end{array}$ & $\begin{array}{l}\text { vs } \\
\text { Fuel Oil }{ }^{\star 2}\end{array}$ & $\begin{array}{c}\text { Brent } \\
(\$ / b b l)\end{array}$ \\
\hline Prior to July 2013 & & 1.98 & 1.67 & 0.49 & 119.2 \\
\hline \multirow{2}{*}{ Jul. 2013 - Aug. 2014} & Exist. & 2.26 & 2.27 & 0.62 & \multirow{2}{*}{114.3} \\
\hline & Incr. & 3.14 & 3.15 & 0.87 & \\
\hline \multirow{2}{*}{ Sep. 2014 - Mar. 2015} & Exist. & 2.66 & 3.01 & 0.77 & \multirow{2}{*}{102.5} \\
\hline & Incr. & 3.14 & 3.55 & 0.91 & \\
\hline Apr. 2015 - Nov. 2015 & & 2.70 & 3.74 & 1.44 & 54.2 \\
\hline Dec.2015 - Aug. 2017 & & 2.00 & 2.78 & 1.42 & 44.7 \\
\hline After Sep. 2017 & & 1.90 & NA & NA & 54.2 \\
\hline
\end{tabular}

Note: *1 Bohai Rim steam coal: Annual average price.Figures in the table are calculated by dividing natural gas prices by the heat-equivalent price of coal. *2 Imported fuel oil prices: Annual average price. Figures in the table are calculated by dividing natural gas prices by the heat-equivalent price of fuel oil.

Source: Beijing City Gate Price: NDRC; Steam coal price: China Coal Research Institute; Fuel oil price: World Trade Atlas; Brent: BP, Statistical Review of World Energy, 2018.

\subsection{Impact of measures against air pollution on natural gas supply and demand (2017-18)}

Following the various developments outlined above, natural gas consumption has increased sharply since 2017. This section reviews the changes in natural gas supply and demand and their backgrounds.

\subsubsection{Trends in supply and demand for natural gas in 2017-18}

\section{$<$ Trends in 2017>}

In 2017, natural gas consumption increased by 15.3 per cent from the previous year (see Table 3.4). Domestic production, on the other hand, grew by only around 8.5 per cent and then imports surged by 27.6 per cent. A breakdown of imports reveals that there was markedly stronger growth in imports of LNG (up 47.1 per cent) than of pipeline gas (up 9.4 per cent). On a monthly basis (see Table 3.5) 2017 saw very high growth in natural gas consumption from the spring in the off-season, followed by a slowdown in growth in the winter. This appears to have been due to the constraints on supply capacity described in a later section.

From the point of view of consumption, although there are considerable differences among the latest statistical data, ${ }^{26}$ rough trends during the period can be observed as follows:

A breakdown of consumption by sector, shown in Table 3.6, reveals double-digit growth in all sectors except the use of natural gas as a feedstock in the chemical industry.

In the city gas sector, strengthened action on air pollution caused rapid growth in consumption for residential heating (considered in detail in the following section).

${ }^{26}$ For example, the figures for natural gas consumption by sector shown below are considerably different from the data shown in Table 3.4 .

Source: PIP (2018).

\begin{tabular}{|l|l|c|c|}
\hline & $\begin{array}{l}2016 \\
(\mathrm{bcm})\end{array}$ & $\begin{array}{l}2017 \\
(\mathrm{bcm})\end{array}$ & $\begin{array}{c}\text { Growth rate } \\
(\text { yoy, \%) }\end{array}$ \\
\hline City Gas & 72.9 & 93.7 & 28.5 \\
\hline Industrial & 73.0 & 76.0 & 4.1 \\
\hline Power generation & 36.6 & 42.7 & 16.7 \\
\hline Chemical feedstocks & 25.3 & 26.2 & 3.5 \\
\hline Total & 207.8 & 238.6 & 14.8 \\
\hline
\end{tabular}



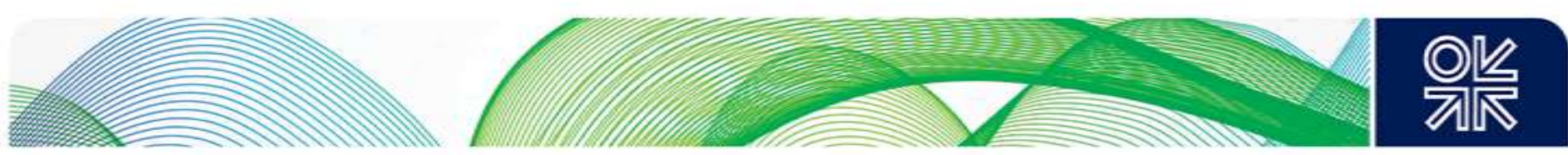

In the industrial sector, growth has been partly attributed to buoyant economic growth and the improved price competitiveness resulting from a lowering of the natural gas price. However, vigorous promotion of coal-to-gas switching for small boilers in the key cities and regions appears to have been a major factor (details are described in chapter 2).

The situation in the power generation sector was as follows. The rate of growth of total electricity consumption was relatively high (6.5 per cent, see Table 3.7). Although this was due at least in part to buoyant economic growth and growth in electricity consumption in tertiary industry, observers have also noted that the replacement of coal by electricity, together with the growth in electric vehicles, accelerated consumption in the consumer sector. ${ }^{27}$ Electricity generated using natural gas rose by 7.7 per cent from a year earlier its highest rate of growth in the previous few years. Natural gas-fired thermal power generation capacity increased to $75.7 \mathrm{GW}$ in 2017 , and the utilization rate simply based on the total electricity generated was around 30 per cent (Table 3.8, 3.9).

In the chemical industry, it is highly probable that growth (see Figure 3.6) was relatively low owing to the restrictions placed on supply capability.

However, the unnaturally low rate of year-on-year consumption growth in December 2017 and January/February 2018 described above is presumed to have been due to the constraints on supply of natural gas. As already widely reported, supplies to some users were suspended and supply volumes were reduced in the winter demand period. While it is extremely difficult to ascertain quantitatively the extent to which consumption might have grown if there had been sufficient supply availability, this is a crucial point to consider if reliable projections about the future are to be made.

Table 3.4: Supply and demand balance of natural gas (bcm)

\begin{tabular}{|l|l|r|r|r|r|r|}
\hline \multicolumn{2}{|c|}{} & 2016 & 2017 & $\begin{array}{l}\text { Growth rate } \\
\text { (yoy) (\%) }\end{array}$ & $2018 \mathrm{H} 1$ & \multicolumn{1}{|c|}{$\begin{array}{l}\text { Growth rate } \\
\text { (yoy) (\%) }\end{array}$} \\
\hline \multirow{4}{*}{ Supply } & Domestic Production & 137.1 & 148.7 & 8.5 & 77.6 & 4.6 \\
\cline { 2 - 7 } & Imports & 72.1 & 92.0 & 27.6 & 58.5 & 39.3 \\
\cline { 2 - 7 } & Pipeline gas & 37.3 & 40.8 & 9.4 & 25.4 & 23.9 \\
\cline { 2 - 7 } & LNG & 34.8 & 51.2 & 47.1 & 33.1 & 54.0 \\
\cline { 2 - 7 } & Total & 209.2 & 240.7 & 15.1 & 136.1 & 17.1 \\
\hline \multicolumn{2}{l|}{ Consumption } & 205.8 & 237.3 & 15.3 & 134.9 & 17.9 \\
\hline
\end{tabular}

Source: 'Monthly Overview on Natural Gas Market', NDRC.

Table 3.5: Growth rate of monthly natural gas consumption (\% over the same month of the previous year)

\begin{tabular}{|c|c|c|c|c|c|c|c|c|c|c|c|c|}
\hline & Jan. & Feb. & Mar. & Apr. & May & June & July & Aug. & Sep. & Oct. & Nov. & Dec. \\
\hline 2018 & 7.0 & 7.0 & 11.5 & 28.4 & 38.1 & 23.5 & 25.8 & 28.2 & 23.1 & - & - & - \\
\hline 2017 & 1.3 & 11.0 & 18.9 & 21.6 & 18.5 & 27.0 & 23.6 & 30.2 & 24.5 & 21.3 & 10.6 & 0.2 \\
\hline
\end{tabular}

Source: 'Monthly Overview on Natural Gas Market', NDRC.

Table 3.6: Natural gas consumption by sector $(\mathrm{bcm} / \mathrm{y})$

\begin{tabular}{|l|c|c|c|}
\hline & 2016 & 2017 & Growth rate (yoy) (\%) \\
\hline City gas & 78 & 89 & 14.2 \\
\hline Industrial & 61 & 73 & 20.2 \\
\hline Power generation & 38 & 47 & 22.9 \\
\hline Chemical feedstock & 25 & 27 & 9.2 \\
\hline
\end{tabular}

Note: Data for 2016 are estimated based on data for 2017.

Source: CNPC ETRI (Apr. 2018).

${ }^{27}$ China Electricity Council (2018). 
Table 3.7: Electricity consumption (TWh)

\begin{tabular}{|c|c|c|c|c|c|c|c|c|c|}
\hline & 2013 & 2014 & $\begin{array}{c}\text { Growth } \\
\text { rate } \\
(\%)\end{array}$ & 2015 & $\begin{array}{c}\text { Growth } \\
\text { rate } \\
(\%)\end{array}$ & 2016 & $\begin{array}{c}\text { Growth } \\
\text { rate } \\
(\%)\end{array}$ & 2017 & $\begin{array}{c}\text { Growth } \\
\text { rate } \\
(\%)\end{array}$ \\
\hline Total & $5,342.3$ & $5,563.7$ & 4.1 & $5,693.3$ & 2.3 & $5,974.7$ & 4.9 & $6,362.4$ & 6.5 \\
\hline Industrial & $4,663.4$ & $4,870.1$ & 4.4 & $4,964.8$ & 1.9 & $5,167.6$ & 4.1 & $5,492.3$ & 6.3 \\
\hline $\begin{array}{c}\text { Residential } \\
\text { \& Commercial }\end{array}$ & 678.9 & 693.6 & 2.2 & 728.5 & 5.0 & 807.1 & 10.8 & 870.3 & 7.8 \\
\hline
\end{tabular}

Source: Basic data from China Electricity Council's 'Power Industry in China'.

Table 3.8: Generation volume by source (TWh)

\begin{tabular}{|l|r|r|r|r|r|r|r|r|r|}
\hline & 2013 & 2014 & $\begin{array}{l}\text { Growth } \\
\text { rate } \\
(\%)\end{array}$ & 2015 & $\begin{array}{c}\text { Growth } \\
\text { rate } \\
(\%)\end{array}$ & 2016 & $\begin{array}{c}\text { Growth } \\
\text { rate } \\
(\%)\end{array}$ & 2017 & $\begin{array}{c}\text { Growth } \\
\text { rate } \\
(\%)\end{array}$ \\
\hline Total & $5,372.1$ & $5,604.5$ & 4.3 & $5,739.9$ & 2.4 & $6,022.8$ & 4.9 & $6,417.9$ & 6.6 \\
\hline Hydro power & 892.1 & $1,060.1$ & 18.8 & $1,112.7$ & 5.0 & $1,174.8$ & 5.6 & $1,194.5$ & 1.7 \\
\hline Thermal power & $4,221.6$ & $4,227.4$ & 0.1 & $4,230.7$ & 0.1 & $4,327.3$ & 2.3 & $4,551.3$ & 5.2 \\
\hline Coal & $3,980.5$ & $3,951.0$ & -0.7 & $3,897.7$ & -1.3 & $3,945.7$ & 1.2 & $4,149.6$ & 5.2 \\
\hline Natural Gas & 116.4 & 133.3 & 14.5 & 166.9 & 25.2 & 188.3 & 12.8 & 202.8 & 7.7 \\
\hline Oil & 5.2 & 4.4 & -15.1 & 4.2 & -6.1 & 2.8 & -33.0 & NA & NA \\
\hline Nuclear & 111.5 & 133.2 & 19.5 & 171.4 & 28.6 & 213.2 & 24.4 & 248.3 & 16.5 \\
\hline Wind & 138.3 & 159.8 & 15.5 & 185.6 & 16.2 & 240.9 & 29.8 & 305.7 & 26.9 \\
\hline PV others & 8.7 & 24.0 & -15.1 & 39.6 & 64.8 & 66.7 & 68.2 & 118.2 & 77.3 \\
\hline
\end{tabular}

Source: Basic data from China Electricity Council's 'Power Industry in China'.

Table 3.9: Power generation capacity (GW)

\begin{tabular}{|l|r|r|r|r|r|}
\hline & \multicolumn{1}{c|}{2013} & \multicolumn{1}{c|}{2014} & \multicolumn{1}{c|}{2015} & \multicolumn{1}{c|}{2016} & \multicolumn{1}{c|}{2017} \\
\hline Total & $1,257.7$ & $1,370.2$ & $1,525.3$ & $1,650.5$ & $1,777.1$ \\
\hline Hydro & 280.4 & 304.9 & 319.5 & 332.1 & 343.6 \\
\hline Thermal & 870.1 & 923.6 & 1005.5 & 1060.9 & 1104.9 \\
\hline Coal & 795.8 & 832.3 & 900.1 & 946.2 & 981.3 \\
\hline Natural Gas & 42.8 & 57.0 & 66.0 & 70.1 & 75.7 \\
\hline Oil & 5.9 & 5.1 & 4.3 & 2.1 & \\
\hline Nuclear Power & 14.7 & 20.1 & 27.2 & 33.6 & 35.8 \\
\hline Wind & 76.5 & 96.6 & 130.8 & 147.5 & 163.7 \\
\hline Solar & 15.9 & 24.9 & 42.2 & 76.3 & 130.3 \\
\hline
\end{tabular}

Source: Basic data from China Electricity Council's 'Power Industry in China'.

$<$ Trends in the first half of 2018>

The trends set in 2017 continued into the first half of 2018. While year-on-year growth in domestic consumption remained high at 17.9 per cent, domestic production grew by a relatively low 4.6 per cent and imports of pipeline gas and LNG surged by 23.9 per cent and 54.0 per cent respectively (Table 3.4). On a month-by-month basis (Table 3.5), there was strong year-on-year growth in 

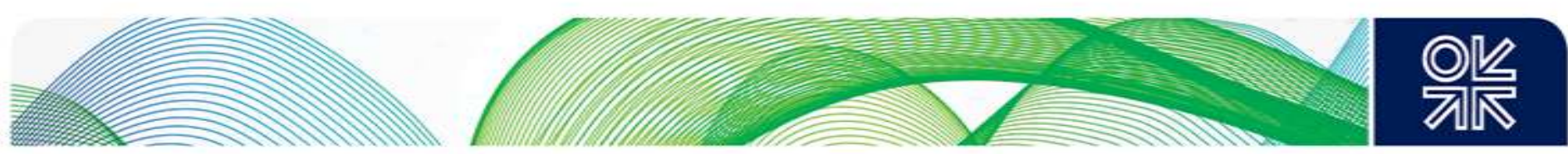

consumption even in the off-season. Information available from various sources as of the beginning of August 2018 indicates that the following were having an impact:

- $\quad$ Demand for power appears to have been driven by buoyant growth in electricity demand, which rose 9.4 per cent from a year earlier in the first half of 2018. This was due to two main factors:

1. growth in industrial demand propelled by strong growth in industries such as manufacturing (up 7.3 per cent) and IT (up 25.5 per cent),

2. strong growth in the commercial and residential sectors (up 13.2 per cent) due to the cold spell at the start of the year and high temperatures from May onwards. ${ }^{28}$

On the electricity supply side, the poor performance of hydroelectric plants due to drought, together with the closure of some ageing thermal power plants, also appear to have contributed to a higher capacity factor for LNG power plants. ${ }^{29}$

- The buoyant economy drove growth in both industrial and commercial demand for natural gas, with industrial demand in particular bouncing back from supply constraints in the winter of 2017. Although more detailed observations and analysis are required, it also appears possible that there was some increase in gas procurement for storage triggered by the natural gas supply shortage the previous winter.

As coal-to-gas boiler switching (for industrial use) has been promoted not only around Beijing-Tianjin-Hebei, but also in key cities and regions across the country to combat air pollution, this is likely to have buoyed natural gas demand during the off-season. LNG road tanker demand is strong, as indicated by rising road tanker prices.

\subsubsection{Impact of action on air pollution and the problem of gas shortages}

As noted in the preceding chapter, measures against PM2.5 air pollution were stepped up in BeijingTianjin-Hebei and the surrounding areas in 2017. Underlying this move was the high priority allocated by the Xi administration to tackling environmental problems at the 19th five-yearly National Congress of the Communist Party of China, in October 2017. Strong political pressure was exerted by the administration throughout the duration of the 12FYP, and moves to strengthen environmental measures appear to have permeated local government. Symbolic of this was the wave of dismissals of local government heads who had failed to achieve environmental targets during the period covered by the 12FYP.

Against this political backdrop, it began to be feared that PM2.5 targets would fail to be achieved in Beijing and the surrounding area during the winter of 2017/18. Failure to achieve the target in 2017, the final year of the Action Plan 2013, would undoubtedly have created a major problem politically, and the barrage of measures taken against air pollution in Beijing-Tianjin-Hebei and the surrounding areas in 2017 appears to have arisen from these political considerations.

Local governments responded by stepping up their own action against PM2.5 pollution. Concrete measures such as coal-to-electricity and coal-to-gas switching projects were vigorously promoted, and the effects of projects implemented consequently surpassed planned targets (as described in subsection 2.4.4).

As these projects to phase out coal-fired industrial boilers and to increase the use of gas or electricity instead of coal for residential heating were worked out in detail, and implemented at the district and municipal levels, balancing the extra demand generated with gas and electricity supply capabilities

\footnotetext{
${ }^{28}$ Source: Material submitted by China Electricity Council, 30 July 2018.

29 'Shortages of electricity supply occur in Zhejiang province and LNG demand in the power generation sector is increasing. 'Interview with an expert on energy market, 3 August 2018.
} 

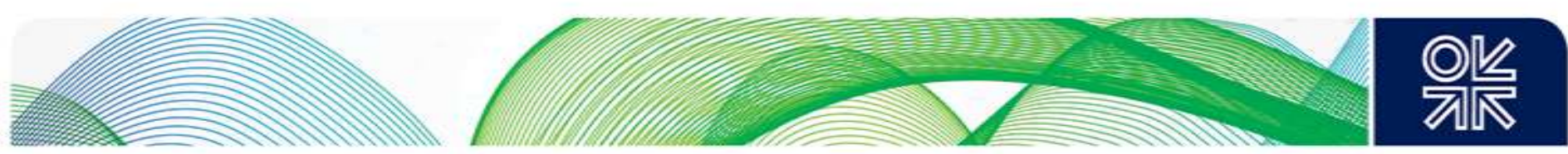

over wide areas proved difficult at times. Below are some of the social problems that arose in central and southern regions, as well as in northern China.

- In cold regions in the north, no natural gas was supplied and homes were left without heating during the winter.

- $\quad$ Households were impoverished by the much higher cost of electricity compared to coal.

- Some factories had to temporarily shut down or shorten their operating hours due to gas shortages.

- $\quad$ The soaring cost of LNG sold from road trucks severely affected some industrial users' operations.

Gas shortages led to drivers of CNG vehicles forming long queues at filling stations.

In response to such social problems, the NDRC published the following emergency measures to secure natural gas supply in December 2017.30

- $\quad$ As of December 2017, indigenous gas production had already increased by 3.7 million $\mathrm{m}^{3} /$ day but a further $3.3 \mathrm{mcm} /$ day were added to the production from January 2018 .

In the initial annual plan for LNG imports, $24.8 \mathrm{bcm}$ (248 cargoes) had been scheduled to be imported, during the winter season, a further $3.5 \mathrm{bcm}$ (39 cargoes) were added to the plan.

- Diversion of $14 \mathrm{mcm} /$ day natural gas supply from the southern provinces such as Guangdong, Fujian, and Zhejiang to the northern region had already been implemented as of December 2017 and this was increased by $5 \mathrm{mcm} /$ day.

Natural gas supplies of $10 \mathrm{mcm} /$ day to power generation plants were diverted to residential use in the northern region, by starting emergency operation of coal-fired power plants.

- $\quad$ Natural gas supplies of $15 \mathrm{mcm} /$ day to the industrial sector were diverted to residential use in the northern region, and also for feedstock in the chemical industry, from gas supply companies such as CNPC, by reducing 'own use'.

Natural gas supply from underground storage was increased to $80 \mathrm{mcm} /$ day, which was 30 per cent higher than the previous year.

In addition to these emergency measures, when natural gas supply shortages emerged as a significant problem at the end of 2017, the central government began to demand that coal-to-gas switching projects only be pursued once access to natural gas supplies had been secured.

Policies on air pollution such as the Winter Clean Heating (NDRC Dec.2017) and the Blue Sky Action Plan (SCPRC Jun.2018) in fact stipulated that local governments should only pursue measures having first secured supplies of natural gas, signalling a stronger recognition of the importance of pursuing action against air pollution while avoiding natural gas supply shortages.

\subsubsection{Outlook for full-year natural gas supply and demand in 2018}

In light of this situation, let us briefly consider how natural gas supply and demand may unfold over the course of 2018 as a whole.

Starting with consumption, expert opinion on the outlook for natural gas consumption varies extremely widely (Table 3.10). Projections of the highest growth (around 15 per cent) appear to assume that action on air pollution will cause the current growth trend to continue throughout the second half of 2018, while projections of low growth (not more than 10 per cent) appear to assume that supply and

\footnotetext{
${ }^{30}$ Material submitted at NDRC's Regular Press Conference on 18 December 2017.
} 

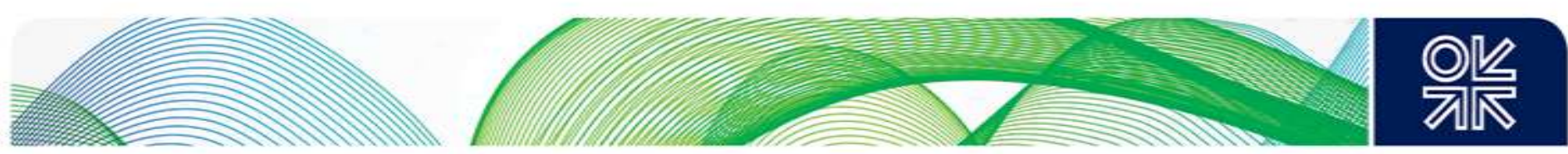

demand adjustments will be made and consumption will be limited by constraints on the supply side. What is certain, however, is that consumption in winter 2018/19 will at least be on a par with the high level reached last year in regions where coal-to-gas switching is already complete, and this year plans exist to convert another 4 million households from coal to gas. ${ }^{31}$ Consumption of gas has already grown by at least 17.9 per cent in the first half of the year (compared with the previous year) and it appears unlikely that growth will slow dramatically in the second half of the year.

Regarding the situation on the supply side, domestic production of natural gas in 2018 is expected to grow by a record rate of about 8.5 per cent. ${ }^{32}$ Pipeline gas imports too are showing more robust growth than in the previous year, and LNG imports remain high.

Assuming, then, that consumption in 2018 as a whole will grow to the maximum extent permitted by supply, ${ }^{33}$ it will grow at a rate of between 15 and 16 per cent over the previous year. In reality, therefore, it is highly likely that growth will settle down to a level not in excess of this rate.

Table 3.10: Various outlooks for natural gas consumption in 2018

\begin{tabular}{|l|c|l|}
\hline Source & Growth rate (yoy) (\%) & Published date \\
\hline CNPC & 10.5 & Beijing, 4 April 2018 \\
\hline CNOOC & 14.5 & AGMF Beijing, 7 June 2018 \\
\hline IHS & 9.0 & Beijing, 6 June 2018 \\
\hline 1st half of 2018 (Actual) & 17.9 & NDRC monthly statistics \\
\hline
\end{tabular}

\subsection{LNG import trends}

China's first receiving terminal was Guangdong Dapeng LNG Terminal, which entered service in 2006. After that, terminals developed by China's three state-owned oil majors (CNOOC, CNPC, and SINOPEC) started operation and recently new entrants such as JOVO, ENN, and others have been active in the terminal business. As of August 2018, China had 18 receiving terminals with a nominal receiving capacity of around $60 \mathrm{mt} / \mathrm{y}$ (see Table 3.11).

Construction of LNG receiving terminals is overseen by the central government. It is pursued systematically through various processes, including approval by NDRC, and receiving capacity has grown steadily to date. LNG imports have risen in tandem with this growth in receiving capacity. As previously noted, however, import growth slowed when natural gas consumption stalled in 2014-15, and terminal capacity utilization has fallen to 50-60 per cent (see Figure 3.2 and Table 3.12).

Two new terminals entered operation in 2017 and four in 2018, and terminal capacity has grown by at least $12 \mathrm{mt} / \mathrm{y}$. This is another reason for the rapid growth in LNG imports since 2017.

China has thus grown to become the world's second-largest importer of LNG after Japan. As imports have grown, their role in the domestic natural gas market gas has changed. When LNG first began to be imported, supplies of gas produced from LNG were limited to the provinces in which terminals were located. However, as trunk pipelines have been developed to handle increased domestic output and pipeline gas imports from Central Asia, LNG has evolved to play an important role in sustaining natural gas supplies throughout China from the coast. During last year's natural gas supply shortages in Beijing-Tianjin-Hebei and the northern regions, for example, the situation was dealt with by both increasing LNG imports in the south-east so that pipeline gas supplies to the north could be temporarily boosted, and by transporting supplies from the south-east to the north by road tanker. LNG has thus ceased to be used solely as a means of meeting demand in coastal regions.

As shown in Table 3.11, China's LNG terminals can be divided into four regions, and regional trends in LNG imports and terminal capacity utilization rates examined. Regarding, firstly, trends in LNG

\footnotetext{
${ }^{31}$ Information published by the Ministry of Ecology and Environment.

32 Based on the outlook by the National Energy Administration as of May 2018.

${ }^{33}$ The assumption of the maximum capacity is estimated based on $50 \mathrm{mt}$ of LNG imports, 55 bcm/y of pipeline gas import capacity, and $5 \%$ year-on-year growth of indigenous gas production. (For details, see chapter 4.)
} 

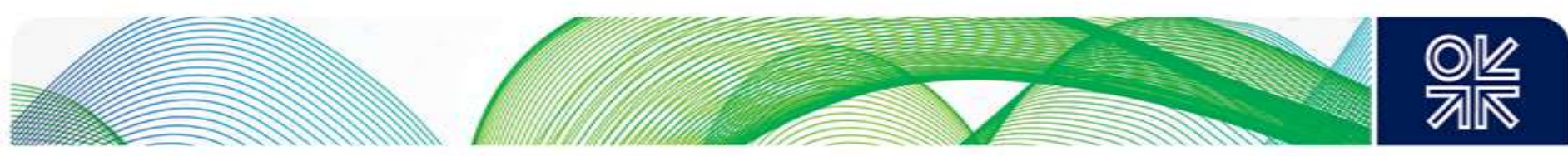

imports (Table 3.13), the north saw strong growth of over 80 per cent throughout 2017 and the first half of 2018. This was due to a combination of the increase in receiving capacity resulting from the expansion of existing terminals and entry into operation of new terminals, together with rapid growth in natural gas demand generated by active promotion of coal-to-gas switching projects. In the east, growth appears to have been driven by growth in receiving capacity combined with increased road tanker shipments to the north in the winter of 2017/18 and strong demand for power generation use from 2017 to the first half of 2018. Growth in the south, on the other hand, was modest compared to that in the north and east.

Table 3.11: LNG terminals as of 2020

\begin{tabular}{|c|c|c|c|c|c|}
\hline Block & Province & City & Main company & Capacit & $\mathrm{nt} / \mathrm{y})$ \\
\hline \multirow{5}{*}{ North } & Liaoning & Dalian & CNPC & 6.0 & \multirow{5}{*}{23.7} \\
\hline & Hebei & Tangshan & CNPC & 8.0 & \\
\hline & \multirow{2}{*}{ Tianjin } & Tianjin & CNOOC & 2.2 & \\
\hline & & Tianjin & SINOPEC & 3.0 & \\
\hline & Shandong & Qingdao & SINOPEC & 4.5 & \\
\hline \multirow{5}{*}{ East } & \multirow{2}{*}{ Jiangsu } & Rudong & CNPC & 6.5 & \multirow{5}{*}{19.1} \\
\hline & & Qidong & GHE & 1.6 & \\
\hline & Shanghai & Shanghai & CNOOC & 4.5 & \\
\hline & \multirow{2}{*}{ Zhejiang } & Ningbo & CNOOC & 3.5 & \\
\hline & & Zhoushan & ENN & 3.0 & \\
\hline \multirow{6}{*}{ South } & Fujian & Putin & CNOOC & 4.5 & \multirow{6}{*}{22.0} \\
\hline & \multirow{5}{*}{ Guangdong } & Shenzhen Dapeng & CNOOC & 7.0 & \\
\hline & & Dongguan & Jovo & 1.0 & \\
\hline & & Zhuhai & CNOOC & 3.5 & \\
\hline & & Yuedong & CNOOC & 2.0 & \\
\hline & & Shenzhen & CNOOC & 4.0 & \\
\hline \multirow{2}{*}{ Others } & Hainan & Hainan & CNOOC & 2.0 & \multirow{2}{*}{5.0} \\
\hline & Guangxi & Beihai & SINOPEC & 3.0 & \\
\hline \multicolumn{4}{|l|}{ Total } & 69.8 & \\
\hline
\end{tabular}

Source: Information published by terminal owners and others.

As for terminal capacity utilization (Table 3.14), rates rose dramatically in the north and east from 2016 to the first half of 2018. In the south, the utilization rate stayed comparatively high consistently throughout this period, while utilization rates of 'Other' terminals (serving local markets) remained low at 30-40 per cent.

Given the above trends, it is likely that supplies of indigenous production and pipeline gas/LNG imports will be further optimized as pipelines and other supply infrastructure continue to expand; it is expected that LNG can play a more important role in the natural gas market.

Table 3.12: LNG imports in China

\begin{tabular}{|l|l|l|l|l|l|l|l|l|}
\hline Year & 2010 & 2011 & 2012 & 2013 & 2014 & 2015 & 2016 & 2017 \\
\hline $\mathrm{bcm}$ & 9.46 & 12.58 & 14.77 & 18.51 & 19.81 & 19.77 & 27.08 & 39.59 \\
\hline
\end{tabular}

Source: GIIGNL ‘Annual Report’. 

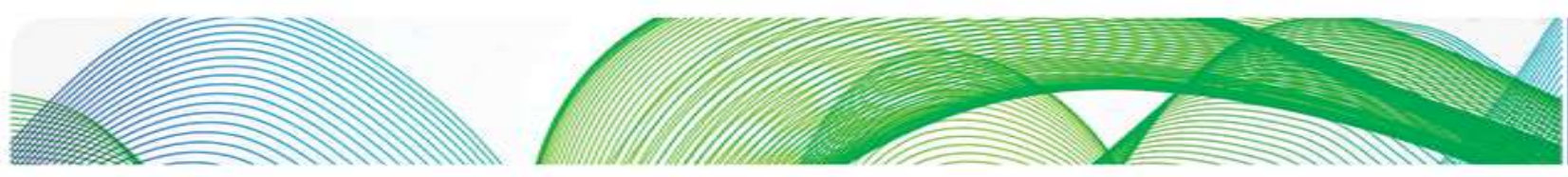

Table 3.13: Growth rate of LNG imports by region

\begin{tabular}{|l|c|c|}
\hline Region & $2017(\%)$ & $20181^{\text {st }} \mathrm{H}(\%)$ \\
\hline North & 86.3 & 81.4 \\
\hline East & 71.3 & 73.9 \\
\hline South & 9.4 & 17.3 \\
\hline Others & 48.6 & 11.8 \\
\hline Total & 48.1 & 53.7 \\
\hline
\end{tabular}

Note: Regions divided by the following definition taking account of natural gas supply systems in China: North: North of Shandong province;

East: Jiangsu, Shanghai, Zhejiang;

South: Fujian, Guangdong.

Source: Estimations based on Customs Statistics of China and Waterborne Trade Data.

Table 3.14: Utilization rate of LNG terminals by region

\begin{tabular}{|l|c|c|c|}
\hline & $2016(\%)$ & $2017(\%)$ & $\begin{array}{c}\text { First half of } 2018 \\
(\%)\end{array}$ \\
\hline North & 57.4 & 80.5 & 82.7 \\
\hline East & 62.8 & 87.2 & 110.0 \\
\hline South & 77.7 & 79.4 & 72.0 \\
\hline Others & 30.6 & 31.8 & 32.9 \\
\hline Total & 63.6 & 77.2 & 82.1 \\
\hline
\end{tabular}

Sources: Estimated based on Customs statistics of China and Waterborne Trade Data.

\section{Figure 3.2: Historical data and outlook for LNG receiving capacity and utilization rate}

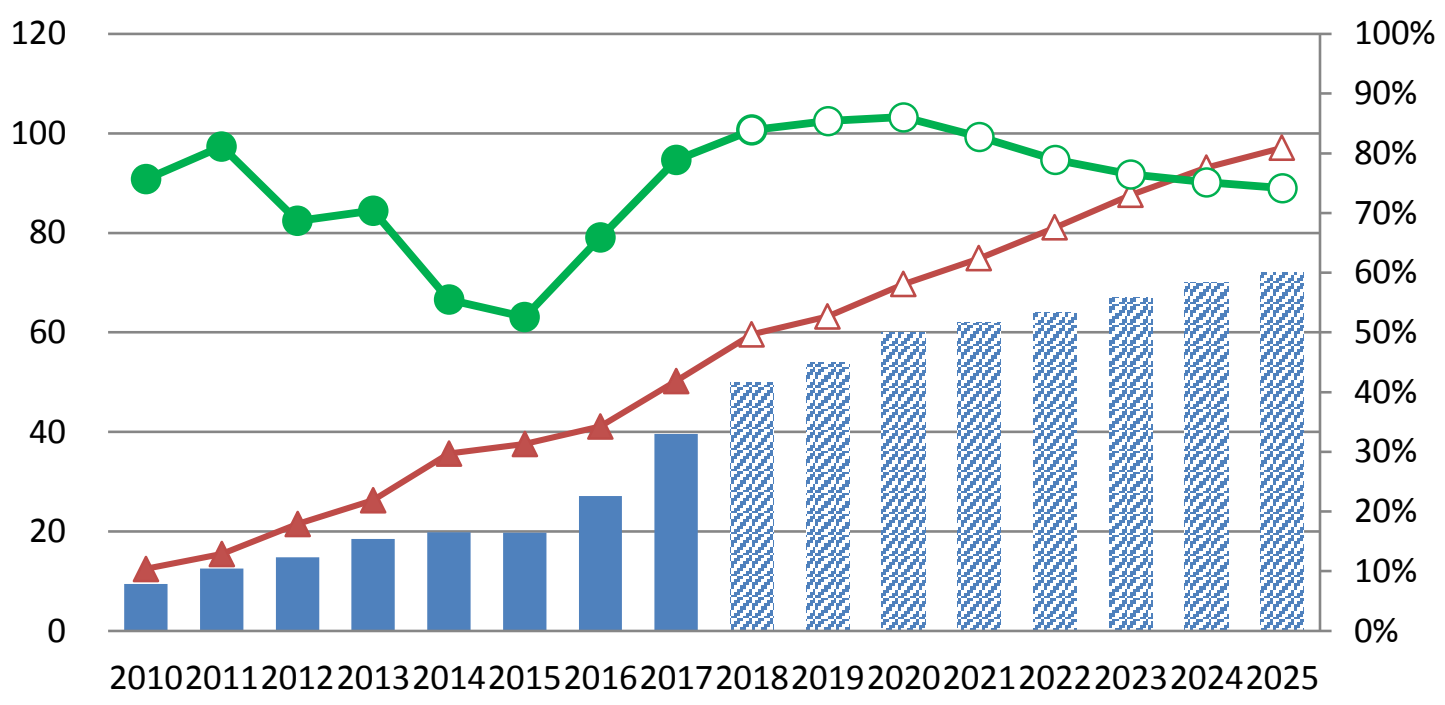

Imports $\quad-$ Terminal capacity $\quad-0$ Utlization Rate

Note: Left axis for terminal capacity and import (mt/year), Right axis for utilization rate of terminal (\%).

Source: Import volumes are based on GIIGNL data, Utilization rates are estimated based on the import volume and nameplate terminal capacity published in various sources. 

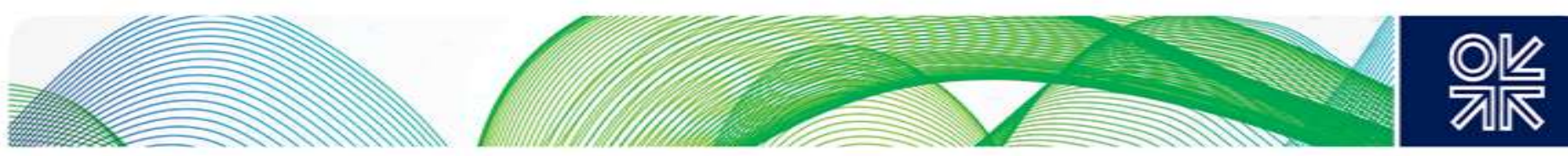

\section{Outlook for natural gas demand}

\subsection{Projections for long term natural gas supply and demand by various organizations}

\subsubsection{Projections and assumptions}

Table 4.1 shows a comparison of the long-term projections made to date for natural gas consumption in China. The purpose of this comparison is to explore the assumptions upon which these projections are based. It is interesting to consider, for example, whether the projections made by CNPC at around the time that the 13FYP was being drafted took national policies of this kind into account. Investigating whether what is actually happening at the moment coincides with the national policies and projections formulated in the past, should make it easier to predict what may happen in the future.

The figures in the tables below compare the main projections over time in this context, and are intended to facilitate the reader's understanding of the following sections.

Table 4.1: Outlooks for natural gas demand by various organizations $(\mathrm{Bcm})$

\begin{tabular}{|c|c|c|c|c|c|c|}
\hline \multicolumn{2}{|l|}{ Source } & 2015 & 2016 & 2017 & 2020 & 2030 \\
\hline \multicolumn{2}{|l|}{ 12th Five year plan } & \multicolumn{2}{|l|}{230} & & & \\
\hline \multirow{2}{*}{ 13th Five year plan*1 } & High & \multirow{13}{*}{193.2} & \multirow{13}{*}{207.8} & \multirow{13}{*}{237.3} & 376 & \\
\hline & Middle & & & & 312 & \\
\hline Action Plan to win Blue Sky*2 & & & & & 376 & \\
\hline \multirow{3}{*}{ CNPC published in2010 } & High & & & & 318 & 438 \\
\hline & Middle & & & & 297 & 392 \\
\hline & Low & & & & 279 & 341 \\
\hline \multirow{3}{*}{ CNPC published in2014 } & High & & & & 334 & 541 \\
\hline & Middle & & & & 298 & 454 \\
\hline & Low & & & & 269 & 381 \\
\hline \multirow{3}{*}{ CNPC published in 2016} & High & & & & 320 & 520 \\
\hline & Middle & & & & 290 & 440 \\
\hline & Low & & & & 260 & 370 \\
\hline \multicolumn{2}{|l|}{ CNPC published in $2018^{* 3}$} & & & & 400 & 600 \\
\hline
\end{tabular}

Note: Data for 2015-17are actual consumption, except the 12FYP. *1 In the 13FTP, the target for natural gas consumption is described as a share in total energy consumption from $8.3 \%$ to $10 \%$. ${ }^{*} 2$ In the document of the Blue Sky Action Plan the share of natural gas in total primary energy is to be $10 \%$. ${ }^{*} 3$ The figure is not described as 'an outlook' but as a 'huge potential'.

Source: NDRC, CNPC 

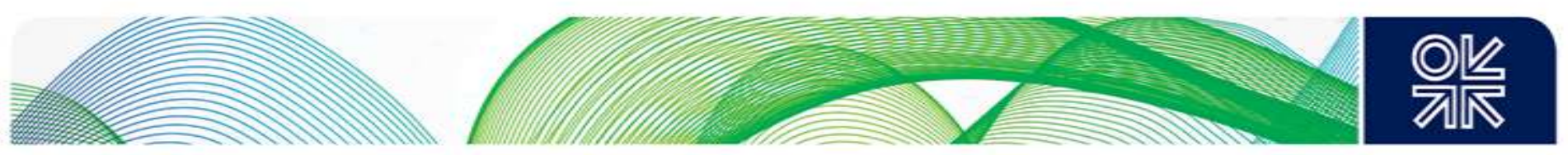

Table 4.2: Outlooks for natural gas supply by various organizations

\begin{tabular}{|c|c|c|c|c|c|c|c|c|c|c|c|c|}
\hline \multirow{2}{*}{\multicolumn{2}{|c|}{ Supply source }} & \multicolumn{3}{|c|}{ Actual } & \multirow{2}{*}{\begin{tabular}{|c|}
$\begin{array}{c}\text { The } \\
\text { Strategic } \\
\text { Plan }^{* 1}\end{array}$ \\
2020 \\
\end{tabular}} & \multirow{2}{*}{$\begin{array}{c}\text { The } \\
13 F Y P \\
2020 \\
\end{array}$} & \multicolumn{2}{|c|}{ CNPC 2010} & \multicolumn{2}{|c|}{$\begin{array}{c}\text { CNPC } \\
2016\end{array}$} & \multicolumn{2}{|c|}{$\begin{array}{c}\text { CNPC } \\
2018\end{array}$} \\
\hline & & 2015 & 2016 & 2017 & & & 2020 & 2030 & 2020 & 2030 & 2020 & 2030 \\
\hline \multirow{4}{*}{$\begin{array}{l}\text { Indigenous } \\
\text { production }\end{array}$} & Conventional & 124 & 121 & 131 & 185 & 157 & & & 170 & 240 & 170 & 240 \\
\hline & CBM & 4.4 & 6.5 & 7 & 30 & 10 & & & 20 & 30 & 16 & 50 \\
\hline & Shale & 4.3 & 7.9 & 9 & 30 & 30 & & & 20 & 50 & 30 & 80 \\
\hline & SNG & 1 & 1.5 & 2 & NA & 10 & & & 10 & 20 & 4 & 20 \\
\hline \multicolumn{2}{|r|}{ Sub-total } & 134.6 & 137.1 & 148.7 & & 207 & 210 & 300 & 220 & 340 & 220 & 390 \\
\hline \multirow{2}{*}{ Imports } & Pipeline gas & 34 & 37 & 41 & & & & & 65 & 130 & 65 & 130 \\
\hline & LNG & 27 & 35 & 52 & & & & & 55 & 70 & 60 & 70 \\
\hline \multicolumn{2}{|r|}{ Sub-total } & 61 & 72 & 93 & & 153 & 90 & 100 & 120 & 200 & 125 & 200 \\
\hline \multicolumn{2}{|r|}{ Total } & 194 & 209 & 242 & & 360 & 300 & 400 & 340 & 540 & 345 & 590 \\
\hline
\end{tabular}

Source: *1 Strategic Action Plan, NDRC, CNPC.

\subsubsection{NDRC position document on establishing long-term stable natural gas supply system (April 2014)}

This document on long-term natural gas supply arrangements was published by the NDRC in April 2014; its publication appears to have been intended to coincide with the natural gas supply shortages caused in some regions by the additional demand from coal-to-gas switching projects. It deals with the following goals:

Achieving a natural gas supply capacity of $400 \mathrm{bcm} / \mathrm{y}$ (and, if possible, $420 \mathrm{bcm} / \mathrm{y}$ ) by 2020.

- $\quad$ Securing supplies of gas for the residential sector, including gas for use by households, public facilities, central heating services, local buses, and taxis.

Replacement of coal-fired boilers with natural gas in the industrial sector.

Preparing an action programme to meet the $112 \mathrm{bcm} / \mathrm{y}$ of natural gas demand expected to be generated from coal-to-gas switching projects by 2020 .

Specific measures described in the document include the following:

- $\quad$ On the supply side, the bolstering of policy support for the development of unconventional natural gas resources such as shale gas.

The implementation of coal-to-gas switching projects, having first ensured access to gas resources.

- $\quad$ The expansion of gas storage capacity.

- $\quad$ The enhancement of arrangements to manage supply and demand for natural gas.

- The avoidance of 'unplanned' coal-to-gas switching projects and in particular the tightening of controls on construction of new gas-fired power generation plants.

The reform of the natural gas market - specifically the introduction of third-party access (TPA) at pipelines and LNG terminals, together with development of the natural gas pricing system.

It is therefore apparent that measures to deal with dislocations of the kind that occurred in the natural gas market in 2017/18 had already been considered, and advice on their implementation circulated, within the Chinese government, in 2014. Quantitative estimates of the additional demand for natural gas generated by coal-to-gas switching projects also appear to have been calculated. 

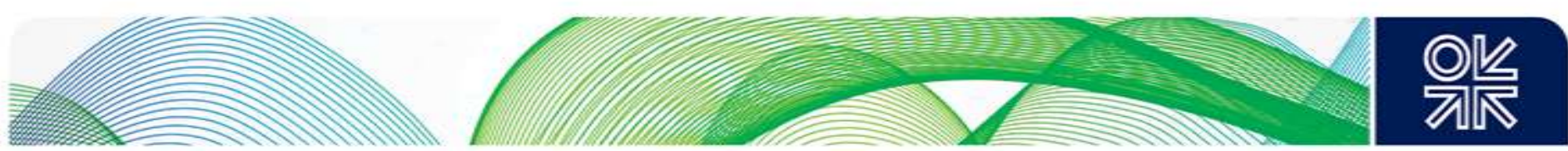

\subsubsection{CNPC estimates of potential natural gas demand generated by coal-to-gas switching (2016)}

Estimates produced by CNPC also provide useful information for projecting future natural gas consumption. As noted, the additional natural gas demand generated by coal-to-gas switching projects implemented to tackle air pollution is an extremely important factor to take into consideration when estimating future consumption.

The results of an analysis of natural gas demand published by CNPC in 2016 are shown in Table 4.3. These indicate that the potential additional demand for natural gas, generated by coal-to-gas switching projects from 2016 to 2020 , will reach $112 \mathrm{bcm}$. Industry will account for the largest portion (47.3 per cent) of this total, followed by the power generation (36.7 per cent) and residential sectors (16.1 per cent). Broken down by region (see Table 4.4), Beijing-Tianjin-Hebei, and Shandong will account for 27.3 per cent, the Yangtze River Delta for 28.1 per cent, Guangdong for 11.3 per cent, and other regions for 33.3 per cent. The amount of additional demand generated thus appears to be correlated more with how much action is taken against pollution in urban areas than with natural gas market size. In addition, it should be noted that these estimates are based on projects implemented up to 2020 , and it is also estimated that an additional $160 \mathrm{bcm}$ of demand will be generated if similar measures continue to be implemented between 2020 and 2025.

Table 4.3: Additional natural gas demand generated by coal-to-gas switching projects (From 2016 to 2020)

\begin{tabular}{|c|c|c|c|c|c|}
\hline Year & Sector & Use & $\mathrm{bcm}$ & Region & $\mathrm{bcm}$ \\
\hline \multirow{13}{*}{ 2016-20 } & \multirow{4}{*}{$\begin{array}{l}\text { Power } \\
\text { generation }\end{array}$} & \multirow{4}{*}{ CCGT etc. } & \multirow{4}{*}{$\begin{array}{l}41 \\
(36.7 \%)\end{array}$} & $\begin{array}{l}\text { Beijing-Tianjin-Hebei/ } \\
\text { Shandong }\end{array}$ & 11.2 \\
\hline & & & & Yangtze River Delta & 12.4 \\
\hline & & & & Guangdong & 5.0 \\
\hline & & & & Others & 12.7 \\
\hline & \multirow{4}{*}{ Industrial } & \multirow{2}{*}{ Gas CHP } & \multirow{4}{*}{$\begin{array}{l}53 \\
(47.3 \%)\end{array}$} & $\begin{array}{l}\text { Beijing-Tianjin-Hebei/ } \\
\text { Shandong }\end{array}$ & 14.0 \\
\hline & & & & Yangtze River Delta & 11.9 \\
\hline & & \multirow{2}{*}{ Gas-fired boiler } & & Guangdong & 7.1 \\
\hline & & & & Others & 20.0 \\
\hline & \multirow{4}{*}{$\begin{array}{l}\text { Residential } \\
\text { heating }\end{array}$} & \multirow{2}{*}{ Gas CHP } & \multirow{4}{*}{$\begin{array}{l}18 \\
(16.1 \%)\end{array}$} & $\begin{array}{l}\text { Beijing-Tianjin-Hebei/ } \\
\text { Shandong }\end{array}$ & 5.6 \\
\hline & & & & Yangtze River Delta & 7.3 \\
\hline & & \multirow{2}{*}{ Gas-fired Boiler } & & Guangdong & 0.6 \\
\hline & & & & Others & 4.8 \\
\hline & \multicolumn{2}{|l|}{ Total } & \multicolumn{3}{|l|}{112.0} \\
\hline $2020-25$ & \multicolumn{2}{|l|}{ Total } & \multicolumn{3}{|l|}{160.0} \\
\hline
\end{tabular}

Source: CNPC (2016), 'China's Natural Gas Market Overview'. 

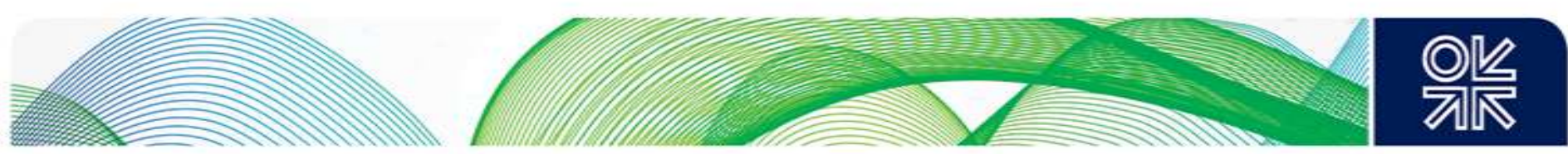

Table 4.4: Share of region regarding additional natural gas demand generated by coal-to-gas switching projects

\begin{tabular}{|l|c|c|}
\hline Region & $\begin{array}{l}\text { Additional natural gas } \\
\text { demand generated by coal to } \\
\text { gas switching (\%) }\end{array}$ & $\begin{array}{l}\text { Natural Gas consumption } \\
\text { in 2016 (\%) }\end{array}$ \\
\hline Beijing-Tianjin-Hebei/Shandong & 27.3 & 19.5 \\
\hline Yangtze River Delta & 28.1 & 18.2 \\
\hline Guangdong & 11.3 & 8.1 \\
\hline Others & 33.3 & 54.2 \\
\hline
\end{tabular}

Source: Natural gas demand by coal to gas switching; based on the amount described in Table 4.3

Natural gas consumption in 2016; China Energy Statistical Yearbook 2017.

\subsubsection{Key figures in the Winter Clean Heating plan in the northern area}

Next, we explain in outline the figures contained in the Winter Clean Heating (2017-21) plan, promulgated in December 2017, that are relevant for estimating future natural gas demand.

The purpose of this plan is to reduce emissions from winter heating systems in 14 northern provinces and part of Henan. Coal-fired appliances provided 83 per cent of all heating in these regions in 2016, and environmentally friendlier energies (including clean coal) accounted for only 33 per cent of the total area of the spaces which are required to be heated (the 'heating area'). This 'clean' heating area is to be expanded to meet the targets (shown in Table 4.5) by 2021, and this will be achieved mainly by phasing out the use of 'dirty' low-grade coal and using natural gas, electricity, geothermal resources, biomass, solar energy, power generated from waste, nuclear power, and clean coal instead. Beijing-Tianjin-Hebei and surrounding areas (in other words, the '2+26' region) are designated as the key regions from the point of view of PM2.5 emissions, and the ways in which they have moved towards switching from coal to gas and electricity are identified as being the main measures to be used in reducing emissions in these regions.

We first summarize the northern region's characteristics in terms of natural gas consumption. Table 4.6 shows the heating area (in billions of square metres) in which gas is presently used, together with the gas consumption of the northern region in 2016. As the total heating area of this region is $20.6 \mathrm{bm}^{2}$, the area in which gas heating is presently used $\left(2.2 \mathrm{bm}^{2}\right)$ represents a comparatively smal 10.7 per cent. The total gas consumption of the northern region, on the other hand, accounts for 47.9 per cent of the Chinese total. It is thus a heavy consumer of natural gas compared with other regions. Heating accounts for 26 per cent of this natural gas consumption, and industrial, power generation, and transportation sectors are also assumed to consume considerable amounts.

Next, we consider the distinguishing features of the ' $2+26$ ', designated as the key regions under this plan. As this region was selected for priority implementation of measures to lower PM2.5 levels from around 2016, it sheds light on possible future directions in natural gas consumption. The total heating area of this region comes to $5 \mathrm{bm}^{2}$, which corresponds to 24.3 per cent of the northern region. The gas heating area $\left(1.24 \mathrm{bm}^{2}\right)$ covers 24.8 per cent of this area, which is high compared with other parts of the northern region.

The ' $2+26$ ' region accounts for large proportions of both total gas consumption (42.2 per cent) and consumption for heating use (61.8 per cent) in the northern region. In addition, total natural gas consumption by the ' $2+26$ ' region accounts for 20.3 per cent of the Chinese total. Beijing, Tianjin, Hebei and the surrounding areas (where action on air pollution has been stepped up) thus constitute about one fifth of the entire market for natural gas in China.

The specific measures available in the key ' $2+26$ ' region under the Winter Clean Heating plan are shown in Table 4.7. It can be seen that implementing these measures would generate $23 \mathrm{bcm} / \mathrm{y}$ of additional natural gas demand in the key ' $2+26$ ' region as a whole. For regions other than the ' $2+26$ ' region, on the other hand, the plan allows a choice of clean heating measures according to the availability of alternative energies (including natural gas), and no explicit figures are given regarding how much natural gas demand would be generated. Judging from statistics for 2016, however, the 

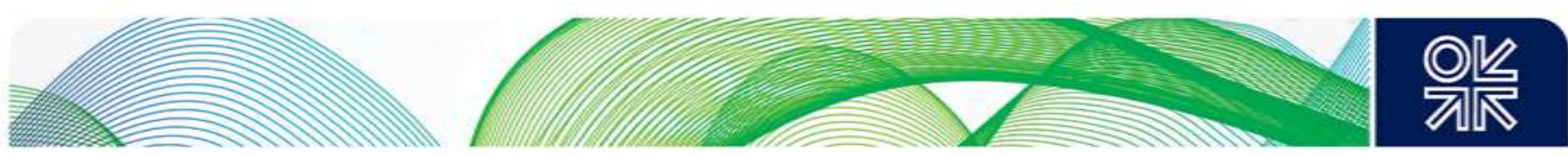

fact that non-' $2+26$ ' regions account for more than 75 per cent of the total heating area and 58 per cent of total natural gas consumption in the north as a whole, suggests that the amount of additional natural gas demand that they will generate is unlikely to be negligible. ${ }^{34} \mathrm{As}$ this demand will depend on the timing and extent of action on air pollution - including the extent of development of the natural gas supply infrastructure and natural gas supply capacity - the quantities involved cannot feasibly be estimated in further detail at present.

Another interesting aspect of this plan is its inclusion of figures on volumes of supply of natural gas to the six provinces (Beijing, Tianjin, Hebei, Shandong, Henan, and Shanxi) that encompass the ' $2+26$ ' (Table 4.8). According to these figures, there are plans for $124 \mathrm{bcm} / \mathrm{y}$ of natural gas to be supplied to the six provinces in 2021. Natural gas consumption in the region came to $51.4 \mathrm{bcm} / \mathrm{y}$ in 2016 . If $124 \mathrm{bcm} / \mathrm{y}$ is to be supplied, therefore, the increase in this five-year period will be $72.6 \mathrm{bcm} / \mathrm{y}$. Consequently, it can be assumed that in addition to a little over $23 \mathrm{bcm} / \mathrm{y}$ of additional demand for clean heating in the residential sector, ${ }^{35}$ the power generation, industrial, and transportation sectors are expected to generate considerable additional demand. Given also the amount of potential demand (estimated by CNPC in 2016) that will be generated by coal-to-gas switching projects in each region, as indicated in Table 4.4, it is estimated that the six provinces' share of the total will be approximately 38 per cent. Based on this figure, natural gas demand in the whole of China in 2021 will come to $399 \mathrm{bcm} / \mathrm{y} .{ }^{36}$

Table 4.5: The targets of the Winter Clean Heating Plan in the northern area

\begin{tabular}{|l|l|c|c|l|}
\hline \multicolumn{2}{|c|}{ Targeted Region } & \multicolumn{1}{|c|}{2019} & 2021 & Reference \\
\hline \multirow{2}{*}{$\begin{array}{l}\text { Northern area } \\
\text { total }\end{array}$} & Rate of Clean Heating & $>50 \%$ & $>70 \%$ & \\
\cline { 2 - 5 } & $\begin{array}{l}\text { Reduction of low-grade } \\
\text { coal }\end{array}$ & $74 \mathrm{mt}$ & $150 \mathrm{mt}$ & \\
\hline \multirow{4}{*}{$\begin{array}{l}2+26 \text { ' } \\
\text { area }\end{array}$} & Urban area & $>90 \%$ & $100 \%$ & $\begin{array}{l}\text { Full-phase out of coal-fired } \\
\text { boilers less than 35 } \mathrm{t} / \mathrm{h}\end{array}$ \\
\cline { 2 - 5 } & Suburban area & $>70 \%$ & $>80 \%$ & $\begin{array}{l}\text { Full-phase out of coal-fired } \\
\text { boilers less than } 20 \mathrm{t} / \mathrm{h}\end{array}$ \\
\cline { 2 - 5 } & Rural area & $>40 \%$ & $>60 \%$ & \\
\hline \multirow{3}{*}{\begin{tabular}{l} 
Other than \\
\multirow{2}{*}{$2+26$ ' area }
\end{tabular}} & Urban area & $>60 \%$ & $>80 \%$ & $\begin{array}{l}\text { Full-phase out of coal-fired } \\
\text { boilers less than } 20 \mathrm{t} / \mathrm{h}\end{array}$ \\
\cline { 2 - 5 } & Suburban area & $>50 \%$ & $>70 \%$ & $\begin{array}{l}\text { Full-phase out of coal-fired } \\
\text { boilers less than 10 } \mathrm{t} / \mathrm{h}\end{array}$ \\
\cline { 2 - 5 } & Rural area & $>20 \%$ & $>40 \%$ & \\
\hline
\end{tabular}

Source: Winter Clean Heating

\footnotetext{
${ }^{34}$ As quantitative targets of gas demand are described only for the ' $2+26$ ' regions in the plan, there is quite a large amount of additional potential gas demand in the non-'2+26' regions.

${ }^{35}$ As $23 \mathrm{bcm} / \mathrm{y}$ is the demand for just the urban area of the ' $2+26$ ', additional demand for the rural area of the ' $2+26$ ' and the south part of Henan province should be added to give the total demand of the six provinces.

${ }^{36}$ See the figure given in note 3 of Table $4.10: 399 \mathrm{bcm}$ is the gas demand in 2021 and it is calculated by the same method as that described in note 3 .
} 

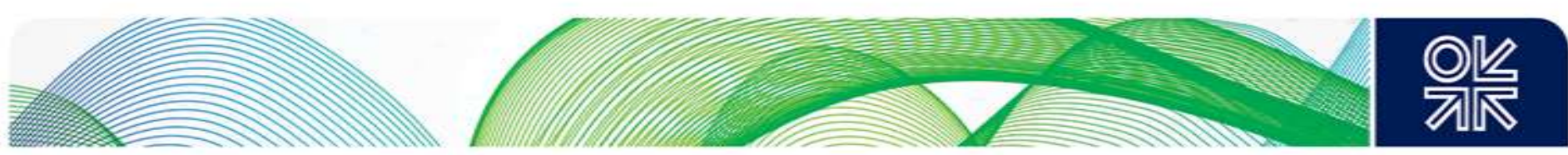

Table 4.6: Heating area (in which gas is currently used) and gas consumption in the targeted regions

\begin{tabular}{|c|c|c|c|c|c|c|c|c|}
\hline \multirow{2}{*}{\multicolumn{2}{|c|}{ Region }} & \multicolumn{2}{|c|}{$\begin{array}{l}\text { Heating area } \\
\text { currently served } \\
\text { by gas }\end{array}$} & \multicolumn{5}{|c|}{ Natural gas consumption as of 2016} \\
\hline & & $\mathrm{bm}^{2}$ & $\begin{array}{l}\text { Share in } \\
\text { northern } \\
\text { region }\end{array}$ & $\begin{array}{l}\text { Consumption } \\
\text { Heating } \\
\text { (bcm/y) }\end{array}$ & $\begin{array}{l}\text { Share in } \\
\text { northern } \\
\text { region }\end{array}$ & $\begin{array}{l}\text { Consumption } \\
\text { Total } \\
\quad(\mathrm{bcm} / \mathrm{y})\end{array}$ & $\begin{array}{l}\text { Share in } \\
\text { northern } \\
\text { region }\end{array}$ & $\begin{array}{l}\text { Share in } \\
\text { China total }\end{array}$ \\
\hline \multicolumn{2}{|c|}{ Northern overall } & 2.2 & $100 \%$ & 25.9 & $100 \%$ & 99.6 & $100 \%$ & $47.9 \%$ \\
\hline \multicolumn{2}{|c|}{6 Provinces } & 1.4 & $63.6 \%$ & 18.5 & $71.4 \%$ & 51.4 & $51.6 \%$ & $24.7 \%$ \\
\hline \multirow{3}{*}{ '2+26’ } & $\begin{array}{l}\text { Urban } \\
\text { area }\end{array}$ & 1.18 & $53.6 \%$ & 15.1 & $58.3 \%$ & & & \\
\hline & $\begin{array}{l}\text { Rural } \\
\text { area }\end{array}$ & 0.6 & $27.3 \%$ & 0.9 & $3.4 \%$ & & - & \\
\hline & Total & 1.24 & $56.4 \%$ & 16.0 & $61.8 \%$ & 42.1 & $42.2 \%$ & $20.3 \%$ \\
\hline
\end{tabular}

Note: Total heating area of northern region is $20.6 \mathrm{bm}^{2}$ (urban area $14.1 \mathrm{bm}^{2}$, rural area $6.5 \mathrm{bm}^{2}$ ). Natural gas consumption of China total in 2016 was $207.8 \mathrm{bcm} / \mathrm{y}$.

Source: Winter Clean Heating.

Table 4.7: Targets and natural gas demand for natural gas heating systems in the ' $2+26$ '

\begin{tabular}{|l|c|c|c|l|c|c|}
\hline \multirow{2}{*}{ Means } & \multicolumn{3}{|c|}{ Actual result in 2016 } & \multicolumn{3}{c|}{ Targets by 2021 } \\
\cline { 2 - 7 } & $\begin{array}{l}\text { Heating } \\
\text { area } \\
\left(\mathrm{bm}^{2)}\right.\end{array}$ & $\begin{array}{l}\text { Gas } \\
\text { consumption } \\
(\mathrm{cm} / \mathrm{y})\end{array}$ & $\begin{array}{c}\text { Share } \\
(\%)\end{array}$ & Target & $\begin{array}{l}\text { Additional Gas } \\
\text { demand } \\
(\mathrm{bcm} / \mathrm{y})\end{array}$ & $\begin{array}{c}\text { Share } \\
(\%)\end{array}$ \\
\hline Gas cogeneration & 0.22 & 6.4 & $40.0 \%$ & $110 \mathrm{MW}$ & 7.5 & $32.6 \%$ \\
\hline Gas-fired boilers & 0.82 & 7.6 & $47.5 \%$ & $50,000 \mathrm{t} / \mathrm{h}$ & 5.6 & $24.3 \%$ \\
\hline $\begin{array}{l}\text { Wall-hung gas-fired } \\
\text { boilers }\end{array}$ & 0.2 & 1.9 & $11.9 \%$ & $\begin{array}{l}12 \mathrm{million} \\
\text { households }\end{array}$ & 9.0 & $39.1 \%$ \\
\hline Distributed gas systems & 0.003 & 0.1 & $0.6 \%$ & $12 \mathrm{MW}$ & 0.9 & $3.9 \%$ \\
\hline Total & 1.24 & 16.0 & & - & $23.0 * 1$ & \\
\hline
\end{tabular}

Note: *1 Additional gas demand; $14.5 \mathrm{bcm} / \mathrm{y}$ in urban area and $8.5 \mathrm{bcm} / \mathrm{y}$ in rural area

Source: Winter Clean Heating

Table 4.8: Targets for natural gas supply in 6 provinces as of 2021

Source: NDRC

\begin{tabular}{|l|l|c|}
\hline \multirow{2}{*}{$\begin{array}{l}\text { Natural gas supply } \\
\text { (bcm/y) }\end{array}$} & NOC 3 majors & 103 \\
\cline { 2 - 3 } & Other than 3 NOCs & 11 \\
\cline { 2 - 3 } & Total & 124 \\
\hline \multirow{4}{*}{$\begin{array}{l}\text { Emergency gas } \\
\text { storage capacity } \\
(\mathrm{mcm})\end{array}$} & Beijing & 170 \\
\cline { 2 - 3 } & Tianjin & 120 \\
\cline { 2 - 3 } & Hebei & 210 \\
\cline { 2 - 3 } & Shandong & 230 \\
\cline { 2 - 3 } & Henan & 160 \\
\cline { 2 - 3 } & Shanxi & 140 \\
\cline { 2 - 3 } & Total & 1,030 \\
\hline
\end{tabular}

\subsubsection{Subsidies to promote use of natural gas under air pollution measures}

Lastly, we focus on the economic feasibility of coal-to-gas switching projects, which is a key factor to consider in estimating future natural gas demand.

Table 4.9 outlines the subsidies that are available for switching from coal to gas for residential heating. Although not shown in the table, subsidies are also provided by local governments to help 

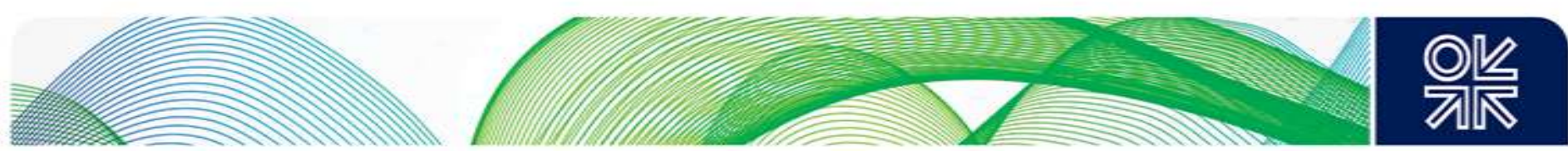

cover the equipment and installation costs ${ }^{37}$ incurred by converting industrial coal-fired boilers to run on natural gas. These subsidies are funded in part by the central government, which provides financial support to provinces to help them tackle air pollution. ${ }^{38}$

Steps are thus being taken to reduce the financial burden faced by ordinary citizens and users, and subsidization of gas prices will likely have a major impact on future natural gas consumption. In Tianjin, for example, the price of gas for residential users is $2.4 \mathrm{yuan} / \mathrm{m}^{3}$, of which half $\left(1.2 \mathrm{yuan} / \mathrm{m}^{3}\right)$ is subsidized; while in Jinan and Shandong, one third $\left(1\right.$ yuan $\left./ \mathrm{m}^{3}\right)$ of the price $\left(3\right.$ yuan $\left./ \mathrm{m}^{3}\right)$ is subsidized. ${ }^{39}$ Residential users in these regions thus effectively pay 1.2 yuan $/ \mathrm{m}^{3}(\$ 4.9 / \mathrm{mmbtu})$ and 2 yuan $/ \mathrm{m}^{3}$ ( $\left.\$ 8.2 / \mathrm{mmbtu}\right)$ for their gas during the winter season. ${ }^{40} \mathrm{In}$ both cases, a negative margin between the price paid by users and the cost of supply of imported LNG is highly likely.

Table 4.9: Subsidy for using natural gas for residential heating

\begin{tabular}{|c|c|c|}
\hline \multicolumn{2}{|l|}{ Object } & Contents \\
\hline \multirow{2}{*}{$\begin{array}{l}\text { Piping } \\
\& \\
\text { Appliance } \\
\text { /Facility }\end{array}$} & Pipework & $\begin{array}{l}\text { Subsidy of } 3,000-6,000 \text { yuan/household ( } 441-882 \$ / \text { household }{ }^{* 1} \text { is } \\
\text { provided for pipe laying and pipework by local governments. The amount of } \\
\text { subsidy differs among provinces. }\end{array}$ \\
\hline & $\begin{array}{l}\text { Appliance } \\
\& \text { facility }\end{array}$ & $\begin{array}{l}\text { Subsidy of } 2,000-6,000 \text { yuan/household }\left(294-882 \$ / \text { household }{ }^{* 1} \text { is }\right. \\
\text { provided for payments of appliance/facility and installation by local } \\
\text { governments. The amount of subsidy differs among provinces. }\end{array}$ \\
\hline \multicolumn{2}{|c|}{$\begin{array}{l}\text { Payment for } \\
\text { gas tariffs }\end{array}$} & $\begin{array}{l}\text { During winter season, subsidy of } 1.0-1.4 \text { yuan } / \mathrm{m}^{3}\left(4.1-5.7 \$ / \mathrm{m}^{3}\right) \text { is } \\
\text { provided for gas tariffs by local governments. The subsidy is applied to the } \\
\text { amount used within the upper ceiling of around } 1,000-1,200 \mathrm{~m}^{3} / \mathrm{year} \text {. The } \\
\text { amount of subsidy and upper ceiling differs among provinces. }\end{array}$ \\
\hline
\end{tabular}

Note: ${ }^{*} 1$ Calculated by exchange rate of 6.8 yuan $\$$.

Source: Notification documents issued by local governments.

\subsection{Discussion on outlook for medium-term natural gas consumption (up to 2020)}

\subsubsection{Approach to projecting natural gas consumption}

Next, we consider the outlook for natural gas consumption by 2020 in light of the above information. We start with the 13FYP, which forms the basis of national policy, and the current Blue Sky Action Plan. These provide a guide to the level of natural gas consumption in 2020 by stipulating that natural gas should account for 10 per cent of energy consumption in 2020. The first question is: to what extent (if any) do these plans take account of the over 15 per cent year-on-year growth in natural gas consumption that occurred in 2017-18 and the measures against air pollution that are actually being implemented? Let us consider, therefore, how much natural gas will be consumed if all policies and measures (including all coal-to-gas switching projects) are implemented as planned.

Table 4.10 summarizes the key data needed to answer this question. The relevant details presented in the preceding section are summarized below.

The quantitative implications of the coal-to-gas switching projects currently underway had already been calculated as of 2014. These calculations indicate that $112 \mathrm{bcm} / \mathrm{y}$ of additional demand will be generated and that $400-420 \mathrm{bcm} / \mathrm{y}$ of natural gas supply will therefore be required if these projects are to be implemented as planned.

\footnotetext{
${ }^{37}$ As for industrial users, it is unclear whether subsidies for gas tariffs are provided or not, but it was reported that such subsidies are applied to some users. Source: Interviews with energy experts in China, June 2018.

${ }^{38}$ In 2017, around 16 billion yuan was distributed from the Ministry of Finance to local provinces as spending for countermeasures against air pollution

${ }^{39}$ As of the end 2017. Gas tariffs described here are the lowest prices in the household rate sheet. Source: Materials published by local governments.

${ }^{40}$ It is reported that such subsidies will continue to be provided at least until 2020.
} 

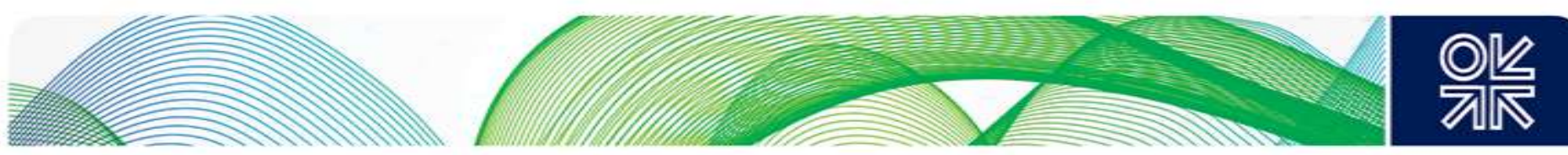

CNPC's 2016 outlook subsequently largely confirmed these figures and provided details of coal-to-gas switching by region and sector.

- The potential demand of $400 \mathrm{bcm} / \mathrm{y}$ estimated in CNPC's 2018 outlook coincides with these figures.

Regarding specifically the switching of coal-fired boilers to natural gas, which is a prime means of replacing coal with gas, the natural gas demand generated by the coal-fired boiler conversions called for by the 13FYP $(45 \mathrm{bcm})$ largely matches the natural gas demand generated by the industrial coal-to-gas projects outlined in CNPC's 2016 outlook (53 bcm).

Lastly and importantly, coal-to-gas switching projects will, as CNPC's 2016 outlook indicates, continue to generate considerable additional demand in the years leading up to 2025 (160 bcm as shown in Table 4.3, and the evidence suggests that action will continue to be expanded from 2020 onward).

From the above, it may be presumed that the target figure of $400 \mathrm{bcm} / \mathrm{y}$ set for 2020 represents the amount of natural gas demand that will be generated if coal-to-gas projects are implemented as originally planned. The focus of interest moving forward, then, should be on the extent to which these plans are actually implemented and at what pace. The key question here is: to what extent will natural gas supply capacity expand as described above?

Table 4.10: Key data to predict natural gas demand by 2020

\begin{tabular}{|c|c|c|c|c|}
\hline & $\begin{array}{l}\text { Published } \\
\text { year/month }\end{array}$ & \multicolumn{2}{|l|}{ Category of target } & $\begin{array}{l}\text { Amount of } \\
\text { natural gas } \\
(\mathrm{bcm} / \mathrm{y})\end{array}$ \\
\hline \multirow{2}{*}{ NDRC position document } & \multirow{2}{*}{$2014 / 4$} & \multicolumn{2}{|l|}{ Supply capacity } & $\begin{array}{l}400- \\
420\end{array}$ \\
\hline & & \multicolumn{2}{|c|}{$\begin{array}{l}\text { Demand generated by coal-to-gas } \\
\text { switching }\end{array}$} & 112 \\
\hline \multirow{2}{*}{ 13FPY } & \multirow{2}{*}{2016} & \multicolumn{2}{|c|}{$8.3-10 \%$ share in total primary energy } & $\begin{array}{l}312- \\
372\end{array}$ \\
\hline & & \multicolumn{2}{|c|}{$\begin{array}{l}\text { Generated by coal-to-gas switching of } \\
\text { coal-fired boilers in key regions }{ }^{* 1}\end{array}$} & 45 \\
\hline Blue Sky Action Plan & $2018 / 7$ & \multicolumn{2}{|c|}{$10 \%$ share in total primary energy } & 372 \\
\hline \multirow{3}{*}{ Outlook by CNPC (2016) } & \multirow{3}{*}{$2016 / 11$} & \multicolumn{2}{|c|}{ Total consumption - Mid case } & 290 \\
\hline & & \multirow{2}{*}{$\begin{array}{l}\text { Potential additional } \\
\text { demand by coal-to-gas } \\
\star 2\end{array}$} & Total & 110 \\
\hline & & & Industrial & 53 \\
\hline Outlook by CNPC (2018) & $2018 / 4$ & \multicolumn{2}{|l|}{ Potential demand } & 400 \\
\hline Winter Clean Heating & $2017 / 12$ & \multicolumn{2}{|c|}{ Estimates of total consumption *3 } & $\begin{array}{l}350- \\
392-\end{array}$ \\
\hline
\end{tabular}

Note: *1 Coal-to-gas switching projects are to be promoted in key regions of Beijing-Tianjin-Hebei, Yangtze River Delta, Pearl River Delta, and North-east area. The target amount of coal-fired boilers is 1,890 thousand $t / h$ and additional natural gas demand is estimated to be $45 \mathrm{bcm} / \mathrm{y}$. ${ }^{*} 2$ See details in section 4.1.3.

*3 Total gas demand in 2020 is estimated to be $392 \mathrm{bcm} / \mathrm{y}$ if we calculate based on the gas supply of $124 \mathrm{bcm} / \mathrm{y}$ to 6 Provinces in 2021 and its share in total Chinese gas demand. And if we calculate based on the increased natural gas demand of $72.6 \mathrm{bcm} / \mathrm{y}$ (from 2016 to 2021) and its share of gas demand generated by coal-to-gas switching in that of Chinese total (see Table 4.3), the total gas demand in China in 2020 is estimated to be $350 \mathrm{bcm} / \mathrm{y}$.

Source: Materials described in the previous sections 

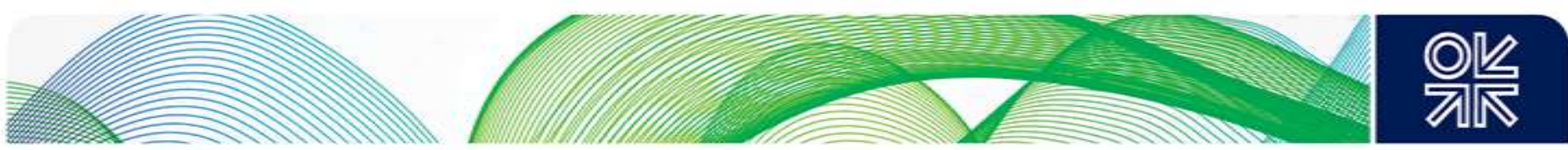

Table 4.11: Scenarios for natural gas consumption by 2020

\begin{tabular}{|c|c|c|}
\hline Case & $\begin{array}{c}\text { Natural gas demand in } 2020 \\
(\mathrm{bcm} / \mathrm{y})\end{array}$ & Annual growth rate from 2016 \\
\hline $\begin{array}{c}\text { Maximum } \\
\text { Coal-to-gas switching }\end{array}$ & 400 & $17.8 \%$ \\
\hline $\begin{array}{c}10 \% \text { share in total primary } \\
\text { energy }\end{array}$ & 372 & $15.7 \%$ \\
\hline $\begin{array}{c}\text { Medium } \\
\text { Coal-to-gas switching }\end{array}$ & 330 & $12.3 \%$ \\
\hline $\begin{array}{c}\text { Minimum } \\
\text { Coal-to-gas switching }\end{array}$ & 300 & $9.6 \%$ \\
\hline
\end{tabular}

Note: The growth rate in 2017 was $15.1 \%$ and in $1 \mathrm{H}$ of 2018 was $17.9 \%$.

Source: Authors' estimates. 

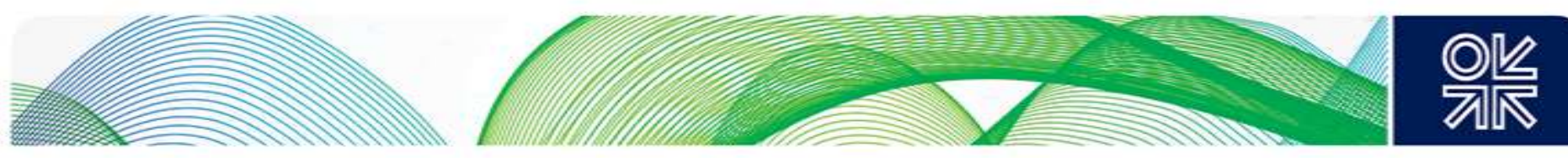

\section{Outlook for medium-term LNG demand and impact on the international market}

Finally, let us consider the LNG demand outlook and the consequences for the international LNG market. LNG demand is basically defined by subtracting the supply volume of pipeline gas from total natural gas consumption. As natural gas consumption was considered in the previous chapter, we begin here by considering the volume of supply of pipeline gas (domestic production and pipeline gas imports).

\subsection{Outlook for indigenous natural gas production}

Due to difficulties in projecting the upstream development and production of national gas (from both a technological standpoint and given the trends in investment by suppliers), we adopt a simplified approach to estimating output, taking into account current trends based on plans and projections published by the government and other relevant agencies (see Table 4.2). As previously indicated, natural gas production in China is being expanded by the development of unconventional resources (such as CBM and shale gas) as well as conventional resources. As the latest five-year plan sets production targets for these resources, these are taken into consideration in the following review.

Regarding, firstly, conventional resources, these exist in abundance ${ }^{41}$ and output is largely trending upward. Recently, however, there has been an incontrovertible slowing of growth in conventional output. The data on supply and demand for natural gas since 2010 also indicates that, except during the temporary slump in demand in 2014-15, gas has tended to be in short supply during the demand season. This being the case, it is unlikely that conventional domestic output will increase dramatically to keep pace with the current double-digit growth in natural gas consumption. Moreover, output appears highly likely to fall short of the production targets and/or projected volume for 2020 shown in Table 4.2.

As for coalbed methane (CBM), the 12 FTP set a production target of $16 \mathrm{bcm} / \mathrm{y}$ in 2015 . In reality, however, output fell short of this target and only reached approximately $4.4 \mathrm{bcm} / \mathrm{y} .{ }^{42}$ Nevertheless, according to the National Bureau of Statistics, output increased to $6.48 \mathrm{bcm} / \mathrm{y}$ in 2016 , and grew further by 8.2 per cent to $7.02 \mathrm{bcm} / \mathrm{y}$ in $2017 .{ }^{43}$ For comparison, the $13 F Y P$ set a target of $10 \mathrm{bcm} / \mathrm{y}$ in 2020. Production is subsidized by the government due to its high cost. This subsidy was raised from 0.2 yuan $/ \mathrm{m}^{3}$ to 0.3 yuan $/ \mathrm{m}^{3}$ in March 2016, and is set to continue until 2020 .

Considering next shale gas, actual output in 2015 reached $4.3 \mathrm{bcm} / \mathrm{y}$ compared to a target under the $12 F Y P$ of $6.5 \mathrm{bcm} / \mathrm{y}$. While the $13 F Y P$ sets a production target for 2020 of $30 \mathrm{bcm} / \mathrm{y}$, actual output came to $7.9 \mathrm{bcm} / \mathrm{y}^{44}$ in 2016 and $9 \mathrm{bcm} / \mathrm{y}^{45}$ in 2017. As in the case of CBM, production costs are high and production is subsidized by the government. The subsidy was 0.4 yuan $/ \mathrm{m}^{3}$ until 2015 and 0.3 yuan $/ \mathrm{m}^{3}$ between 2016 and 2018, and will be 0.2 yuan $/ \mathrm{m}^{3}$ between 2019 and $2020 .{ }^{46}$

Output of unconventional natural gas will thus probably struggle to reach the 2020 target set by the $13 F Y P$, and is extremely unlikely to exceed this target by any significant amount.

\footnotetext{
${ }^{41}$ Recoverable natural gas resources are: $50 \mathrm{tcm}$ of conventional gas, $22 \mathrm{tcm}$ of shale gas and $12.5 \mathrm{tcm}$ of CBM. Source: Development Research Center of State Council, 6th Asian Gas Market Forum, 7 June 2018.

42 Materials published by National Energy Administration.

43 Interfax, 23 January 2018.

${ }^{44}$ Ministry of Land and Resources, February 2018.

${ }^{45}$ Reuters, 17 April 2018.

${ }^{46}$ Bloomberg, 29 April 2015.
} 

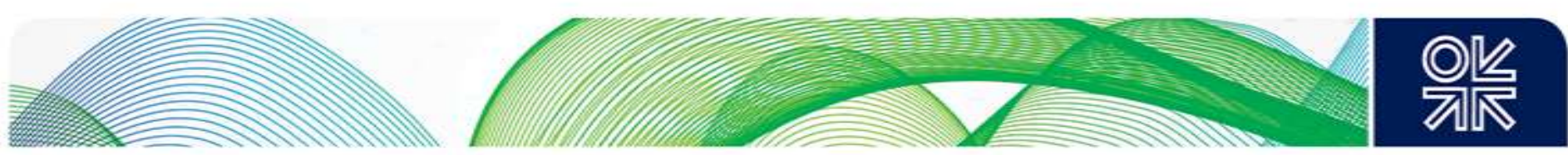

Table 5.1: Outlook for indigenous gas production by $2020(\mathrm{bcm} / \mathrm{y})$

\begin{tabular}{|c|c|c|c|c|}
\hline & 2017 actual & Base case & Optimistic case \\
\hline \multicolumn{2}{|l|}{ Conventional } & 131 & 153 & 163 \\
\hline \multirow{3}{*}{ Unconventional } & CBM & 7 & 10 & 10 \\
\hline & Shale gas & 9 & 15 & 25 \\
\hline & SNG & 2 & 2 & 2 \\
\hline \multicolumn{2}{|l|}{ Total } & 149 & 180 & 200 \\
\hline
\end{tabular}

Source: Authors' estimates.

\subsection{Outlook for pipeline gas imports}

We consider next the outlook for pipeline gas imports. China has begun importing from Myanmar and the three Central Asian countries of Turkmenistan, Uzbekistan, and Kazakhstan. A project is underway to import gas from Russia, and the outlook regarding imports from these sources is explored below.

\subsubsection{Pipeline capacity}

Natural gas imports from Central Asia use the Central Asia-China Gas Pipeline, which consists of a system of three pipelines - Lines A, B, and C - that run from Turkmenistan to China via Uzbekistan and Kazakhstan. Presently, this system has a total transportation capacity of $55 \mathrm{bcm} / \mathrm{y}$. At the beginning of 2018, plans were underway to boost the transportation capacity of Lines A and B between Kazakhstan and China by $10 \mathrm{bcm} / \mathrm{y}$ by the end of $2019 .{ }^{47}$ When completed, this will raise capacity to $65 \mathrm{bcm} / \mathrm{y}$.

In September 2013, agreement was also reached between the four countries concerned regarding construction of a Line D from Turkmenistan to China via Uzbekistan, Tajikistan, and Kyrgyzstan. Negotiations on construction of sections of the pipeline are underway between China and each transit country on an individual basis, and progress on the project varies. For example, in January 2018 it was reported that pipeline construction had commenced in Turkmenistan. ${ }^{48}$ As of April, however, construction of the Uzbek section had been reportedly postponed indefinitely. ${ }^{49}$ Construction of Kyrgyzstan's section, meanwhile, is reportedly scheduled to commence at the end of 2019 and be completed during 2020.50 The project has thus fallen far behind the original schedule and it is uncertain when the pipeline will enter service.

Talks with Russia are currently underway regarding three pipeline projects. One is an eastern route (Power of Siberia 1), and construction of this pipeline was reportedly approximately 90 per cent complete as of July 2018. This is scheduled to enter service in December 2019. ${ }^{51}$ Plans to supply $30 \mathrm{bcm} / \mathrm{y}$ of gas for 30 years via a western route (Power of Siberia 2), on the other hand, were discussed between China and Russia in September 2014, but no final agreement was reached. ${ }^{52} \mathrm{~A}$ project to connect the Power of Siberia 1 to Sakhalin via Khabarovsk has also been under consideration since a memorandum of understanding was signed between the two countries in 2015, but a final agreement on the project has yet to be reached.

The pipeline from Myanmar has a transportation capacity of $12 \mathrm{bcm} / \mathrm{y}$. However, $2 \mathrm{bcm} / \mathrm{y}$ of this is used to supply gas within Myanmar. The remaining $10 \mathrm{bcm} / \mathrm{y}$ is allocated to exports, and this entered operation in July 2013.

\footnotetext{
${ }^{47}$ AzerNews, 15 January 2018.

${ }^{48}$ Asia Plus, 31 January 2018.

${ }^{49}$ Eurasianet, 3 March 2017.

${ }^{50}$ Kabar, 18 December 2017.

${ }^{51}$ Gazprom website, 25 July 2018.

52 At the Vladivostok summit in September, it was announced that agreement on the Western Route would be reached by end of this year. Although this may be optimistic it seems as if the Chinese are now serious about this project. Source: Interview with Jonathan Stern, 30 September, 2018.
} 

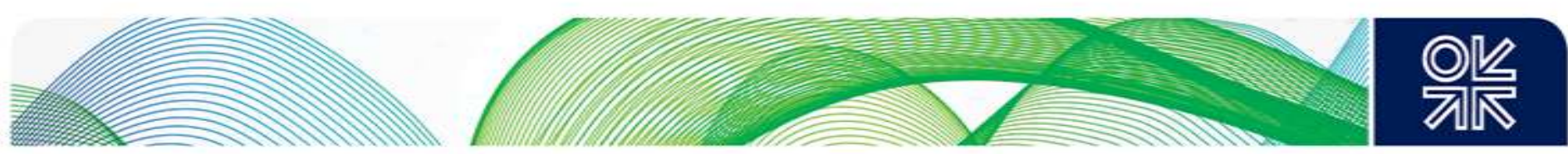

Table 5.2: Capacity of natural gas import pipelines

\begin{tabular}{|l|l|c|c|c|}
\hline \multicolumn{1}{|c|}{ Pipeline } & Capacity & Start Operation & \multicolumn{1}{c|}{ Expansion } \\
\hline \multirow{4}{*}{ Central Asia } & Line A & 13 & $12 / 2009$ & $+10 \mathrm{bcm} / \mathrm{y}$ \\
& Line B & 17 & $10 / 2010$ & By the end of $2019^{* 1}$ \\
\cline { 2 - 5 } & Line C & 25 & $5 / 2014$ & \\
\cline { 2 - 5 } & Line D & 30 & $\mathrm{~N} / \mathrm{A}$ & \\
\hline \multirow{3}{*}{ Russia } & East & 38 & $12 / 2019$ & \\
\cline { 2 - 5 } & West & 30 & $\mathrm{~N} / \mathrm{A}$ & \\
\cline { 2 - 5 } & Far East & $8^{\star 2}$ & $\mathrm{~N} / \mathrm{A}$ & \\
\hline Myanmar & & 10 & $7 / 2013$ & 173 \\
\hline Total & & 163 & & \\
\hline
\end{tabular}

Note: *1 Agreed between China and Kazakhstan in Jan.2018. *2 Reuters, 8 June 2017.

Source: CNPC, Gazprom and others

\subsubsection{Pipeline gas import trends and outlook}

Next, we consider how much natural gas is likely to be supplied through these pipelines, taking into account gas sales agreements and other relevant factors. We start with Turkmenistan, with which China signed a natural gas sales agreement for $30 \mathrm{bcm} / \mathrm{y}$ in $2007 . .^{33}$ This volume was subsequently raised to $40 \mathrm{bcm} / \mathrm{y}$, and reports in 2013 indicated that an additional agreement had been reached on supplying another $25 \mathrm{bcm} / \mathrm{y}$ and that the total volume of exports would be increased to $65 \mathrm{bcm} / \mathrm{y}$ by $2020 .{ }^{4}$ Simply boosting the transportation capacity of existing lines alone is unlikely to be sufficient to accommodate this increase, however, and Line D will have to be completed. It is therefore likely to take some time for supplies to reach $65 \mathrm{bcm} / \mathrm{y}$.

Uzbekistan, meanwhile, agreed in June 2010 to sell $10 \mathrm{bcm} / \mathrm{y}$ of natural gas to China. However, several factors provide grounds for scepticism over whether Uzbekistan will be able to rapidly increase exports to China. These include Uzbekistan's flat or minimal level of growth in natural gas production, its high level of domestic consumption due to its large population compared to other countries in Central Asia, and the fact that it also exports to neighbouring former members of the Soviet Union.

In Kazakhstan, projected growth in gas output alongside growth in oil production around the Caspian Sea makes it very likely that export capacity will increase. For exports to China to expand, however, trunk pipeline and pressure booster station capacity will need to be increased to transport gas across the vast distance from west to east. It is therefore likely to take time for exports to China to grow.

In view of the above, it is estimated that the potential volume of exports from Central Asia to China in 2020 will be as shown as Table 5.3 .

From a longer-term perspective, the above $85 \mathrm{bcm} / \mathrm{y}$ of pipeline capacity (Table 5.2) that will ultimately be available for exports from Central Asia will break down as follows: $65 \mathrm{bcm} / \mathrm{y}$ from Turkmenistan, $10 \mathrm{bcm} / \mathrm{y}$ from Uzbekistan, and $10 \mathrm{bcm} / \mathrm{y}$ from Kazakhstan.

Turning next to Russia, it is likely that the eastern route (Power of Siberia 1) will be the only route in service in 2020. Although capacity will ultimately increase to $38 \mathrm{bcm} / \mathrm{y}$, reports suggest that it will take several years for a plateau to be reached due to construction of compressor stations along the pipeline. ${ }^{55}$ Although this period may be shortened by rapid growth in natural gas consumption in China, this is relatively unlikely as the pipeline will not enter service until December 2019. In effect, therefore, 2020 will be its first year of commercial operation.

\footnotetext{
${ }^{53}$ CNPC, 18 July 2007.

${ }^{54}$ Reuters, 3 September 2013.

${ }^{55}$ Roberts (2016), 'Russia's gas challenge: the consequences for China, Central Asia, Europe and the USA'.
} 

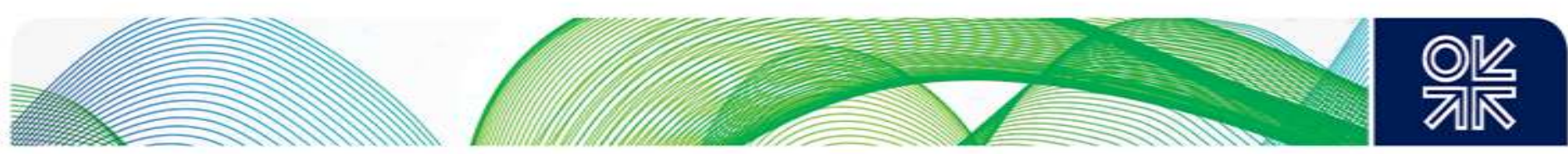

Regarding lastly Myanmar, a 30-year gas sales agreement was signed in December 2008 between CNPC and a consortium (consisting of Myanmar Oil and Gas Enterprise, Daewoo of South Korea, and ONGC and GAIL of India) formed to develop the Shwe gas field off the coast of Myanmar, ${ }^{56}$ and actual gas exports commenced in 2013. The Shwe gas field currently produces about $5 \mathrm{bcm} / \mathrm{y}$ and exports over the past few years have remained at around $3.1 \mathrm{bcm} / \mathrm{y}$, which is below the contracted volume $(4.1 \mathrm{bcm} / \mathrm{y})$. Given production plans for this gas field, it is unlikely that exports will increase to the point that they reach the pipeline capacity limit, and there are no reports of additional exports from neighbouring gas fields. It is therefore highly likely that exports from Myanmar will remain at around $2-5 \mathrm{bcm} / \mathrm{y}$ for the time being.

Table 5.3: Outlook for pipeline gas imports $(\mathrm{bcm} / \mathrm{y})$

\begin{tabular}{|l|c|c|}
\hline Country & 2020 & Long-term outlook \\
\hline Turkmenistan & $35-45$ & 65 \\
\hline Uzbekistan & 5 & 10 \\
\hline Kazakhstan & 5 & 10 \\
\hline Russia & 6 & $68+$ \\
\hline Myanmar & 4 & $10-$ \\
\hline Total & $55-65$ & 163 \\
\hline
\end{tabular}

Source: Figures for 2020 are estimated by author. Long-term outlook is based on various materials.

\subsection{Outlook for LNG demand}

\subsubsection{Capacity of LNG receiving terminals and LNG imports}

As stated above, China had 19 LNG receiving terminals in operation as of August 2018, and these have an annual receiving capacity of approximately 59.6 million tons. Looking ahead to 2020, capacity generated by the new terminals entering service, combined with the construction of tanks at currently operational terminals, will raise receiving capacity to around 69-70 mt/y (see chapter 3).

Considering next the upper limit on the volume of LNG imports, there are several uncertainties to bear in mind:

- The LNG receiving capacities indicated in Figure 3.2 and Table 3.11 represent the nominal capacities published by terminal operators. If the capacity utilization rate is calculated on the basis of these capacities, it is possible that terminals may actually operate at a rate exceeding 100 per cent. ${ }^{57}$

- As previously noted, if terminals are used to serve closed regional markets such as Hainan Island, for example, it will be impossible for them to receive more than the amount of demand in the regional market.

- Similarly, it is possible that without sufficient development of the pipeline network, receiving capacity may be limited by demand-side constraints. ${ }^{58}$

Nominal receiving capacity is thus subject to both positive and negative factors. However, given that receiving terminals were operating at near full capacity in the first half of 2018 and overall terminal

\footnotetext{
${ }^{56}$ Source: CNPC. Note: Currently the members of the consortium are POSCO DAEWOO 51\%, ONGC $17 \%$, MOGE $15 \%$, KOGAS $8.5 \%$, GAIL $8.5 \%$.

${ }^{57}$ Annual terminal capacity is basically determined by how many times the storage tanks can be used (namely how much LNG can be withdrawn and/or consumed during a certain period) and/or how many times the berth can be used for unloading LNG annually. Therefore, it should be noted that actual handing volumes can differ considerably even if storage tank capacities and the number of berths are the same. But, we assume here that the nameplate capacity published by the terminal owners is estimated by taking account of their operation.

${ }^{58}$ As described in the previous footnote, the receiving capacity of each terminal will be determined by how quickly the natural gas produced from the LNG will be absorbed in regional markets. In relation to this point, it should be noted that unprecedentedly large amount of LNG are being sent out from receiving terminals by road tankers at present, due to insufficient pipeline supply networks.
} 

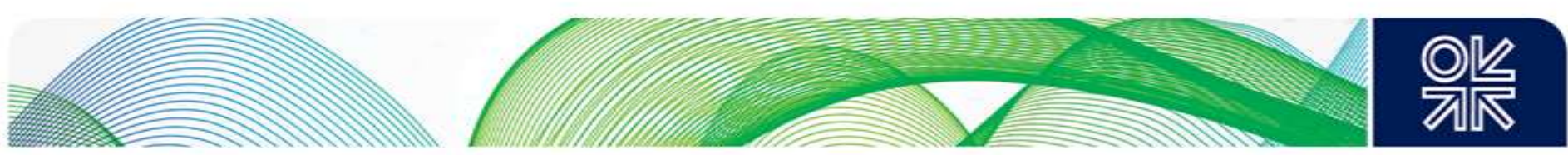

capacity utilization came to approximately 82 per cent, the capacity utilization rate will probably remain at around 85 per cent even if pushed up by infrastructure development. ${ }^{59}$ Based on this assumption, the upper limit on LNG imports in 2020 is estimated to be around $60 \mathrm{mt}$.

\subsubsection{Observations on the LNG demand outlook}

Then, let us consider the outlook for LNG demand in 2020. As described in the previous chapters, the following two key assumptions can be made:

- The 13FYP and various other energy and environmental policies announced by the government and other agencies suggest that natural gas consumption in 2020 is estimated to be between 300 and $400 \mathrm{bcm} / \mathrm{y}$.

The volume of pipeline gas supply (domestic natural gas output plus pipeline gas imports) is very likely to enter the $240-260 \mathrm{bcm} / \mathrm{y}$ range.

Calculating LNG demand (required volume) under four consumption scenarios and two pipeline gas supply scenarios based on the above assumptions yields the results shown in Table 5.4.

This clearly shows that it will be virtually impossible to meet projected demand under the '(A) maximum coal-to-gas switching' and '(B) 10 per cent share of primary energy' scenarios due to constraints on $L N G$ receiving terminal capacity.

Under the ' $(C)$ intermediate coal-to-gas switching' scenario, around $66 \mathrm{mt}$ of LNG will be required if the supply of pipeline gas is low. As this exceeds the upper limit on LNG imports indicated above, it is highly uncertain whether this will be attainable. In the remainder of the scenarios, receiving capacity will be physically sufficient to handle the required volumes of LNG imports.

Based on the above, the LNG demand outlook for 2020 may be summarized as follows:

- If coal-to-gas switching projects and other measures against air pollution are implemented to the maximum practical extent (insofar as permitted by natural gas supply commitments), the maximum physically receivable volume of LNG will need to be imported to meet demand for LNG. Given the amount of receiving terminal capacity available, this maximum is estimated to be in the region of $60 \mathrm{mt} / \mathrm{y}$. However, this physically limited amount may fluctuate as indicated in footnote 57.

- $\quad$ The first half of 2018 saw growth in excess of 50 per cent from a year earlier and, if existing terminals in the north and east continue to operate at near full capacity as in the second half of 2017, total imports in 2018 will come to around $50 \mathrm{mt} / \mathrm{y}$ (an increase of 26.3 per cent from the previous year ${ }^{60}$ ). Even assuming that approximately the same volume is received in the second half of 2018 as in the first half, imports for the whole of in 2018 will come to around $50 \mathrm{mt} / \mathrm{y}$ as well. Therefore, if we allow for the occurrence of supply shortages on the natural gas market around this period, it can be assumed that imports were almost equal to the maximum receivable volume between the second half of 2017 and first half of 2018.

If the supply of pipeline gas under the ' $(C)$ intermediate coal-to-gas switching' scenario is high, on the other hand, $52 \mathrm{mt}$ of LNG will be required in 2020. In this case, while the government's energy and environmental policy strictly orders that coal-to-gas switching projects should only be implemented having first secured supplies of natural gas, it is also evident that projects have not been implemented on the scale planned. It is therefore

\footnotetext{
${ }^{59}$ For example, low utilization rates of terminals are expected in 'other regions' and there are operational and/or capacity restrictions on the supply systems needed to reallocate the natural gas produced from LNG more widely. For reference, the amount of imported LNG is estimated to be around $60 \mathrm{mt}$ with a (total) terminal utilization rate of around $85-86 \%$ in 2020 , when we assume utilization rates of $95 \%$ in the North and East, $80 \%$ in the South, and $30 \%$ in other regions.

60 In comparison with the data of GIIGNL 'Annual Report'.
} 

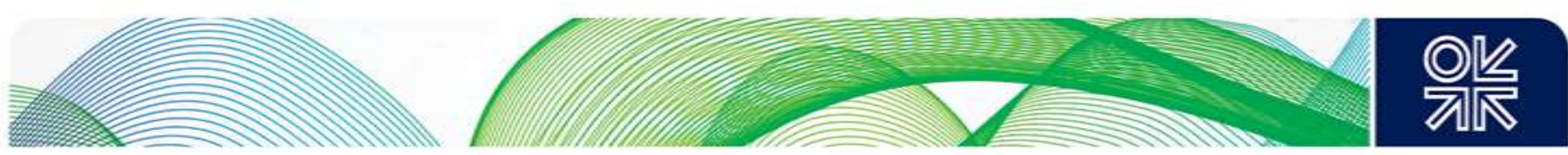

highly likely ${ }^{61}$ that imports will be raised to the physical receivable limit of $60 \mathrm{mt}$ and coalto-gas projects will continue to be pursued. If this occurs, natural gas consumption will grow more than projected. (The results of scenario '(D) Minimum coal-to-gas switching' are the same as this case.)

Although the upper limit on LNG imports is put at $60 \mathrm{mt}$, this may decrease depending on LNG prices. While coal-to-gas switching projects in the north will increase natural gas demand during the winter season, the shortage of storage capacity will make it necessary to increase procurements of LNG on the spot market in the winter, which will push up winter spot LNG prices. As noted, coal-to-gas switching projects are heavily subsidized by the government and it is quite possible that an increase in fuel costs would act as a brake on such projects. A rise in LNG prices could thus make it more likely that the volume of LNG imports falls short of $60 \mathrm{mt}$. The question of international prices is considered in the next section.

However, uncertainty in the event of a rise in LNG prices is magnified by growth in LNG road tanker sales - and there has recently been rapid growth in road tanker sales from the $L N G$ receiving terminals, relative to $L N G$ imports. ${ }^{62}$ This is an indication of the general extent of deregulation of the market for LNG sold in liquid form and of tight supply and demand on the domestic market which is driving up prices. ${ }^{63}$ Under these conditions, LNG will not be sold at a negative margin even if LNG prices rise on the international market, and $L N G$ imports destined for sale in liquid form may increase.

Table 5.4: Outlook for LNG demand in 2020 by natural gas consumption case

\begin{tabular}{|c|c|c|c|c|c|}
\hline \multicolumn{2}{|c|}{ Case } & $\begin{array}{c}\text { NG Consumption } \\
(\mathrm{bcm} / \mathrm{y})\end{array}$ & $\begin{array}{l}\text { Pipeline gas supply } \\
(\mathrm{bcm} / \mathrm{y})\end{array}$ & $\begin{array}{c}\text { LNG } \\
\text { (mt/year) }\end{array}$ & $\begin{array}{l}\text { Supply } \\
\text { Capability }\end{array}$ \\
\hline \multirow{2}{*}{ A } & \multirow{2}{*}{$\begin{array}{l}\text { Maximum } \\
\text { Coal-to-gas switching }\end{array}$} & \multirow{2}{*}{400} & 260 & 103 & $x$ \\
\hline & & & 240 & 118 & $x$ \\
\hline \multirow{2}{*}{ B } & \multirow{2}{*}{$\begin{array}{l}10 \% \text { share in total } \\
\text { primary energy }\end{array}$} & \multirow{2}{*}{372} & 260 & 82 & $x$ \\
\hline & & & 240 & 97 & $x$ \\
\hline \multirow{2}{*}{ C } & \multirow{2}{*}{$\begin{array}{l}\text { Intermediate } \\
\text { Coal-to-gas switching }\end{array}$} & \multirow{2}{*}{330} & 260 & 52 & 0 \\
\hline & & & 240 & 66 & $\Delta$ \\
\hline \multirow{2}{*}{ D } & \multirow{2}{*}{$\begin{array}{l}\text { Minimum } \\
\text { Coal-to-gas switching }\end{array}$} & \multirow{2}{*}{300} & 260 & 29 & 0 \\
\hline & & & 240 & 44 & 0 \\
\hline
\end{tabular}

Notes: $x$ Insufficient receiving terminal capacity. $\Delta$ uncertainty over receiving terminal capacity.

$\bigcirc$ sufficient receiving terminal capacity.

\subsection{Impact on the international LNG market}

In closing, we consider what such an increase in imports by China would mean for the international LNG market.

\footnotetext{
${ }^{61}$ If we consider various measures on coal-to-gas switching projects which have already been implemented and also those that will be implemented by 2020, natural gas supply is (and will be) far below the demand and definitely insufficient, as explained in chapter 4

${ }^{62}$ For example, 1 million tons of the total LNG imports in 2016 and 1.57 million tons out of the total 2 million tons imported in 2017 were sent out by road tankers at Tianjin terminal. Source: Interview by authors with an expert on the Chinese natural gas industry, 4 July 2018. It is also reported that LNG supply by road tankers from terminals in the South and the East to the northern region has increased substantially. The Maritime Executive, 5 June 2018.

${ }^{63}$ For example, prices of domestic LNG sales temporarily increased beyond 10,000 yuan/ton in the Northern regions during the winter of $2017 / 18$.
} 

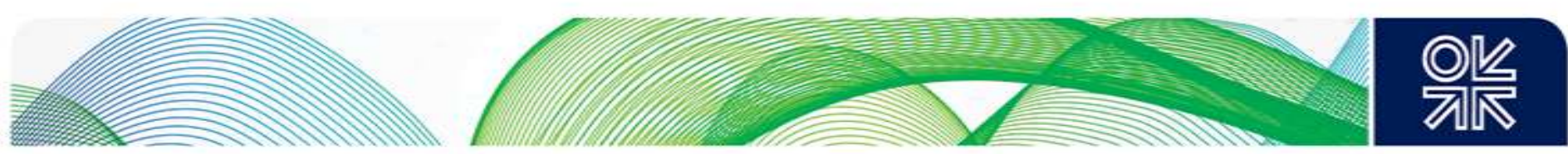

\subsubsection{Impact on international LNG supply and demand up to around 2020}

We begin by reviewing projections of international LNG supply and demand formulated in mid-2017 before the 2017/18 winter seasons, when China experienced a marked surge in demand for LNG. These indicated that:

- $\quad$ The wave of new LNG liquefaction projects coming on stream mainly from Australia and the USA will ease international supply and demand for LNG from 2018 and create excess supply capacity in the market that will last until around 2023.

- $\quad$ This excess supply capacity will accumulate to reach a fairly high level of $44 \mathrm{mt}$ in 2020 .

- $\quad$ The slackening of the supply and demand situation makes it highly likely that spot prices will stabilize below the average of term-contracted prices.

Recent changes in LNG prices in East Asia are shown in Figure 5.1. From this it can be seen that whereas spot prices rose from winter 2017 to the first half of 2018 (when Chinese and South Korean imports of LNG rose sharply), they were only marginally above term prices and the market did not tighten significantly. The market thus appeared to have sufficient supply capacity to absorb rapid growth in LNG demand among countries in East Asia.

Next we look at projections of international LNG supply and demand that were made in August 2018, taking into account these latest changes in LNG supply and demand. These projections revised Chinese LNG demand in 2020 upward from the previously forecast $41 \mathrm{mt}$ to $60 \mathrm{mt}$.

LNG demand is increasing rapidly in China, South Korea, and other East Asian countries, and global LNG demand in 2020 will increase by around $21 \mathrm{mt}$ compared with the amount projected last year.

- Supply capacity, on the other hand, has also been revised upward. As a result, the international LNG market is projected to still have around $28 \mathrm{mt}$ of excess supply capacity ${ }^{64}$ in 2020.

- However, rapid growth in LNG demand in China and other countries will shorten the period of slackness on the international LNG market and thus accelerate progress in new liquefaction projects. If these projects do not come on stream when needed, the supply and demand situation on the international market will be more likely to tighten temporarily. This may occur after 2020.

As this will have the effect of reducing excess supply capacity on the international LNG market for the duration of the supply glut period, it is quite possible that supply and demand will either enter equilibrium or tighten temporarily during the winter demand season. As seasonal gaps in gas demand are getting larger, due to increased natural gas demand in particular it is thus more likely that spot prices will increase during the demand season.

\footnotetext{
${ }^{64}$ The outlook for the international LNG market's supply and demand is revised every year by the Osaka Gas's Research Team. In their latest outlook, the global demand in 2020 is estimated to be 352 million tons, which is the sum of demand in each importing country estimated individually, on the basis of each country's latest situation. The global supply in 2020 is estimated to be 380 million tons, which consists of the existing projects plus post-FID new projects as of August 2018, while the latest situation of each liquefaction project is reflected in the estimates.
} 

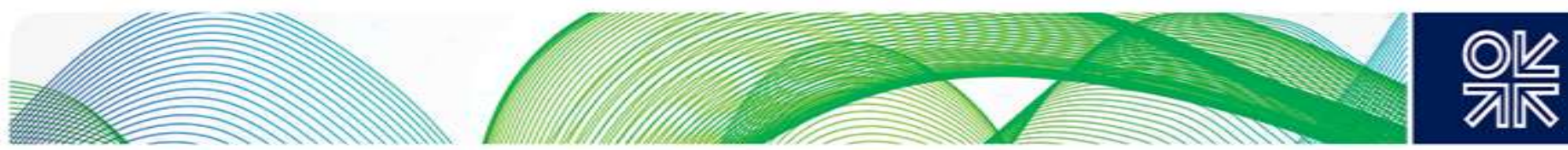

Figure 5.1: LNG prices in East Asia (\$/mmbtu)

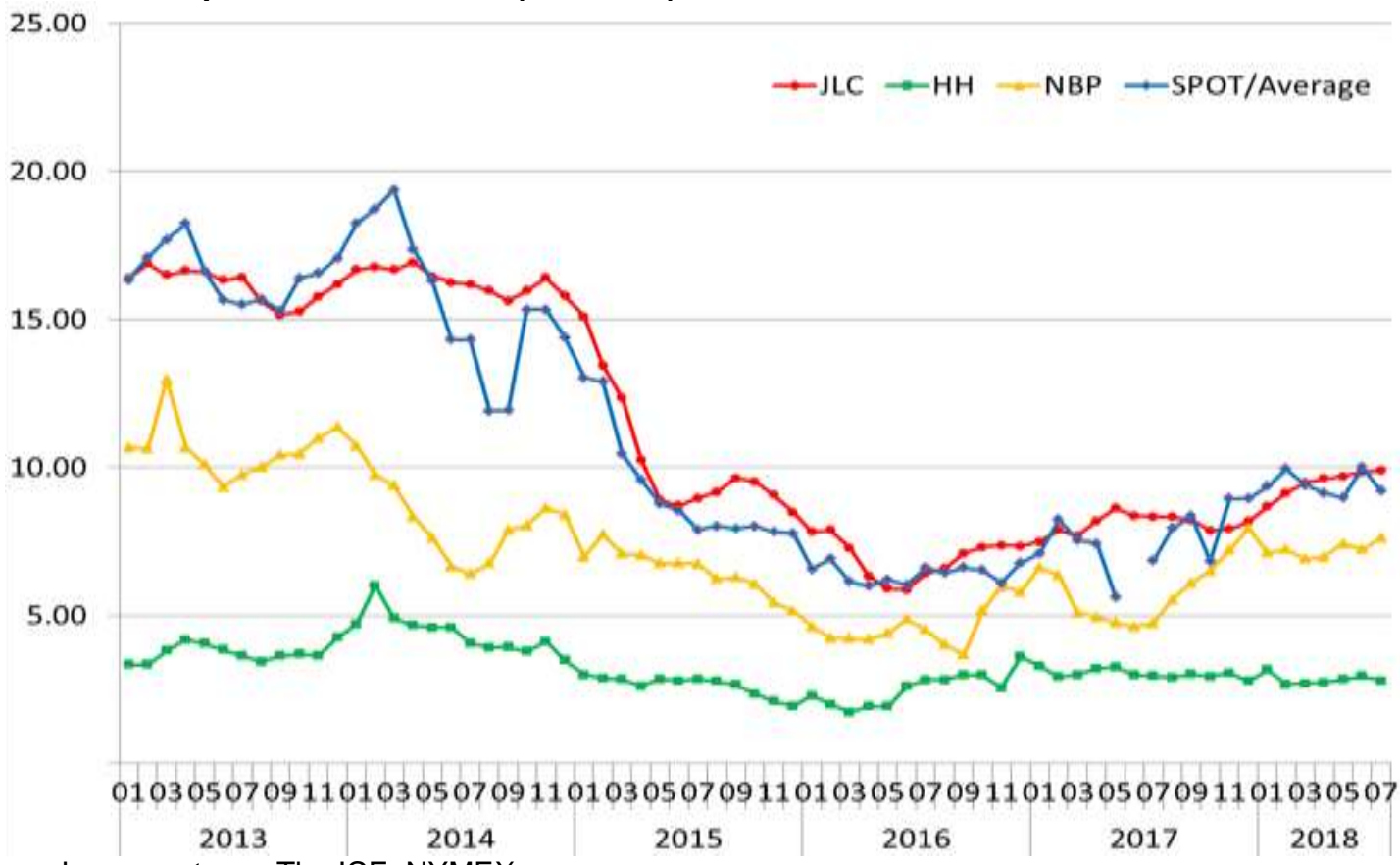

Source: Japan customs, The ICE, NYMEX.

Figure 5.2: Outlook for LNG supply and demand in the global market

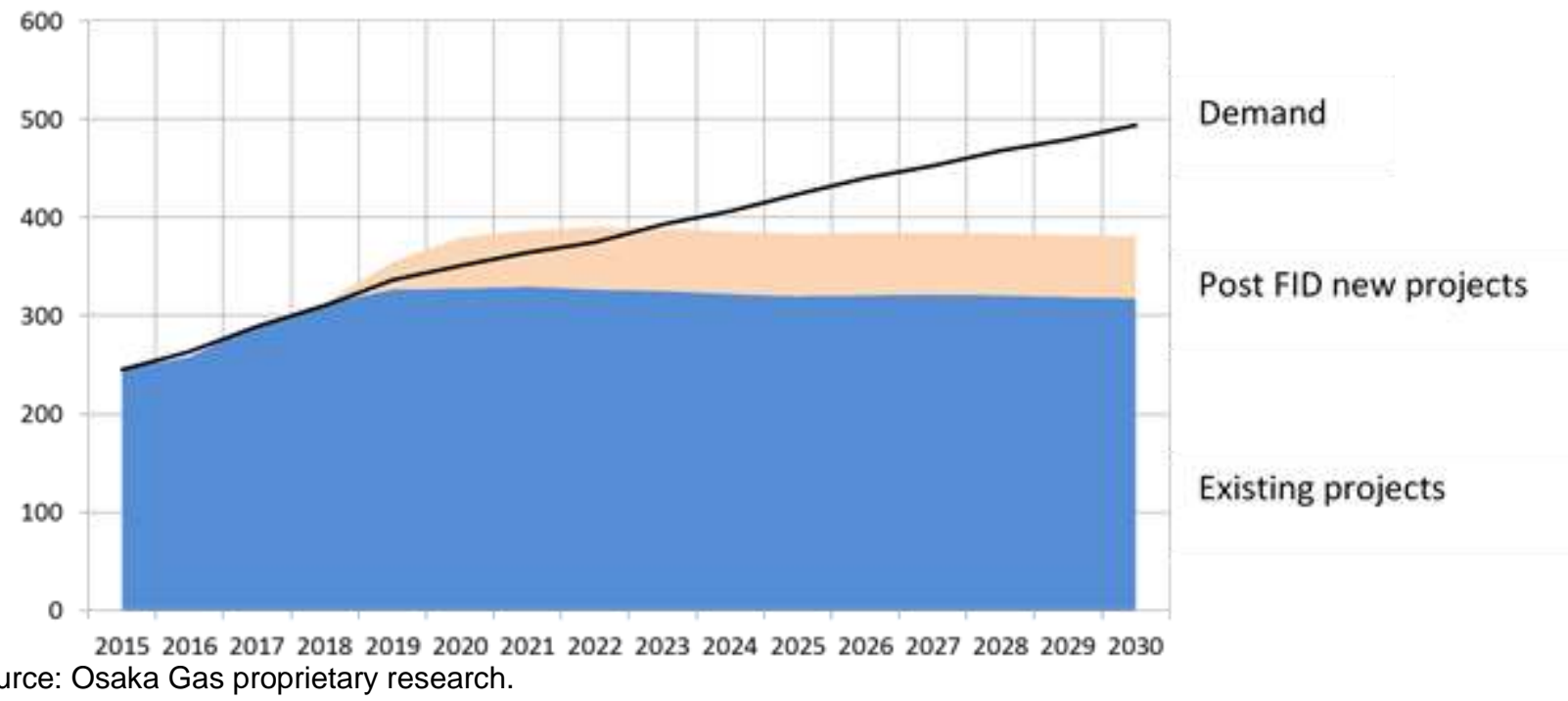

5.4.2 Long-term impacts up to around $\mathbf{2 0 3 0}$

As a supplementary consideration, several key implications for long-term projections deriving from medium-term projections are now considered. These are as follows.

Of the various measures that China is taking to combat air pollution, the coal-to-gas projects that have increasingly been promoted since 2017 to reduce PM2.5 emissions will very probably become a sustained campaign. 

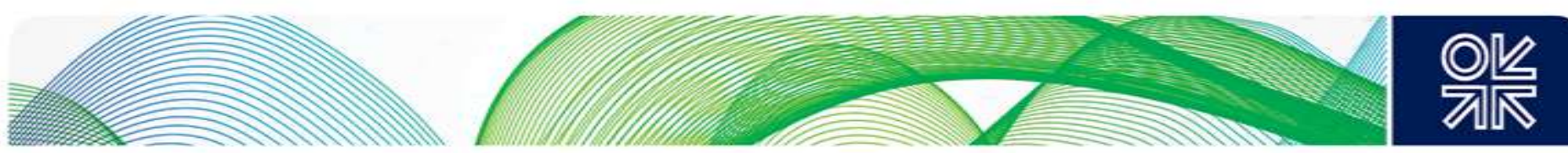

This may be proven by the fact that the current air quality in many cities (shown in Figure 2.3) has yet to be improved to reach the national target level, which is still lax in comparison with international standards.

As this campaign will not be completed in the next few years, the high rate of growth in natural gas consumption is very likely to continue.

Supply capacity will need to be secured to feed this growth in consumption, and natural gas supply capacity will be crucial. As there is little likelihood of major growth in domestic production of conventional gas resources, the key consideration will be whether, among the unconventional options, shale gas development proceeds smoothly.

However, LNG demand will depend above all on steady growth in natural gas imports from Russia from 2020 onward. If imports from Russia grow steadily, this makes it more likely that LNG imports will slow from 2020. Conversely, if natural gas imports from Russia do not, for some reason, grow as planned, dependence on LNG will increase further.

Yet, as the coal-to-gas switching projects currently underway are heavily subsidized, central and local governments may face financial constraints. Although various possibilities exist - such as the possibility of an increase in both oil prices and term prices for LNG, and the possibility of a tightening of the LNG market and rise in spot prices - it is consequently also quite possible that the implementation of coal-to-gas switching projects will slow. 

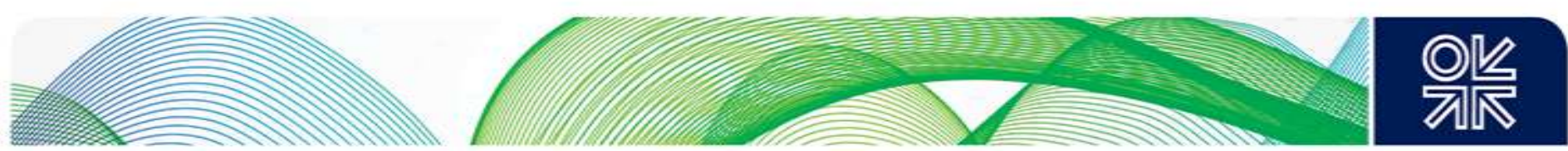

\section{References}

\section{BP, Statistical Review of World Energy.}

CCRI (2016), 'An Analysis of Coal Trends in China', China Coal Research Institute, December 2016.

Chen, Jainghua (2018), 'Shale Gas Exploration and Development Progress in China and the way forward', IOP Conference Series: Earth \& Environmental Science 113, IOP publishing.

China Coal Cap Project (2017), 'China Coal Consumption Cap Plan and Policy Research Project', China's low-grade coal comprehensive treatment research report November 2017.

China Electricity Council (2018), 'Outlook and review on China's supply and demand of electricity in 2017-2018', 1 February.

China Electricity Council, 'Power Industry in China'.

China Statistics press, China Energy Statistical Yearbook 2017.

CNPC (2016), 'China's Natural Gas Market Overview', presentation, 9 November 2016, Tokyo.

CNPC ETRI (Apr.2018), 'China Natural Gas Market Status and Outlook', presentation, 26 April.

GIIGNL, 'Annual Report', The International Group of Liquefied Natural Gas Importers.

Miyamoto, Akira and Ishiguro Chikako (2006), 'Pricing and Demand for LNG in China: Consistency between LNG and Pipeline Gas in a Fast Growing Market', OIES paper, NG 9, Oxford Institute for Energy Studies, January. Available at: https://www.oxfordenergy.org/wpcms/wpcontent/uploads/2010/11/NG9PricingandDemandForLNGinChinaConsistencyBetweenLNGan dPipelineGasInAFastGrowingMarket-AkiraMiyamotoandChikakolshiguro-2005.pdf.

MNEP (2007), '11th Five-Year Plan for National Environmental Protection', (11FYPE), Ministry of National Environmental Protection, November.

MNEP (2011), '12th Five-Year Plan for National Environmental Protection', (12FYPE). Ministry of National Environmental Protection, December.

MNEP (Feb.2012), 'Ambient National Air Quality Standards', Ministry of National Environmental Protection, February.

MNEP (Dec.2012), '12th Five-Year Plan for the Prevention and Control of Air Pollution in Key Areas', Ministry of National Environmental Protection, December.

MNEP (Aug.2013), 'National environmental quality situation in the first half of 2013', Ministry of National Environmental Protection, August.

MNEP (Sep.2013), 'Implementation Rules for Action Plan for Air Pollution Prevention in BeijingTianjin-Hebei and Surrounding Area', (Action Plan B-T-H), Ministry of National Environmental Protection.

MNEP (Jul.2014), 'Emission Standard of Air Pollutants for Boiler', Ministry of National Environmental Protection.

MNEP (2016), 'Intensive Air Pollution Prevention and Control Measures for Beijing-Tianjin-Hebei (2016-2017)', (Control Measures B-T-H), Ministry of National Environmental Protection and the governments of Beijing, Tianjin, and Hebei.

MNEP (Jul.2016), 'Interim Report on the Air Pollution Prevention and Control Action Plan (2013)', Ministry of National Environmental Protection.

MNEP (Mar.2017), 'Work plan for air pollution prevention and control in Beijing, Tianjin and Hebei and surrounding areas in 2017', (Work Plan B-T-H), Ministry of National Environmental Protection,. 

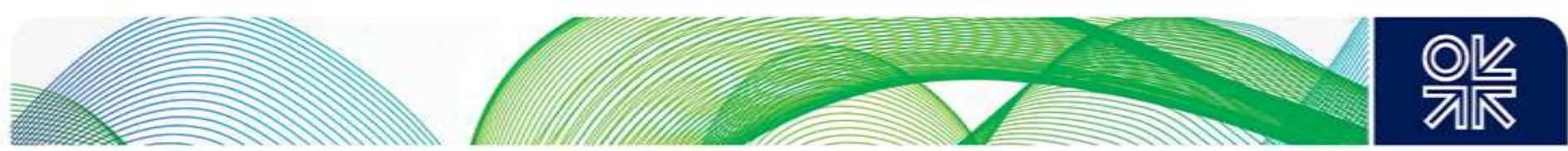

MNEP (Apr.2017), '13th Five-Year Plan for National Environmental Protection', (13FYPE). Ministry of National Environmental Protection.

MNEP (Jul.2017), 'Air Pollution Control Action Plan Implementation Assessment Method', Ministry of National Environmental Protection.

MNEP (Aug.2017a) '2017-18 Autumn/Winter Action and Inspection Plan for Tackling and Comprehensive Management of Air Pollution in Beijing-Tianjin-Hebei and Surrounding Areas', (2017 Autumn/Winter B-T-C), Ministry of National Environmental Protection.

MNEP (Aug.2017b), '2017-2018 Autumn/Winter Action and Inspection Plan for Tackling and Comprehensive Management of Air Pollution in Beijing-Tianjin-Hebei and Surrounding Areas - Strengthened Supervision Plan', Ministry of National Environmental Protection.

MNEP, Chinese Environmental Status Bulletin, Ministry of National Environmental Protection.

NDRC (Apr.2007), '11th Five-Year Plan for National Energy Development', National Development and Reform Commission.

NDRC (Jan.2013a), '12th Five-Year Plan for National Energy Development', National Development and Reform Commission.

NDRC (Jan.2013b), '12th Five-Year Plan for Natural Gas Development', National Development and Reform Commission.

NDRC (Oct.2013), 'Opinion on the winter work of the natural gas system in 2013', National Development and Reform Commission, 12 October 2013.

NDRC (Mar.2014), 'Reinforced Work Program for Air Pollution Prevention in Energy Industry', National Development and Reform Commission.

NDRC (Dec.2014), 'Interim Measures for Management of Substitution and Reduction of Coal Consumption in Key Areas', National Development and Reform Commission.

NDRC (Dec.2016a), '13th Five-Year Plan for Natural Gas Development', National Development and Reform Commission.

NDRC (Dec.2016b), '13th Five-Year Plan for National Energy Development', National Development and Reform Commission.

NDRC (2016), '13th Five-Year Plan for Key projects for ecological construction and environmental protection', National Development and Reform Commission.

NDRC (Apr.2017), 'Revolutionary Strategy for Energy production and consumption', National Development and Reform Commission.

NDRC (Jun.2017), '13th Five-Year Plan for Power development', National Development and Reform Commission.

NDRC (Dec.2017), 'Winter Clean Heating Plan in Northern Area (2017-21)', (Winter Clean Heating), National Development and Reform Commission.

RNDC, 'Monthly Overview on Natural Gas Market', National Development and Reform Commission.

NDRC and MNEP (Jul.2015), 'Strengthened Work Plan for Controlling Air Pollution and Total Coal Consumption in Key Cities', National Development and Reform Commission and Ministry of National Environmental Protection.

NDRC and MNEP (Mar. 2017), '11th Five-Year Plan for Sulfur Dioxide Emission Control in Existing Coal-fired Power Plants', National Development and Reform Commission and Ministry of National Environmental Protection.

NDRC, MEE, and RG (Sep.2018), 'Action Plan for Comprehensive Management of Air Pollution in Autumn and Winter in Beijing-Tianjin-Hebei and surrounding areas 2018-2019, National Development and Reform Commission, Ministry of Ecology and Environment and Regional Governments. 

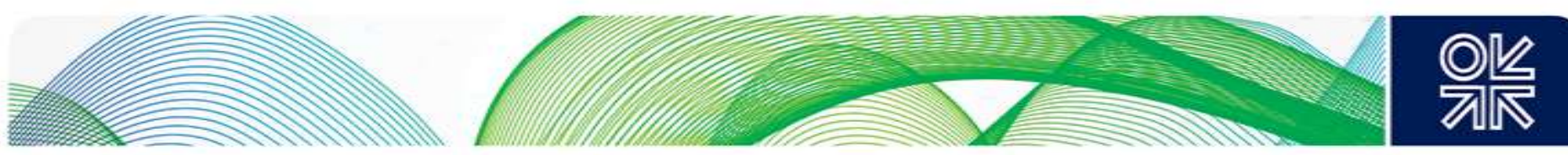

NPC (Mar.2001), '10th Five-Year Plan for Economic and Social Development of the People's Republic of China', (10FYP), The National People's Congress.

NPC (Mar.2006), '11th Five-Year Plan for Economic and Social Development of the People's Republic of China', (11FYP), The National People's Congress.

NPC (Mar.2011), '12th Five-Year Plan for Economic and Social Development of the People's Republic of China', (12FYP), The National People's Congress.

NPC (Mar.2016), '13th Five-Year Plan for Economic and Social Development of the People's Republic of China, The National People's Congress', (13FYP).

PIP (2018), 'China Natural Gas Development Report 2018', Petroleum Industry Press, August 2018.

Roberts, John (2016), 'Russia's gas challenge: the consequences for China, Central Asia, Europe and the USA', Journal of World Energy Law \& Business, 9 (2), 22 January, pages 83-104.

RUC (Sep.2017), 'Coal-fired combustion control in Beijing-Tianjin-Hebei', Research report, Renmin University of China.

SCPRC (May.2007), 'Comprehensive work plan for energy saving and emission reduction', The State Council of the People's Republic of China.

SCPRC (May,2010), 'Guidance on Joint Prevention and Control Work for Air Pollution for Improving Regional Air Quality', (Guidance), The State Council of the People's Republic of China.

SCPRC (Sep.2013), 'Air Pollution Prevention and Control Action Plan (2013-2017)', (Action Plan 2013), The State Council of the People's Republic of China.

SCPRC (Nov. 2014), 'Strategic Action Plan for Energy Development (2014-2020)', (Strategic Action Plan), The State Council of the People's Republic of China.

SCPRC (Jun.2018), 'Action Plan to Win the Blue Sky Defence War', The State Council of the People's Republic of China (Blue Sky Action Plan).

The Air Pollution and Control Law (revision in Aug. 2015).

US EPA ‘Clean Air Act’, US Environmental Protection Agency.

Asia Plus

AzerNews

Bloomberg

China Daily

China News Service

Eurasianet

Global Trade Atlas

Interfax

International Gas Report

Kaba

People's Daily

Reuters
The Beijing News

Waterborne Trade Data

World Gas Intelligence

Xinhua News

Ministry of Environment (Japan) Website

National Bureau of Statistics Website

Gazprom Website

CNPC Website

CNOOC Website

China Economic Information Network Website 